\title{
A One-Session, Brief Acceptance and Commitment Therapy Workshop for Chronic Pain Patients: A One-Sample Pretest- Posttest Prospective Exploratory Study
}

\author{
Kelly Anne Thomas MS \\ West Virginia University, kat0016@mix.wvu.edu
}

Follow this and additional works at: https://researchrepository.wvu.edu/etd

Part of the Clinical Psychology Commons, Counseling Psychology Commons, Health Psychology

Commons, and the Pain Management Commons

\section{Recommended Citation}

Thomas, Kelly Anne MS, "A One-Session, Brief Acceptance and Commitment Therapy Workshop for Chronic Pain Patients: A One-Sample Pretest-Posttest Prospective Exploratory Study" (2021). Graduate Theses, Dissertations, and Problem Reports. 7777.

https://researchrepository.wvu.edu/etd/7777

This Dissertation is protected by copyright and/or related rights. It has been brought to you by the The Research Repository @ WVU with permission from the rights-holder(s). You are free to use this Dissertation in any way that is permitted by the copyright and related rights legislation that applies to your use. For other uses you must obtain permission from the rights-holder(s) directly, unless additional rights are indicated by a Creative Commons license in the record and/ or on the work itself. This Dissertation has been accepted for inclusion in WVU Graduate Theses, Dissertations, and Problem Reports collection by an authorized administrator of The Research Repository @ WVU.

For more information, please contact researchrepository@mail.wvu.edu. 
A One-Session, Brief Acceptance and Commitment Therapy Workshop for Chronic Pain Patients: A One-Sample Pretest-Posttest Prospective Exploratory Study

Kelly Thomas, M.S.

Dissertation submitted

To the College of Education and Human Services

At West Virginia University

In partial fulfillment of the requirements for the degree of

Doctor of Philosophy

In

Counseling Psychology

Jeff Daniels, Ph.D., Chair

Edward Baker, Ph.D.

Richard Gross, Ph.D.

Lisa Platt, Ph.D.

Department of Counseling, Rehabilitation Counseling, and Counseling Psychology

Morgantown, West Virginia

2020

Keywords: Acceptance and Commitment Therapy, Chronic Pain, Workshop, Rural Copyright 2020 Kelly Thomas 


\begin{abstract}
A One-Session, Brief Acceptance and Commitment Therapy Workshop for Chronic Pain Patients: A One-Sample Pretest-Posttest Prospective Exploratory Study
\end{abstract}

\author{
Kelly Thomas
}

Chronic pain affects one in every four persons (NIH, 2010). For individuals residing in rural communities where chronic pain treatment is often not accessible (Artnak et al., 2011), a onesession brief mental health intervention is a critical healthcare need. More specifically, acceptance and commitment therapy (ACT) for chronic pain is a novel treatment approach in need of more research (Society of Clinical Psychology, 2016). This current study contributes to the gap in the literature by implementing an ACT workshop in a rural healthcare setting for individuals with chronic pain. It was hypothesized that the workshop would increase adaptive coping mechanisms such as total pain acceptance, activity engagement, and pain willingness. Additionally, it was hypothesized that the workshop would decrease pain catastrophizing postworkshop. Nineteen participants completed pre- and four-week post-workshop questionnaires. The results of this study indicated that those who attended the workshop reported higher total pain acceptance and pain willingness as measured by the CPAQ-R (McCracken et al., 2004). There were no significant results for pain catastrophizing and activity engagement. A majority of the participants who attended the workshop and completed the follow-up questionnaires reported satisfaction with the group and would refer their family and friends to a similar workshop. Future recommendations are aimed at increasing intervention repertoire and providing insight on group composition and workshop layout. 


\section{Dedication}

This dissertation is dedicated to all the strong women in my life. Most importantly, my mother. Even with chronic pain, you dedicated time imparting wisdom and pushing me to believe that my dreams are limitless with hard work, compassion towards others, and the support of family. Your ability to live a life that is valuable to you in the midst of hardship has aided me both professionally and personally.

To my father. You have consistently celebrated my accomplishments every step of the way. You have taught me that working hard means nothing if you are not supporting your community. You have shown me the importance of believing in something greater than myself.

To my two older brothers. I truly believe I would not be the person I am today without you. You both ground me and push me to be better every day.

Finally, to my partner, Kurt. You, along with your family, provided me with unwavering support as you encouraged, pushed, and stood beside me through every step of this difficult journey. Thank you for your many sacrifices you gave to help me fulfil my dreams. I could never express the love and respect I have for you.

I love you all more than I could ever say. Thank you. 


\section{Acknowledgements}

The completion of this dissertation would not have been possible without the guidance and support of the many faculty and staff members at West Virginia University. More specifically, I would like to thank my dissertation chair, Dr. Jeffrey Daniels, who provided me with support and guidance. I would also like to thank my dissertation committee members. Dr. Richard Gross, whose contribution to this project has been remarkable. Thank you for your invaluable supervision, mentorship, and the space to work with a population that will follow me into my professional career. To Dr. Lisa Platt, who aided my professional development not only just with this project, but as a student and person. To Dr. Edward Baker, who provided me with supervision and support throughout my clinical experiences.

I also want to thank many of the staff members and colleagues who assisted me with recruitment and data collection. Specifically, McKenzie Given and Missy Wilson, who dedicated their time to helping me recruit and collect data for this project. To Christian Carey, who supported me with data collection. Thank you to Whitney Myers and Lynn Dobbs, for helping with participant recruitment, spending hours listening to my workshop, and providing me with valuable feedback.

Finally, I want to thank my friends, family, and past professional mentors for offering support throughout my education. To Dr. Mike McCall, Dr. Tziporah Rosenberg, Dr. Aubrey Guiffre, Dr. Jenny Speice, Dr. Carol Podgorski. and Dr. Ellen Poleshuck, you all saw potential and encouraged me to pursue additional graduate experiences, as well as helped me integrate personal meaningfulness into my professional interests. 


\section{Table of Contents}

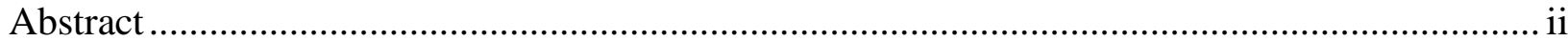

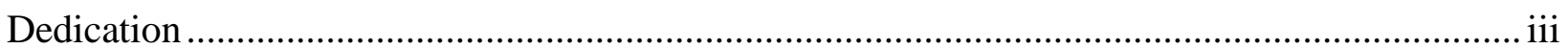

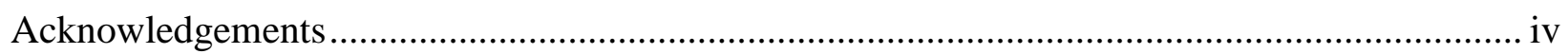

Chapter 1: Introduction and Literature Review .................................................................... 1

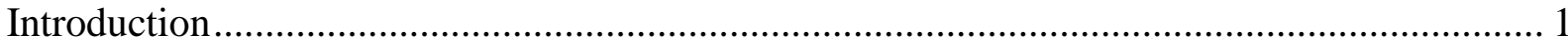

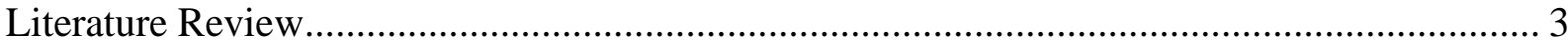

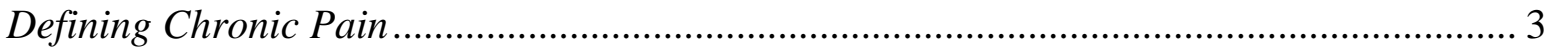

Extent of the Problem............................................................................................................ 5

Chronic Pain through the Sociological, Psychological, and Biological Lenses .................. 7

Theoretical Models of Chronic Pain................................................................................. 19

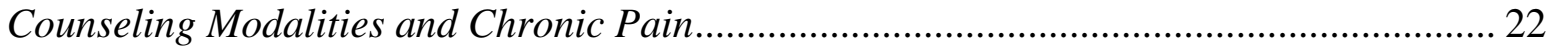

Brief Interventions for Chronic Pain .......................................................................... 32

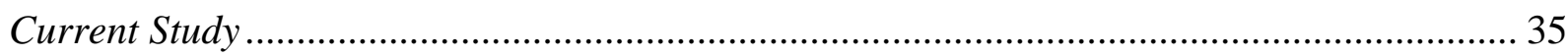

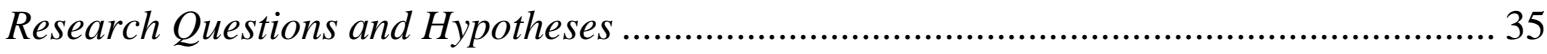

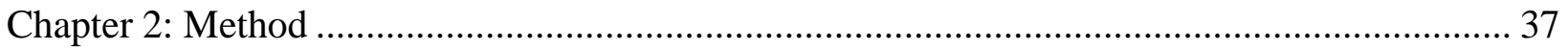

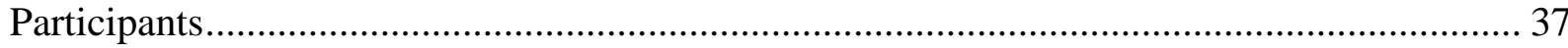

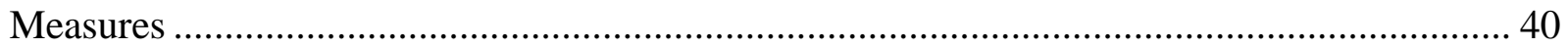

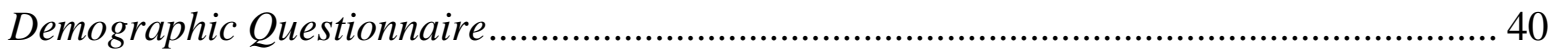

Chronic Pain Acceptance Questionnaire ..................................................................... 41

Two-Item Pain Catastrophizing Questionnaire ............................................................ 43

Two-Item Client Statisfaction Questionnaire .................................................................. 44

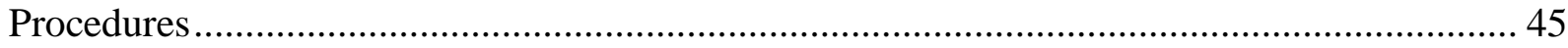

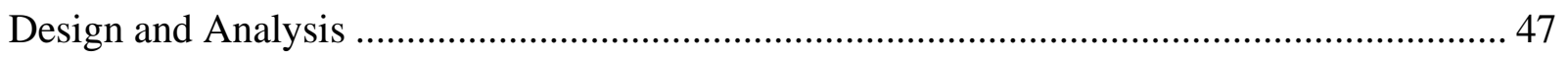

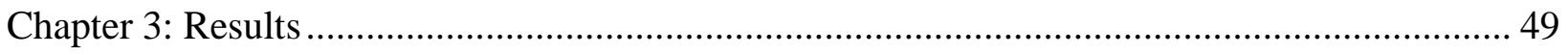

Tests of Assumptions: Paired-Samples $t$-Test ................................................................ 49

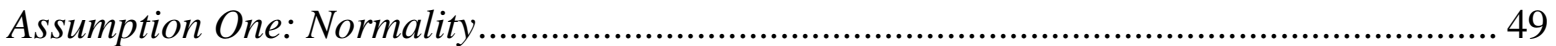

Assumption Two: Independence within Groups ........................................................ 55

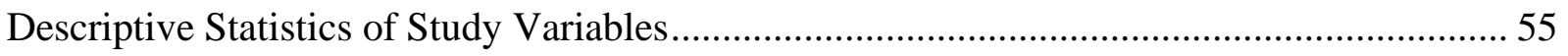

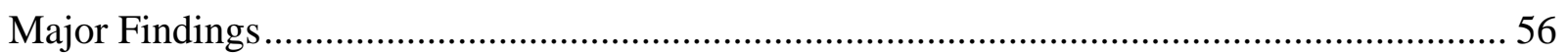

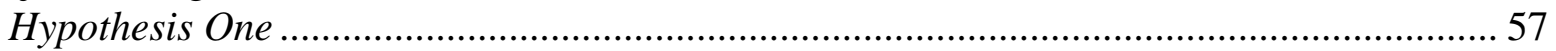

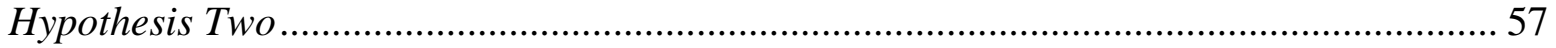

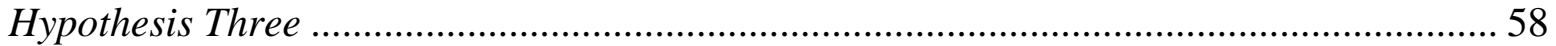

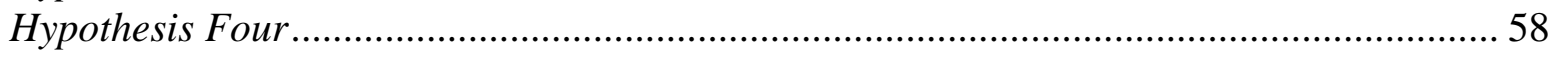

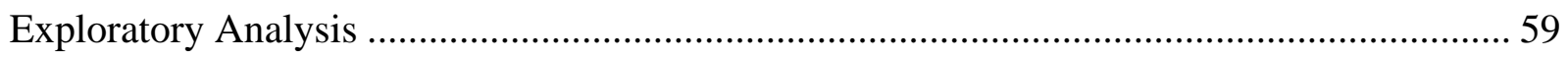

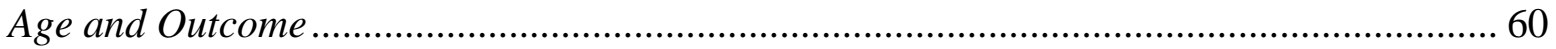

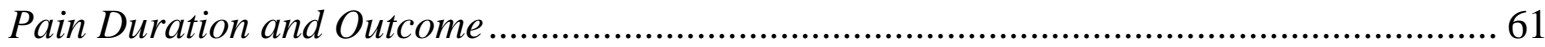

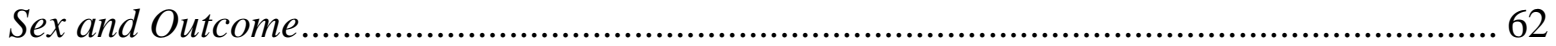




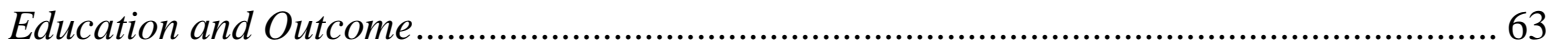

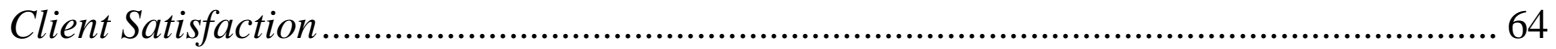

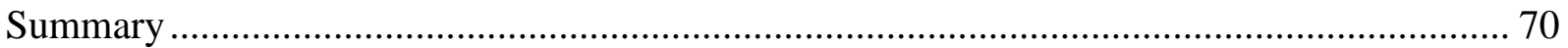

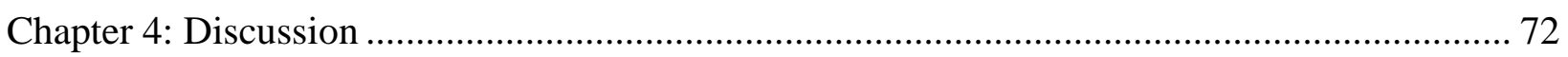

Development of One-Session ACT-Based Chronic Pain Workshop.................................... 73

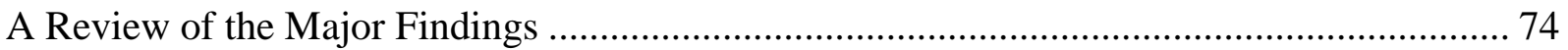

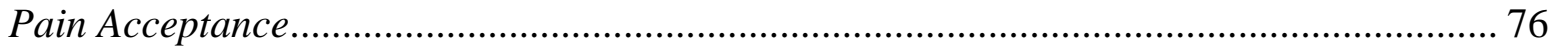

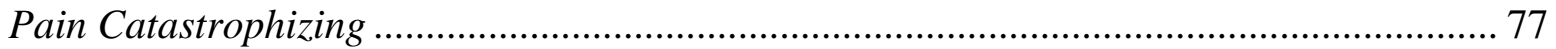

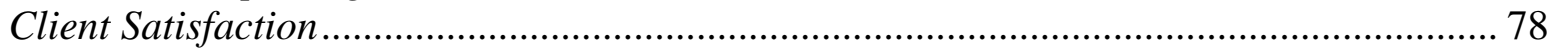

Strengths, Limitations and Recommendations for Future Research.................................... 79

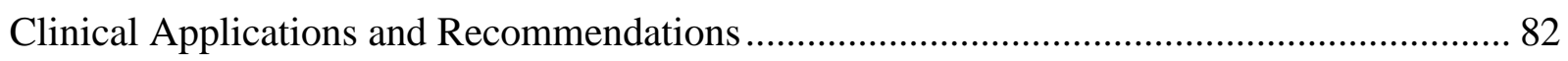

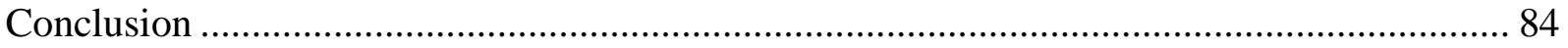

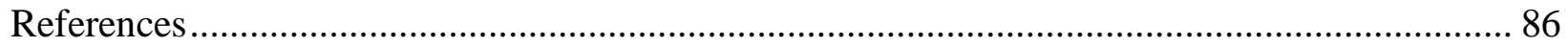

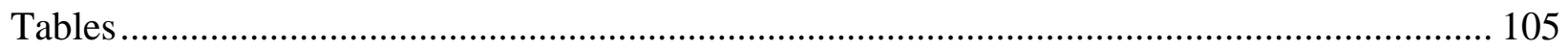

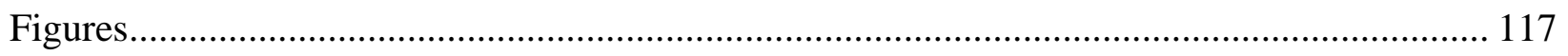

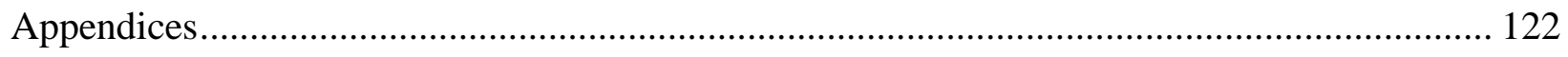

Appendix A: Informed Consent for Treatment............................................................ 122

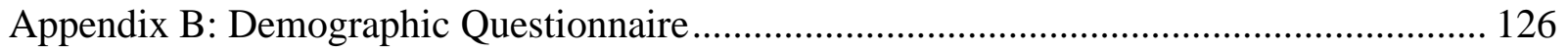

Appendix C: Chronic Pain Acceptance Questionnaire - Revised (CPAQ-R) ...................... 128

Appendix D: Two-Item Pain Catastrophizing Questionnaire (2-PCQ) ............................... 129

Appendix E: Two-item Client Satisfaction Questionnaire .............................................. 130

Appendix F: Participant Invitation Flyer ….............................................................. 131

Appendix G: Workshop Outline and Handout.............................................................. 132

Appendix H: Gift Card Letter to Participants ................................................................ 140 


\section{Chapter 1: Introduction and Literature Review}

\section{Introduction}

Chronic pain has been extensively studied; from the biological, psychological, and social impacts, an individual who is suffering from such a complex diagnosis can be negatively affected in many ways. In fact, chronic pain is so comprehensively studied, that there are various journals that are specifically dedicated to the topic, including the American Academy of Pain Medicine, Pain, Journal of Pain, Journal of Pain and Symptom Management, Journal of Pain and Relief, and several more. Within these journals, there is extensive literature on medical and psychological interventions for use in the chronic pain population. One of these psychological interventions is acceptance and commitment therapy (ACT). The Society of Clinical Psychology (2016) reported that there is strong evidence for the utilization of ACT for chronic pain based on criteria proposed by Chambless and Hollon (1998) on defining empirically supported therapies. However, ACT is currently under re-evaluation by the Society of Clinical Psychology (2016) because more recent and stringent criteria have been proposed by Tolin and colleagues (2015). This re-evaluation indicates that more research on ACT and chronic pain is necessary in order to validate this intervention to the extent that other interventions, such as cognitive behavioral therapy (CBT), have been validated.

$\mathrm{ACT}$ is a contextual behavioral approach to treatment that focuses on variables such as acceptance, mindfulness, and commitment to future behavior change (Hayes \& Lillis, 2012). Although it may seem strongly rooted in behavioral science, in practice ACT is actually more closely related to cognition, and theoretical orientations such as gestalt, existential, and humanistic psychology (Hayes \& Lillis, 2012). One of the key tenets of ACT is the psychological flexibility model. Steven Hayes and Jason Lillis (2012) stated psychological 
flexibility is having thoughts, feelings, sensations, and memories without feeling the need to change them. Additionally, one must modify their behaviors to match their values, and make a commitment to meet their goals based on said values. Psychological flexibility consists of six processes, including acceptance, cognitive defusion, flexible attention, perspective-taking, values, and committed action (Hayes \& Lillis, 2012). These processes will be further detailed in subsequent sections (see Acceptance and Commitment Therapy for Chronic Pain).

Although CBT and ACT both share characteristics such as challenging cognition and behavior, ACT for chronic pain possesses a unique quality by not attempting to reduce pain severity, but rather attempting to increase the willingness to have chronic pain. Furthermore, it devotes attention to committed action, which is to live a life that is meaningful and consistent with one's values. McCracken and Zhao-O'Brien (2010) reported that acceptance within the chronic pain context is, "a willingness to engage in activity with pain present and to allow pain to register in experience without attempts to control or avoid it" (p. 170). Furthermore, chronic pain acceptance has been found to be associated with less pain intensity, less pain related distress, lower levels of depression and anxiety, lower levels of disability, and is predictive of daily activity levels (McCracken, 1998; McCracken et al., 1999; McCracken et al., 2004). Pain acceptance, pain willingness, and activity engagement are factors that drive ACT and are important to cover in subsequent sections (see Acceptance and Commitment Therapy and Chronic Pain).

In a systemic review of randomized controlled trials of ACT for chronic pain, Hann and McCracken (2014) reviewed ten studies to obtain evidence on efficacy, as well as define primary, secondary, and process variables. One of the characteristics reported in this metaanalysis was the treatment duration of these ten randomized controlled trials, which was 
approximately eight weeks; the shortest being two weeks, and the longest being twelve weeks. Additionally, they included the number of hours per intervention. The shortest recorded intervention time was one hour, while the longest time of one single session was four hours (Hann \& McCracken, 2014). However, Darnall and colleagues (2014) revealed that a singlesession, CBT-based intervention lasting approximately two hours was capable of reducing symptoms such as pain catastrophizing.

Single session interventions have many qualities that are appealing to individuals suffering from chronic pain, such as time it takes to complete the intervention, travel costs, and the costs of attending psychological services every week. These variables are especially pertinent in areas like the mid-Atlantic region, where individuals living in rural communities are likely to have lower SES, lower access to medical care, and longer travel times to appointments. Therefore, an intervention that is single-session and provides long-term coping skills for sufferers of chronic pain is altogether a critical area of research that has largely been untapped. These aforementioned gaps in chronic pain research provide the overall research agenda. In sum, the current study provides individuals experiencing chronic pain with a one-session, brief, ACTbased intervention with the purpose of increasing pain acceptance and decreasing pain catastrophizing. It is hopeful that future implications of this study provide psychologists and other mental health professionals with a novel intervention that targets the psychological components that accompany chronic pain.

\section{Literature Review}

\section{Defining Chronic Pain}

There are positives and negatives for the chronic pain research being so vast. One of the negatives is that defining chronic pain as a construct is challenging due to how broad the term 
spans, as well as how difficult it is to capture all of its intricacies. The International Association for the Study of Pain ([IASP], 2017) defines pain as "an unpleasant sensory and emotional experience associated with actual or potential tissue damage, or described in terms of such damage" (§ 1). In this definition, the IASP (2017) acknowledges both the physical and emotional aspect that pain, which will be further discussed in subsequent sections (see Chronic Pain through the Sociological, Psychological, and Biological Lenses).

In attempting to classify three separate constructs that are regularly seen in chronic pain research, Epping-Jordan et al. (1998) referred to acute pain as pain lasting less than six months, chronic pain lasting for six months or longer, and chronic pain syndrome having a minimum sixmonth duration and a decrease in functioning and increase in disability. Other definitions of chronic pain explain the diagnosis as being past the normal amount of time it takes for an individual to heal, which is approximately three to six months (Merskey \& Bogduk, 1994). However, these definitions have been too vague and lack diagnostic clarification, leaving researchers and clinicians to make their own judgments between acute and chronic pain.

There are various diagnoses an individual with chronic pain may receive based on numerous factors, including the origin of pain, location of pain, and the quality of pain. However, it is important to differentiate chronic pain from cancer-related pain. For example, the spreading of a tumor may cause severe pain for longer than three months, injury to tissues can result in nerve pain, and bone related pain can be related to specific types of cancer (American Society of Regional Anesthesia and Pain Medicine, n.d.).

Since these elusive definitions have caused ambiguity in the field, current researchers are investigating ways to turn away from these broad definitions and instead produce more concise and narrowly defined diagnoses. One example of this narrowing is a categorization system was 
proposed by the ICD-11 task force. The proposed classification system includes terms such as, primary pain, cancer pain, postsurgical and posttraumatic pain, neuropathic pain, headache and orofacial pain, visceral pain, and chronic musculoskeletal pain (Treede et al., 2015).

Additionally, the IASP (2018) does not list a duration of chronic pain, but rather employs a different classification system based on the causal agent contributing to the pain syndrome (i.e., central pain, peripheral neuropathy, complex regional pain syndrome, and polymyalgia rheumatica). However, the majority of pain literature operationalizes chronic pain as, "persistent or recurrent pain lasting six months or more" (Epping-Jordan et al., 1998, p. 422). Therefore, for the purpose of this study, the above definition will be utilized as a participant criterion.

\section{Extent of the Problem}

Chronic pain currently affects one in four individuals, or approximately 76.2 million Americans (National Institute of Health [NIH], 2010). Chronic pain is so common in the United States, that it exceeds the number of individuals who suffer collectively from diabetes, coronary heart disease, and cancer combined, which are currently considered the most major conditions in the U.S. (NIH, 2018). Due to the tremendous impact it has on affected individuals, it is important that we consider the impacts of this problem at a personal level as well as within our health-care system. Individually, the expenses related to a chronic pain diagnosis are not only associated with high healthcare costs, but also other secondary costs such as disability compensation, loss of work productivity, loss of tax revenue, and legal services (Dansie \& Turk, 2013). Additionally, the economic impact of chronic pain is significant. It is estimated that the direct medical costs, lost productivity, and disability programs for chronic pain amount to approximately $\$ 560$ billion every year (Institute of Medicine, 2011). 
In a study consisting of a representative sample of the United States population on the prevalence of specific chronic pain disorders, Hardt et al. (2008) found that $10.1 \%$ of individuals reported back pain, $7.1 \%$ reported pain in legs and feet, $4.1 \%$ reported pain in arms/hands, and over $3 \%$ reported chronic headaches. Additionally, they found that women reported higher headache, abdominal pain, and chronic widespread pain than men. Mexican-Americans had lower instances of acquiring chronic pain than other populations (Hardt et. al., 2008). Having a representative sample in research is critical, and there is still more research that needs to be done in this area. Specifically, populations such as people suffering from fibromyalgia, temporomandibular, and cancer-related chronic pain remain understudied (Knoerl et al., 2016).

Due to the enormous number of individuals that chronic pain affects, there are considerable economic impacts for these individuals and the health care system. Chronic pain is one of the most common causes of long-term disability (NIH, 2018). There are also large economic impacts on the United States in lost productive time and medical costs. It is predicted that chronic pain alone costs Americans \$635 billion a year, which exceeds cancer, heart disease, and diabetes-related expenses (Gaskin \& Richard, 2012). Additionally, chronic pain not only provides an economic burden on the individual with pain, but also to the caregivers. Maniadakis and Gray (2000) conducted a survey in the United Kingdom, in which they found an estimated $35 \%$ of the costs related to chronic pain were paid by either the patient or the family members. Additionally, they discovered that back pain had higher related costs than coronary heart disease, Alzheimer's disease, stroke, arthritis, insulin dependent diabetes, and other major health disorders (Maniadakis \& Gray, 2000).

Chronic pain conditions lead to loss of productive time, which has an economic impact on individuals who are suffering from common chronic pain disorders such as headache, 
arthritis, and back pain. Stewart (2003) found that 13\% of the United States workforce had a loss in productive time due to common pain conditions. The most common condition that contributed to loss of productive time in their workweek was headache, with $5.4 \%$ of individuals missing work. Second was back pain with 3.2\%, followed by arthritis (2.0\%), and musculoskeletal pain $(2.0 \%)$. Additionally, Stewart (2003) found that workers with these common chronic pain conditions would lose approximately four hours of work per-week, adding up to an estimated cost of $\$ 61.2$ billion per year of lost productive time in the United States. Therefore, not only does chronic pain affect the individual physically, but also has substantial impacts on their financial wellbeing. With the considerable costs associated with having a chronic pain disorder, the economic impacts of treatment should be a critical consideration in the medical field, and for the patient and patient's family when deciding treatment.

\section{Chronic Pain through the Sociological, Psychological, and Biological Lenses}

In the past, medical models have been primarily concerned with physical symptomology that accompanies pain as a way to diagnose and treat the patient. However, Engle (1977) called for a new approach to health and wellness, which eventually lead to new fields in psychology; namely behavioral medicine and health psychology (Gatchel \& Baum, 1983). Since this call for a different and more comprehensive model of health care, there has been an influx of research that approaches the biological, psychological, and sociological aspects of an individual's wellbeing as it pertains to treating chronic pain. Ehde and colleagues (2014) also understood the collaboration of these three mechanisms by stating, "chronic pain is an inherently complex and subjective experience influenced by biological, psychological, and social factors" (p. 153).

The intersection between these three factors is producing controversies in the field, as there are attempts to differentiate chronic pain as being a biological problem versus a 
psychological diagnosis. It is difficult to distinguish or separate chronic pain between being a medical problem versus a psychological or sociological problem for many reasons. While an individual's chronic pain may have had a medical reason for onset, it is still unknown why specific types of pain persist past normal healing time physiologically if not due to fractures, tumors, infections, inflammatory disease or some other type of musculoskeletal abnormality (Fordyce, 1995). McCracken (2005) suggested through his own review that each individual should be treated as a separate case. Additionally, he reported that this never-ending search for an organic cause can increase frustration for the patient as well as for the medical professional. Regardless, physical cause should never be ruled out, but other factors should also be investigated to provide a full assessment of the individual's needs (McCracken, 2005).

Sociological Characteristics. Failure to address pain through a sociological lens can lead to an overall deficient treatment. It is acknowledged in the pain literature that group processes such as family, job, culture, and religion play an essential role in the treatment of chronic pain (Carr \& Bradshaw, 2012). Therefore, Carr and Bardshaw (2012) proposed that we 'flip the curriculum' that is currently being taught to medical students. They suggested that instead of teaching from a bottom-up approach (i.e., the biopsychosocial model), we instead work from a sociopsychobiological model (Carr \& Bradshaw, 2012). They proposed several reasons as to why this is an appropriate change. First, they described that there is enough evidence to support this change. Secondly, they explained the problems with teaching pain through a reductionist lens, in that students are taught the cellular level first, which later translates to pain as being "small scale phenomena" (p. 13). Carr and Bradshaw suggested that the medical world should be able to address major problems in the social lives of these clients, 
giving examples, such as knowing how to obtain disability certification, and understanding the complexities of family and mental health issues in relation to chronic pain.

Chronic pain is a problem that is best treated with an integrative care approach (Eisenberg et al., 2012). Integrative care is an inter-disciplinary approach, which is critical for the treatment of chronic pain since it not only affects the individual physically, it also has emotional and social impacts that should be considered. Unfortunately, not all patients are able to access multiple types of care, including seeing a medical professional that specializes in chronic pain problems, mental health care, physical therapy, surgery, injection therapy, and many other treatment modalities, due to their geographical location or socioeconomic status. This is especially prevalent for those living in rural communities, where chronic pain treatment is often not accessible (Artnak et al., 2011). In fact, the United States Department of Agriculture (2018) described in a report that rural communities experience higher rates of opioid-related deaths, and continue to rise. One example of this increasing opioid problem occurred in 2016, in which West Virginia had the highest opioid-related overdose deaths per year, even though they did not have the highest rate of prescribed opioids per capita (NIDA, 2018b). This is a large societal issue, as limited health care in rural communities affects 47 million adults 18 -years and older in the United States (United States Census Bureau, 2016).

There are several social factors to consider that contribute to chronic pain. One important variable to consider is how pain is expressed within different levels of socioeconomic statuses (SES). In a longitudinal study conducted by Fliesser et al. (2017), they conceptualized SES with a multidimensional approach that defines SES through variables such as income, education, and job position. Utilizing a hierarchical regression model to predict the impact SES has on pain severity, they found those who had higher SES, better job positions, and higher education 
reported overall lower pain intensity. Interestingly, income was not a predictor of pain intensity over education and job positions. Additionally, Fliesser and colleagues (2017) also found that pain disability was lower for individuals with higher education and job position.

Another variable that has been cited in literature that contributes to the chronic pain experience is ethnicity. Currently, there are disparities in pain treatment based on ethnic background, which could hinder marginalized groups from receiving care for existing conditions that could contribute to chronic pain (Campbell et al., 2012). Meints et al. (2018), were interested in the differences between sex and race in regard to chronic low back pain. Participants included 324 Black and non-Hispanic White individuals with chronic low back pain. The researchers were specifically interested in variables such as depression and pain catastrophizing. Through the utilization of sensory testing with pin-prick stimulators, participants were measured on their response to pain sensitization. The results of this study indicated that men and women with chronic low back pain differ in their experience of pain, with women reporting higher pain sensitivity. In regard to race, Black individuals reported higher pain sensitivity than nonHispanic White individuals. The researchers also found that pain catastrophizing mediated the relationship between race and deep muscle pain, showing an additional contributing factor to differences between groups.

Consequently, this difference in the way individuals express pain may contribute to how they are treated within the health care system. Although an older study, Bernabei and colleagues (1998) were some of the first researchers to show that patients belonging to an ethnic minority population were less likely to be prescribed analgesics as a part of their pain management. In a later review by Green and colleagues (2003), they reported that racial minorities were underserved in the healthcare system in regard to chronic pain management as compared to the 
White population. They proposed that part of the problem is that ethnic minorities are largely overlooked, despite the literature supporting the need that these individuals have for a comprehensive approach to chronic pain management (Green et al., 2003).

Unfortunately, there are limitations in the literature on race differences and the care racial minority patients receive. Campbell et al. (2012), described reasons as to why racial disparities occur in pain management. One of the first ethical challenges discussed is how pain management research is conducted. Due to the economic burdens vulnerable populations may be experiencing, receiving care through research-based interventions alone could put these individuals at an unfair risk for little to non-effective treatment. The second difficulty Campbell and colleagues (2012) reported are challenges in psychometric construction in pain research. They described that current measurements should undergo additional research that focuses on the reliability and validity of measurements with marginalized populations. Finally, Campbell and colleges (2012) discussed the importance of advocacy in decreasing the disparities in research and pain management. These recommendations included increasing data collection utilizing varied populations, increasing advocacy at all levels of research, and re-examining policy within pain management research. It is vital that we address these limitations to research and practice, as these aforementioned disparities increase the likelihood of discrimination within the healthcare system, specifically in chronic pain management.

The chronic pain experience can differ within cultures. For some individuals, this might permit any kind of expression of pain. For example, an individual may not feel permitted to express pain because of a religious belief (Peacock \& Patel, 2008). Some religions view chronic pain and suffering through different lenses. The Hindu religion views pain through the concept of acceptance due to the belief that pain is not a random sensation, but rather is thought of as a 
consequence to past or current actions (Whitman, 2007). These beliefs may lead an individual to not seek medical treatment or mental health treatment because they find meaning through their spirituality (Peacock \& Patel, 2008).

In a study on spiritual beliefs and practices of individuals with chronic pain, ninety-five patients were surveyed utilizing the Spirituality and Chronic Pain Survey (SCPS) (Glover-Graf et al., 2007). The two comparison groups consisted of religious vs. non-religious individuals who had chronic pain. Researchers found that spirituality in the religious group was ultimately beneficial in increasing adaptive coping styles whilst experiencing pain (Glover-Graf et al., 2007). Therefore, clinical and research implications of knowing how individuals perceive chronic pain based on their religious beliefs could prove to be a critical component to wellrounded care.

To further amplify the complexity that sociological characteristics contribute to the chronic pain experience, there are also differences at the individual level, in which chronic pain is cited some populations more than others. In the latest report, more than 26 million Americans between the ages of 20 and 64 experience frequent back pain (NIH, 2010). In military populations, $43 \%$ of active military members report various types of pain, and over $20 \%$ of those individuals report persistent pain lasting over three months (Haskell et al., 2009). In regard to sex, women have been cited to be more likely to experience acute and chronic pain than men (Fillingim et al., 2009; Gerdle et al., 2008). However, in the military population, women are less likely to report chronic pain (Haskell et al., 2009). There has not been much literature to state the prevalence of chronic pain and socio-economic status of individuals within the United states, but there have been several studies done in other countries, including England (Morgan et al., 2011), Sweden (Molarius et al., 2008), and Spanish countries (Rodrigues-de-Souza et al., 2016); all of 
which found that individuals with middle/upper socio-economic status report less chronic pain than in economically disadvantaged classes.

One analysis that considered the psychosocial aspects of chronic pain was in a postsurgical longitudinal study conducted by Dovorak and colleagues (1988). In this study, they compared three groups. The first group consisted of participants with no complaints, the second were individuals with complaints, and the third were pensioned patients with complaints. All 135 patients received surgery for lumbar disc herniation and were followed for approximately 4-17 years. Each participant was administered the Minnesota Multiphasic Personality Inventory (MMPI) and was also interviewed to assess the sociological aspects of these individuals' lives. The results of this study were noteworthy. The second and third group (i.e., with complaints and with complaints and pension) showed less satisfaction with areas such as occupational, family, and social life as compared to individuals who reported no complaints (Dovorak et al., 1988).

This study has interesting findings for several reasons. First, Dovorak et al. (1988) found a relationship between social functioning and chronic pain coping. Additionally, this study was fundamental in understanding how personality traits contribute to chronic pain, as well as how one may perceive their social situations. Specifically, the individuals who were receiving a pension showed higher psychopathology than the individuals who had no physical complaints after the first operation, as measured by the MMPI (Dovorak et al., 1988). However, one of the limitations of this study is that psychopathological characteristics were not defined in the results section. It is important to note that the results do not show a causal relationship between the three variables, but instead indicates that individuals who had more complaints about their pain experience were more likely to show higher pathology and generally less satisfaction in their social functioning. 
Psychological characteristics. Having chronic pain can be psychologically difficult for many individuals. In fact, patients with chronic pain frequently have some form of psychopathology as a comorbid diagnosis (Dvorak et al., 1988; Katz, Rosenbloom, \& Fashler, 2015). The most common are depressive disorders, anxiety disorders, somatization disorders, drug dependence, and occasionally personality disorders (Manchikanti, Fellos, \& Singh, 2002). These diagnoses were also presented in two other studies on the comorbidity of mood and anxiety disorders in relation to chronic pain. Both studies found a significant relationship between chronic pain, depression, and anxiety (Demyttenaere et al., 2007; Von Korff et al., 2005). Furthermore, Linton (2000) conducted a meta-analysis of 37 studies on the psychological risk factors for back and neck pain. He reported, "the data reviewed distinctly shows that psychological factors also are pivotal in the transition from acute to chronic pain as well as an influential contributor to the onset of pain" (p. 1153). Therefore, there are some that believe that psychological factors are predictive of both chronic pain and increases in the experience of chronic pain.

Psychological factors can also affect surgical outcomes. McCracken and Turk (2002) reported two of the strongest predictors of surgical outcome are the severity of one's depression and perceptions of work. Linton's (2000) review suggests that psychological variables are predictive of higher rates of disability, are associated with back and neck pain, and cognitive factors are related to the development of pain and an increase in disability. One example of a cognitive factor that significantly affects chronic pain severity is pain catastrophizing. Pain catastrophizing is defined as, "an exaggerated negative orientation toward actual or anticipated pain experiences...current conceptualizations most often describe it in terms of appraisal or as a set of maladaptive beliefs" (Gatchel et al., 2007, p. 602). Sullivan et al. (2001) notes that pain 
catastrophizing is highly correlated with an increase in pain intensity experienced by the individual and shows a relation between catastrophizing and heightened disability. Sullivan and colleagues (2001) also report that there is a significant relationship between chronic pain and depression, anxiety, fear of future pain, and efficacy of coping mechanisms. Overall, research suggests that psychological factors play a significant role in chronic pain, both pre-and-post diagnosis.

One of the more thought-provoking conversations occurring in the medical and mental health communities is the relationship between chronic pain and somatization disorders, and whether chronic pain is better defined as a psychological disorder. As discussed above, it has been argued that chronic pain is not a medical condition (McCracken, 2005), so what is it? Although the DSM-IV included pain disorders such as psychogenic pain disorder, somatoform pain disorder, and pain disorder, the DSM-5 has removed these disorders and has instead replaced them with a more inclusive somatic symptom disorder (SSD) (Katz et al., 2015). Frances and Chapman (2013) described that all medical illnesses and side effects of medications must be ruled out before concluding that the experience of pain is a result of a mental health diagnosis. Additionally, they explained that there are serious risks to over-psychopathologizing a person with a chronic pain disorder. One of these risks is the dilemma associated with increasing the stigma that could ultimately add to the individuals suffering with pain may experience, especially when these judgements are paralleled by vague wording presented in the DSM-5, leading to a misdiagnosis (Frances \& Chapman, 2013).

Frances and Chapman (2013) also provided 10 concerns of the new SSD diagnosis, including, but not limited to: (1) stigma related to chronic pain conditions, (2) the risk of overlooking diagnoses that may be attributing to SSD, and (3) the increased risk of 
marginalization of women in the health care system. Additionally, the DSM-5 lists under SDD a specifier of with predominate pain, whether it is persistent (lasting more than six months), and if the severity is mild, moderate, or severe (American Psychiatric Association [APA], 2013). This language adds further complications to diagnosis and treatment, as most individuals with chronic pain meet most to all criteria for SDD.

Due to the psychological factors that are associated with chronic pain, it is beginning to become an increasingly common practice for individuals with chronic pain to be psychologically evaluated before being prescribed long-term opioids or receiving a spinal-cord stimulator implant. These evaluations have several purposes: (1) to determine one's pain intensity, (2) to understand their physical functioning, (3) to assess their emotional functioning, (4) to determine the patient's global rating of improvement, (5) to determine one's comorbid symptoms/current life stressors, and (6) to determine the patient's disposition (e.g., adherence, risk factors, positive and negative treatment indicators) (Williams, 2013). Additionally, assessments are generally given in order to obtain even further information about the patient's experience of pain and distress. Some of these assessments include the numerical rating scale, visual analog scale, McGill Pain Questionnaire, Medical Outcomes Study Short Form Health Survey (SF-36), Beck Depression Inventory, Pain Catastrophizing Scale, and Pain Behavior checklist (Dansie \& Turk, 2013). However, SDD and chronic pain are similar in regard to diagnostic criteria. Therefore, it is likely an individual with chronic pain will be diagnosed with SDD after an evaluation.

Biological Characteristics. There is currently no evidence to suggest why chronic pain develops and is sustained for longer than six months. However, there have been studies indicating that surgery as a treatment for chronic pain is not always the most effective option (Mirza \& Deyo, 2007). Furthermore, surgery has the possibility of not only producing zero to 
minimal effects for decreasing symptoms, but can also lead to additional problems with chronic pain. Between $2-10 \%$ of patients who have a surgical operation can develop persistent postsurgical pain, which increases the risk factors for those with chronic pain to have additional surgeries (Kehlet et al., 2006). In a longitudinal study by Dvorak et al. (1988), data suggests minimal effectiveness of surgery for lumbar disc herniation. They noted that of the 575 patients followed, $70 \%$ reported back pain post-operation, and $23 \%$ reported an increase in constant and severe pain. Dvorak and colleagues (1988) noted additional concerns with the somatic aspects of the pain experience of these individuals, and found that those who were receiving a disability pension had higher self-reported psychopathology.

There are other non-surgical medical interventions that are utilized for treating specific types of pain. For chronic back pain, which has the highest prevalence among individuals with chronic pain (Hardt et al., 2008), treatments can include trigger point injections, epidural steroid injections, medial branch blocks, radiofrequency ablations, intrathecal infusion devices, and spinal cord stimulators (Patel et al., 2015). However, according to the Cochrane review database, there is no strong evidence for the use of injections, radiofrequency denervation, or transcutaneous electrical nerve stimulation (TENS) in chronic back pain populations (Khadilkar et al., 2008; Maas et al., 2015; Staal et al., 2008).

One of the limitations in pain management literature are the inconsistencies on the efficacies of specific treatments. For example, in a randomized double-blind placebo-controlled study conducted by Perruchoud and colleagues (2013), they concluded that there was no significant difference between the use of a high frequency spinal cord stimulator versus a placebo condition. However, in a separate study on spinal cord stimulator efficacy for neuropathic pain and other pain etiologies, they found that $70 \%$ of respondents with neuropathic 
pain reported good outcomes with spinal cord stimulation. This was true for chronic pain disorders including failed back surgery syndrome and complex regional pain syndrome, among others (Krames et al., 2008).

One of the more controversial interventions for chronic pain is the utilization of longterm opioid-based medication treatment. The National Institute on Drug Abuse ([NIDA], 2018a) reported that common opioids include hydrocodone, oxycodone, oxymorphone, morphine, codeine, and fentanyl. Long-term opioid therapy is controversial because opioid medication has not been found to have higher pain reduction efficacy compared to other types of treatment, including but not limited to, spinal cord stimulators, injections, and radiofrequency ablations (Patel et al., 2015). In a recent meta-analysis on the analgesic efficacy of opioids for chronic pain treatment, 46 studies were examined for the maximum effectiveness for pain reduction between opioid and non-opioid medication compared to placebo (Reinecke et al., 2015). Reinecke and colleagues (2015) stated, “In summary, our assessment of maximum efficacy showed no significant differences between opioids and other pharmacological and non-pharmacological treatments" (p. 330). Additionally, a Cochrane review found very low to moderate evidence for opioid-therapy for long-term use in non-cancer related pain (Chaparro et al., 2013). Therefore, not only does opioid medication show little efficacy in terms of pain reduction by themselves, they are also dangerous and addictive. The NIDA (2018a) reported that opioid medications work by binding themselves to opioid receptors in the brain, which are closely related to organs that are responsible for pleasure. This serves as a positive reinforcement for continuation, increasing rapid tolerance for opioid-based medications; consequently, making them highly addictive. Additionally, opioids have the capability of overdose, which can lead to death. In the year 1999, 16,849 opioid overdoses were recorded. Since this time, there has been an exponential increase 
in overdoses among all ages. Shockingly, there were 70,237 opioid-related deaths recorded in 2017, illustrating a two-fold increase over a decade (NIDA, 2019).

With medical treatments not being effective on their own (Reinecke et al., 2015), it can often be discouraging for medical providers in pain management to provide comprehensive multimodal care. However, with the main goal of chronic pain care being to increase the overall functioning and reduce pain severity for these individuals, an important treatment consideration is to investigate predictors that increase the ability for chronic pain sufferers to participate in functional tasks, self-care activities, and recreational activities with the purpose of improving patient well-being.

\section{Theoretical Models of Chronic Pain}

The philosopher Descartes theorized in the 1664 Treatise of Man, that the mind and body are two separate entities and work as a machine. In relation to pain, he proposed that nerve fibers communicate pain signals to the brain (Melzack \& Katz, 2004). This theory became a foundation to future theories. Subsequently, there have been many more models that attempt to describe the biological mechanisms that contribute to chronic pain. Examples of past theories include specificity theory, intensive theory, and pattern theory (Dallenbach, 1939). Other theories utilize a systems approach, such as the familial model for chronic pain, which propose that families contribute to ones' perception of pain (Violon \& Giurgea, 1984). Additionally, a new model has emerged that attempts to address all biopsychosocial concerns; the complexity model (Peppin et al., 2015). However, there are two models of chronic pain that are primarily used for intervention construction. The most recognizable to pain specialists is the gate control theory of pain (GCT), which is a biological model of chronic pain. Secondly is the fear-avoidance model (FAM), which is a model of disability within the chronic pain framework. 
Gate control theory was proposed in 1965 by Ronald Melzack and Patrick Wall. Gate control theory combines past concepts, such as specificity theory and peripheral pattern theory (Moayedi \& Davis, 2012). According to the GCT, the areas of the brain that are responsible for thought (frontal cortex), emotions (limbic system), and regulatory processes (hypothalamus) are responsible for influencing how pain is communicated to the spinal cord, via neurotransmitters, endogenous opiates, and hormones such as cortisol. All of these systems, according to this theory, contribute to the way the individual feels and responds to pain (Melzack \& Wall, 1966). Melzack (1999) suggested that due to multiple sensory, cognitive, visual, peripheral, and emotional inputs, there is a disruption in the regulatory patterns of the brain's neurons, which ultimately leads to a prolonged stress response. Over time, this increases an individual's cortisol levels, which sequentially increases fatigue in muscle, bone, and neural tissues. All these conditions create the perfect storm for chronic pain to occur. Over time, this cycle of limited behavioral activation increases disability (Melzack, 1999).

Gate control theory broadly suggests that increasing stimulation in one area will decrease the experience of pain due to the excitement of other senses. This is done through the peripheral nervous system and its interaction with the central nervous system, where ultimately pain is communicated with the brain (Kirkpatrick et al., 2015). Wall and Sweet (1967) first examined this theory and tested if electrical stimulation of the large sensory fibers would improve pain in eight patients. They discovered that four patients with chronic pain syndromes experienced pain relief for more than thirty minutes after stimulation (Wall \& Sweet, 1967). This theory of pain has informed various types of medical treatment for chronic pain. Common treatments that are based on the GCT model include the transcutaneous electrical nerve stimulation units, spinal cord stimulators, and psychoeducational interventions. 
While GCT seeks to explain the biological and cognitive mechanisms that contribute to the severity of pain, the fear-avoidance model seeks to explain pain disability through a cognitive-behavioral lens. Developed after GCT, Lethem and colleagues (1983) first suggested this model to describe how pain-avoidance patterns can lead to disability. The fear-avoidance model of chronic pain (FAM) has been cited as being one of the leading models of chronic pain disability treatment (Lethem et al., 1983). The FAM is described as a "theoretical model to guide pain research and management, describing the cascade of events after pain that is perceived as threatening" (Vlaeyen et al., 2016, p. 1588). In the context of chronic pain, the FAM describes fear of the anticipated pain after an event is the primary mechanism that perpetuates the chronic pain experience. This may be due to an individual having a novel event in which they suffered pain, resulting in a conditioned response. Therefore, an individual may avoid this novel experience in the future due to predicted pain. Once this cognitive-behavioral experience is learned, it often remains as a schema that the individual creates (Vlaeyen et al., 2016). What this schema eventually becomes is a learned lifestyle of disability. This learned disabled lifestyle can inadvertently affect one's muscle strength, coordination, and physical health overall. Thus, disability continues to reinforce the pain problem (Pfingsten et al., 2001).

In a study by Trost and colleagues (2011), they sought to understand the relationship between pain-related fear and how individuals experienced lower-back pain. Thirty-three participants with no prior history of back pain were asked to partake in an exercise that would subsequently increase soreness in the lumbar/muscle areas. Through the utilization of measures that predict fear of pain and anxiety, they found that there is a psychological component that impacts an individual's willingness to participate in activities post-soreness, thus interfering with 
daily activities. This is an important study showing that fear and anxiety are psychological variables that impact the chronic pain experience, and contributes to persistent disability.

In another landmark study to demonstrate the psychological components and their relationships to chronic pain and disability, Pfingsten and colleagues (2001) conducted a randomized control trial in which they investigated if future fear of pain would ultimately lead to avoidance. Fifty-five participants with chronic low back pain were examined by first establishing a baseline of general mobility. They informed one group that the experiment would cause no pain, and the other group was told that a slight increase in pain would be expected. Results reflected that the participants in the pain-anticipation group reported elevated pain severity. Results also showed that the pain-anticipation group had lower behavioral performance and higher fear. While this study did not communicate what mechanism is responsible for the avoidance behavior, it did support the notion that the fear of pain increases ones' anxiety and ultimately contributes to the pain disability cycle. This study provided future researchers with direction for needed research in the field of chronic pain and psychology. Pfingsten et al. (2001) described this study as having significant clinical implications, in that the expectation of future pain can negatively influence the client's pain experience.

\section{Counseling Modalities and Chronic Pain}

As mentioned in previous sections, research has led to the development of many medical treatments in an attempt to decrease suffering for an individual with chronic pain (i.e., opioidbased medications, spinal cord stimulators, intrathecal pump, etc.). Additionally, GCT conceptualizes chronic pain through biological and cognitive contexts. Furthermore, this literature review has also examined how psychological and behavioral factors can provide a framework of disability through the fear-avoidance model (FAM). However, it is critical to 
discuss how these widely used theories have been utilized to conceptualize psychotherapeutic modalities. Since GCT and FAM both apply a cognitive-behavioral framework, Dietrich (2010) provided context on the treatments that are currently in the forefront of chronic pain intervention research, stating that treatments such as cognitive behavioral therapy, mindfulness, and acceptance and commitment therapy have the ability to potentially decrease distress and mitigate the development of chronic pain. Dietrich (2010) provides a framework on psychological intervention modalities that may be helpful for patients' management of their pain. Literature on cognitive behavioral therapy (CBT) is vast, whilst acceptance and commitment therapy (ACT) for chronic pain still has room for expansion.

Cognitive Behavioral Therapy for Chronic Pain. Cognitive behavioral therapy (CBT) has been considered the "gold standard" for therapy when working with patients with chronic pain (Seminowicz et al., 2013). The Beck Institute for Cognitive Behavioral Therapy (2016) describes CBT as an intervention that is structured, brief, and has goals directed at psychoeducation and changing an individual's dysfunctional thoughts and behavior. Theory has helped shape how CBT for chronic pain has become the "gold standard" through past models. Specifically, the fear-avoidance model has been connected to CBT for chronic pain and disability (Lethem et al., 1983).

CBT for chronic pain has had substantial literature produced over the years that attempts to improve the quality of life of individuals with chronic pain. CBT is a noteworthy intervention, in that it has utility for a variety of symptoms related specifically to chronic pain. Examples of its breadth of utilization are the CBT treatments for sleep abnormalities, mental health disorders, and chronic lower back pain severity (Gatchel \& Rollings, 2008; Nash et al., 2013; Tang, 2009). Treatment for chronic pain utilizing CBT typically focuses on reducing pain and distress through 
modifying physical sensations, catastrophic thinking, and maladaptive behaviors (Knoerl et al., 2016). Another positive aspect of CBT is that it has been well researched in different groups and populations. Some examples of this include individuals with HIV (Cucciare et al., 2009), people in rural communities with low literacy rates (Thorn et al., 2011), and older adult populations (Beissener et. al., 2009).

In a meta-analysis conducted by Knoerl et al. (2016), thirty-five studies were examined in which $43 \%$ of the trials yielded results that suggest a relationship between CBT as a treatment modality and pain reduction. As mentioned previously, this is only slightly less than the percentage of patients who perceived their prescription medication was an effective for treatment of their chronic pain (NIH, 2010). They also found that the most commonly studied duration of treatment using CBT for chronic pain was about six to ten weeks, and that the effectiveness varied across different interventions (Knoerl et al., 2016). However, time of treatment was shown to be an important factor in reducing pain intensity, finding that participants experienced positive effects ranging from $0 \%$ (1-5 weeks of CBT treatment) to $75 \%$ (>20 weeks of CBT treatment) (Knoerl et al., 2016).

In an additional study utilizing CBT for individuals disabled by chronic pain, McCracken and colleagues (2007) examined the effects of contextual cognitive-behavioral therapy on a chronic pain population versus no treatment. This study followed 53 highly disabled individuals affected by chronic pain as they received a CBT intervention. Results of the study indicated that participants involved in the treatment group showed a significant change in distress related to their chronic pain, disability, depression, pain related anxiety, daytime rest, and activity performance. Additionally, they found the results were still clinically meaningful after a three 
month follow up (McCracken et al., 2007). This study, among many others, has shown CBT as an evidenced-based treatment modality has demonstrated to be effective for chronic pain.

To counter CBT, a wave of literature has begun to be published on ACT, which has prompted researchers to determine the benefits of one intervention over the other. In a systematic review, Öst (2008) compared studies that applied CBT and ACT as a treatment intervention. In this review, he suggested that CBT was a better modality overall due to having more empirical support. Öst (2008) also mentioned that CBT was more effective modality due to the generalizability that CBT offers its clients. However, in a defense against Öst's article, Gaudiano (2009) did not agree with Öst's (2008) attempts to challenge ACT. In fact, Guadiano (2009) refuted Öst's (2008) conclusions, stating that his empirical matching methodology bolstered his argument for CBT while minimizing the research on the significance of ACT. With such a divide between CBT and ACT, it is more important than ever to review the literature on ACT, and more specifically its use in the chronic pain population.

Acceptance and Commitment Therapy. Acceptance and commitment therapy (ACT) is part of a third wave in behavioral therapy (Hayes, 2004). Included among the third wave of behavioral interventions are functional analytic psychotherapy, dialectical behavior therapy, integrative behavioral couple's therapy, and mindfulness-based cognitive therapy (Zettle, 2011). ACT is a segment of a larger scientific approach, termed contextual behavioral science (CBS). CBS is a new wave in behavioral science that led to Relational Frame Theory (RFT), which subsequently assisted in the development of ACT.

Zettle (2011) provided a comprehensive history of ACT by describing ACT's development in three stages: (1) the formative period in the 1970's-1980's that provided the conceptual foundation, (2) the development of relational frame theory in the mid-late 1980's that 
provided a clear theoretical orientation, and (3) the investigational period in which ACT was further studied and validated as a contextualistic approach. The formative period of ACT (late 1970's-1985), was a time in which Steven Hayes and Robert Zettle were working together at the University of North Carolina at Greensboro and conceptualized the idea of the role that thoughts play in human behavior. Utilizing a Skinnerian framework for behavioral markers in clinical settings, Hayes (1981, as cited by Zettle, 2011) developed a handbook that described what is now referred to as comprehensive distancing. The concept has components of ACT, including defusion, metaphors, and de-literalization, which later helped to move this theory into the transitional period (Zettle, 2011).

The transitional period (1985-1999) began with a presentation by Hayes and Brownstein in 1985 , in which they provided an overview of relational frame theory and ended with the publication of the first ACT book in 1999 (Zettle, 2011). Within relational frame theory, the concepts of speaking and listening are at the core. This later became a foundation for ACT. The transitional period coined the term comprehensive distancing which later becomes one of the tenets of ACT. Zettle (2011) described this transition as occurring once he and Hayes distanced themselves from cognitive behavioral therapy. Third, the coming-of-age dissemination period (2000-present) has consisted of considerable growth in the form of outcome research and process research. Although it is unknown when ACT was formally established, it is clear that the mid2000's is when the number of publications on ACT drastically swelled.

One of the key tenets of ACT is the psychological flexibility model, which is "the process of contacting the present moment fully as a conscious human being and persisting or changing behavior in the service of chosen values" (Hayes \& Lillis, 2012, p. 41). The six core processes of intervention and human flourishing within the psychological flexibility model include (1) 
acceptance, (2) defusion, (3) perspective taking sense of self, (4) flexible attention to the present moment, (5) values, and (6) committed action. The Association for Contextual Behavioral Science ([ACBS], n.d.) described acceptance as involving the active and mindful recognition of one's thoughts without making efforts to change these private events in their frequency or form. Secondly, defusion is defined as "attempting to change the way one interacts with or relates to thoughts by creating context in which their unhelpful functions diminished" (ACBS, n.d., § 3). In other words, an individual may feel stuck in their thoughts, rather than seeing them as they are as just cognitions. Flexible attention to the present moment (Hayes \& Lillis, 2012) has also been referred to as being present (ACBS, n.d.). Being present is described as experiencing the world around oneself more directly so that behaviors can be observed objectively, and in turn will increase control over behaviors (ACBS, n.d.)

The fourth of the core processes is perspective taking (Hayes \& Lillis, 2012). This is also known as sense of self (ACBS, n.s.) Sense of self is described as an awareness of one's own experiences and their stories, whilst attempting to remove attachment of these stories by attempting to not 'read into' or investigate these experiences (ACBS, n.d.). Values is defined as, "chosen qualities of purposive action that can never be obtained as an object but can be instantiated moment by moment” (ACBS, n.d., § 6). ACT, in its nature, is meant to bring individuals closer to their values by living a more fulfilling life that is in line with what is central to them (i.e., values). In doing so, one must participate in the final of the six core processes, committed action. Committed action is the behavior change that occurs once an individual participates in activities that are consistent with one's values. This can be done though activities such as exposure, gaining skills, and goal setting (Hayes \& Lillis, 2012) 
ACT can be used with an individual or group modality. However, the role of the therapist is similar to humanistic approaches. Thus, the therapist and the clients' relationship hold a central role within the therapeutic space. Additionally, the therapist must be mindful of the processes that are taking place within, along with the patient during treatment (Hayes \& Lillis, 2012). The role of the client in the therapeutic context is also similar to the humanistic approach, in that ACT is considered to be client-centered. The values set forth by the client become the center of the therapeutic work, and set the treatment plan for future goal attainment (Hayes \& Lillis, 2012).

Acceptance and Commitment Therapy for Chronic Pain. ACT has been the subject of less research than some other treatment modalities (e.g., CBT), especially in relation to the research pertaining to the chronic pain population. However, ACT is becoming increasingly popular. Hayes et al. (2006), stated that this intervention has been gaining recent momentum as a result of an increase in empirical support through literature reviews and clinical trials.

McCracken et al. (2005), provided an important call for more research in ACT. They stated:

Psychological approaches to chronic pain, including current CBT, have a strong evidence base suggesting their effectiveness. However, missing from this evidence base are the necessary evaluation studies, high in ecological validity, that confirm the particular treatment components that lead to success, or that address the processes by which patients improve. This gap is slowly being filled. An acceptance-based treatment approach, with its particular view of private experience, provides a promising base for further therapy development. (McCracken et al., 2005, p. 1344)

Twohig (2012) also described ACT as emerging from the CBT model, with ingredients that closely resemble CBT. As mentioned in the previous section, ACT possesses six core 
processes of intervention and human flourishing. These processes include (1) acceptance, (2) cognitive defusion, (3) flexible attention to the present moment, (4) perspective taking/sense of self (5) values, and (6) committed action (Hayes \& Lillis, 2012). Within the chronic pain context, all of these processes have been studied as a way to enhance the literature supporting ACT as a treatment modality. Acceptance has been thoroughly studied regarding chronic pain. In a study on the process of pain acceptance in women with arthritis and fibromyalgia, LaChapelle and colleagues (2008) sought to further understand the variables that contribute to acceptance of pain. They found factors that hindered pain acceptance included difficulties with their pain identity, the negative impact that pain has on relationships, and others not accepting their personal pain experiences. Factors that increased acceptance included having a clear diagnosis, education of self and others, self-care, and an increased social support network.

In a separate study on acceptance-based treatment for those with chronic pain, McCracken et al. (2005), considered the effects of acceptance and outcome variables in a preposttest study. After administering an acceptance-based treatment for those with complex chronic pain, they found significant results in areas such as pain severity, reductions in depression, reduction in physical disability, and reductions in psychosocial disability. These results are noteworthy for several reasons. They described that these individuals failed several types of treatment, but still found notable effects with this psychological intervention. Additionally, for this intervention, they used a more integrative approach (help of nurses, occupational therapists, etc.), which further corroborates the idea that using an integrative approach to chronic pain care may be a better option for these patients (McCracken et al., 2005).

The second of the six core processes of ACT is cognitive defusion. McCracken and colleagues (2014) described cognitive defusion as having the least amount of evidence of the six 
core processes. As a way to provide support for the construct validity of cognitive defusion, McCracken et al. (2014) recruited 325 participants in a four-week interdisciplinary pain management program. The purpose was to investigate factors that are related to rumination in a chronic pain population. They found support for this construct, reporting that rumination and decentering were both factors that were involved in the cognitive defusion process. Additionally, they found significant results pertaining to how rumination and decentering play a role in mental health, social functioning, and depression (McCracken et al., 2014).

The third of the six core processes is flexible attention to the present moment (Hayes \& Lillis, 2012). This is also sometimes referred to being present (ACBS, n.d). While the term being present is sparse in regard to chronic pain literature, there is an immense amount of literature on mindfulness-based interventions, ACT, and chronic pain. de Boer and colleagues (2014) sought to understand the implications that mindfulness and acceptance may have in decreasing catastrophic thinking in a chronic pain population. They found that individuals with higher levels of acceptance tended to catastrophize less compared to those who did not (de Boer et al., 2014).

The fourth of the six core processes of ACT, self as context, shows the same limitations in literature as the third core process, which is that there is sparse literature validating this construct within the chronic pain context (Liu \& McCracken, 2016). Nonetheless, in a metaanalysis of self as context in chronic pain literature, Liu and McCracken (2016) reported the content-based self has been studied in forms of self-esteem, self-concept, and processes specific to a pain condition. Additionally, Liu and McCracken (2016) suggested that one of the limitations of the literature pertaining to self-as-context is that there is not a current model of the self that one could utilize as a theoretical base for future research. 
The fifth of the six core processes of ACT is values. A study on adolescents with chronic pain utilizing a values-based treatment was conducted with the objective of exploring the relationship between acceptance and functional outcome (Gauntlett-Gilbert, Connell, Clinch, \& McCracken, 2012). Results showed that ACT as a form of treatment was effective for this population in that these participants showed improvements in psychological functioning, school attendance and a decrease in health-care service utilization (Gauntlett-Gilbert et al., 2012).

In an additional publication on the effectiveness of utilizing a values-based treatment for individuals with chronic pain, Vowles and McCracken (2008) recruited 171 participants involved in an interdisciplinary treatment program for chronic pain. The treatment program consisted of an adaptation of ACT and mindfulness techniques over a course of three to four weeks, with treatment lasting approximately seven hours per day, and was held five times per week. Vowles and McCracken (2008) found this treatment to be effective in significantly improving reported pain severity, symptoms of depression, pain-catastrophizing, lowered disability, fewer medical visits, and an increase in physical performance. The results of this study indicate the importance of values and other ACT-based components when working with chronic pain patients.

The difficulty with chronic pain is that the small behaviors learned over time can have a spiraling effect that contributes to overall long-term disability. Although this is a complicated issue, ACT for chronic pain has been shown to be an effective method of treatment for various sorts of targeted behaviors, thoughts, and cognitions that may lead to future social, physical, and psychological concerns. Additionally, ACT is a noteworthy intervention that has the possibility of improving quality of life for individuals suffering from chronic pain (McCracken et al., 2005). 


\section{Brief Interventions for Chronic Pain}

Brief interventions for mental health are not a new phenomenon. In fact, they began to appear with the emergence of the second wave of psychotherapy. The first force in psychotherapy (psychoanalysis) would generally take a long-term commitment by the therapist and client (Jones-Smith, 2012). However, once the second force of psychotherapy (including behavior therapy, cognitive approaches to therapy, and reality/choice therapy) emerged, four to six session therapies became a better treatment option for many clients (Jones-Smith, 2012). This was a significant advancement for counseling psychology because it broadened the cliental that could be seen and allowed for psychologists to be more accessible within community health settings and hospitals.

Brief therapies share characteristics that other long-term therapies do not. Bor and colleagues (2004) stated the overarching characteristics of brief therapies include, but are not limited to, (1) an intention to move towards goals within an effective time-span, (2) the therapeutic alliance as an important component, (3) flexibility and creativity is increased due to limited time, and (4) interventions are introduced early in the therapeutic setting. Also, in a chapter written on brief therapies for chronic pain, Roy (2008) concluded that brief therapy is one of the most common, effective, and economical forms of psychotherapy, as compared to long-term psychodynamic psychotherapy.

This conclusion, as well as the overarching characteristics presented by Bor et al. (2004), show the breadth of brief interventions as a modality in general. Additionally, Roy (2008) explained that brief therapies are also an effective treatment for chronic pain within the setting of pain clinics. He cited that cognitive behavioral therapy, solution focused therapy, and interpersonal therapy are all viable options for treatment (Roy, 2008). 
With brief interventions being the primary mental health treatment modality within pain clinics, there has been a new wave recently that has attempted to reduce four-ten sessions to only one single-session. In an article by Darnall and colleagues (2014), they developed a 120-minute workshop with the goal of reducing pain catastrophizing. As mentioned in previous sections, catastrophizing is a psychological factor that has been noted to contribute to the development of chronic pain (Darnall et al., 2014). Their study was an uncontrolled prospective pilot trial that treated 57 total patients who attended a free, educational, CBT-based pain class. This class had two main components. The first was to provide didactic content, such as mind-body science, and how to identify pain catastrophizing in themselves. Secondly was skills acquisition, such as deep-breathing activities and progressive muscle relaxation. When the treatment was completed, participants were given tangible items to leave the class with, including their own pain catastrophizing plan, a 20-minute relaxation audio, and the content of the class. Overall, the findings were significant in many ways. First, they found that this pilot study was effective in reducing pain catastrophizing two- and four-weeks post-treatment. Secondly, they found that the treatment effect increased over time, with participants reporting reduced levels of catastrophizing at four-weeks post-treatment. They stated, "Our finding that a single-session class may effectively reduce PC is particularly exciting because this novel form of specific and concentrated pain-CBT treatment may greatly expand access to low-cost, efficient care" (p. 224).

Dindo and colleagues (2018) have also recently published a study on a preventative, onesession ACT workshop to reduce the risk of chronic pain and opioid use post-surgery for at-risk veterans. The variables Dindo et al. (2018) described as increasing risk of chronic pain and opioid use post-surgery included high levels of pain and significant levels of depression and 
anxiety pre-surgery. This single-blinded, prospective randomized control study utilized a treatment as usual (TAU) group $(n=44)$ and a 1-day ACT workshop group $(n=44)$.

TAU consisted of a nurse-led group educating patients on what to expect after surgery. The psychologist-led, one-day ACT workshop covered topics such as acceptance, mindfulness, management of maladaptive thoughts, pain willingness, recognizing behavioral patterns contributing to pain, and commitment to future goals regardless of potential pain sensations (Dindo et al., 2018). Outcome measures included the Chronic Pain Acceptance Questionnaire (McCracken et al., 2004) and the Chronic Pain Values Inventory (McCracken \& Yang, 2006). After baseline measurements were received, and treatment had been administered, a three-month follow-up was conducted to determine if the group was successful. The findings of this study were promising. Participants in the four-hour ACT workshop group achieved pain and opioid cessation at higher rates compared to the TAU group.

Single-session treatment modalities for chronic pain is a novel approach. However, with the publication of both Darnall et al. (2014) and Dindo et al. (2018) studies, there has been an increased interest in the continuation of this research. Recently, Darnall and colleagues (2018) published a protocol for a prospective study in which they will investigate the difference between three classes. The first group will consist of the single-session CBT class mentioned in the above study, the second group will include a single-session health education class, and the third group will be an eight-week cognitive behavioral therapy treatment. Although this has not been published, this study is promising for increasing our knowledge on symptom reduction through a single-session brief intervention that has the possibility of increasing the quality of life for individuals with chronic pain (Darnall et al., 2018). 


\section{Current Study}

There have been studies that have attempted to utilize single-session ACT workshops for other purposes, including decreasing weight for obese individuals (Lillis et al., 2009) and body dissatisfaction with disordered eating (Pearson et al., 2012). Regarding the chronic pain population, there have been few studies that address one-session interventions for decreasing psychological factors that contribute to the severity and duration of symptoms. Even fewer studies provide one-session interventions for individuals with chronic pain by utilizing acceptance and commitment therapy (ACT). The current study attempted to address a major gap in the literature on whether or not ACT is to be considered an evidence-based treatment approach to chronic pain (McCracken \& Vowles, 2014; Society of Clinical Psychology, 2016).

Additionally, past literature has reported the effectiveness of single-session workshops in reducing pain-related worry (Darnall et al., 2014), and can be used as a preventative measure in future treatments (Dindo et al., 2018). Therefore, there is a need for research on a one-session, ACT-based treatment for individuals with chronic pain. It is anticipated that this study will provide tools for individuals practicing in underprovided rural areas and/or for individuals who are unable to receive care due to financial burdens.

\section{Research Questions and Hypotheses}

The current study investigated how a brief ACT workshop may increase adaptive painrelated coping mechanisms, such as pain acceptance, as well as decrease maladaptive coping mechanisms such as pain catastrophizing. The larger purpose is to provide mental health practitioners with a brief intervention workshop that will support communities of people who often experience difficulties accessing mental health care. From this purpose, two questions were addressed. First, does a brief one-session, ACT-based workshop intervention lead to a significant 
improvement in chronic pain acceptance among chronic pain individuals? Secondly, does a brief, one-session ACT-based workshop lead to a significant improvement in pain catastrophizing among chronic pain individuals? To answer the research questions, the following hypotheses were tested.

Hypothesis 1. Individuals experiencing chronic pain who attend a brief ACT workshop will report a significant improvement in overall pain acceptance scores post-workshop as compared to overall pain acceptance scores pre-workshop.

Hypothesis 2. Individuals experiencing chronic pain who attend a brief ACT workshop will report a significant improvement in activity engagement scores post-workshop as compared to activity engagement scores pre-workshop.

Hypothesis 3. Individuals experiencing chronic pain who attend a brief ACT workshop will report a significant improvement in pain willingness scores post-workshop as compared to pain willingness scores pre-workshop.

Hypothesis 4. Individuals experiencing chronic pain who attend a brief ACT workshop will report a significant improvement in pain catastrophizing scores post-workshop as compared to pain catastrophizing scores pre-workshop. 


\section{Chapter 2: Method}

\section{Participants}

Individuals over the age of 18 , and reporting chronic pain persisting for six months or more were eligible to participate in this study. Participants were also required to be a patient and receiving treatment at a medical center specific to pain management. These individuals were recruited through an integrative pain clinic located in the Mid-Atlantic Appalachian region. The ideal sample size of participants needed to reach an appropriate effect size was 27 . This sample size was calculated utilizing a G*Power software (Faul et al., 2008). This was based on a Cohen's $d=0.5$, a Power (1- $\beta$ err prob) of .80, and an alpha ( $\alpha)$ of .05. Therefore, an initial total sample of 45 participates were asked if they were willing to participate in a free, one-session, ACT-workshop to account for moderate dropout rates. However, approximately half $(n=21)$ did not agree to participate, leading to an initial 24 participants who agreed to enroll in the study. Of these 24 individuals, five cases were removed from the final analyses due to incompletion of the four-week post-treatment follow-up phone call. Therefore, a total of 19 participants were included in the final data analysis. Unfortunately, this total sample size did not meet the projected 27 participants needed to reach the appropriate effect size. However, due to the onesample, pretest-posttest, prospective, and exploratory nature of this study, the data from the final 19 participants were analyzed to determine the potential effectiveness of the group.

After receiving approval from the West Virginia University Institutional Review Board, recruitment was conducted via two convenience sampling strategies. First, patients who were already enrolled in a chronic pain group were asked to participate during the times their usual psychotherapy groups were scheduled. Secondly, patients were also able to be referred by medical professionals employed at the integrative pain clinic. The medical professionals who 
could refer included physicians, physician assistants, nurse practitioners, registered nurses, chiropractors, physical therapists, movement therapists, psychiatrists, psychologists, and other mental health professionals. Recruitment for this study took place over a six-month period, to maximize the total number of participants.

The final sample demographics of participants are summarized in Table 1. The participants' ages ranged from 30 to 75 years old $(M=51.26, S D=12.40)$. Zip codes reported by the participants were compared to the Federal Office of Rural Health Policy (FORHP) (Health Resources \& Services Administration [HRSA], 2018) data files to determine the number of participants located in a rural location versus a non-rural location. Through the utilization of the FORHP's zip code database, $52.6 \%(n=10)$ of the participants resided in a rural location and 47.4\% $(n=9)$ participants were located in a non-rural location (HRSA, 2018). Regarding participant education, $10.5 \%(n=2)$ had less than high school diploma, $15.8 \%(n=3)$ reported a general education diploma, $15.8 \%(n=3)$ reported holding a high school diploma, $31.6 \%(n=6)$ reported having some college experience, $15.8 \%(n=3)$ reported having a bachelor's degree, and $10.5(n=2)$ reported having a graduate degree. Regarding the duration of chronic pain experienced by participants, $5.3 \%(n=1)$ reported less than one year but more than six months, $15.8 \%(n=3)$ reported six to ten years, $42.1 \%(n=8)$ reported eleven to twenty years, $38.1 \%(n$ =6) reported twenty-one to thirty years, and 5.3\% $(n=1)$ reported experiencing pain between thirty-one and forty years. Participants were asked to circle a blank figure to describe the location of their pain. They were able to circle as many areas as they experienced pain. Please refer to Table 2 for frequencies and percentages associated with clients' location of pain. Overall, participants experienced pain in their lower extremity region $(52.6 \%, n=10)$, their lumbar 
region $(47.4 \%, n=9)$, and their thoracic region $(42.1 \%, n=8)$ at higher frequencies than other pain locations.

Table 1

Participant Demographics

\begin{tabular}{|c|c|c|}
\hline \multirow{2}{*}{ Variable } & \multicolumn{2}{|c|}{ Frequency } \\
\hline & $\%$ & $n$ \\
\hline \multicolumn{3}{|l|}{ Sex } \\
\hline Male & 52.6 & 10 \\
\hline Female & 47.4 & 9 \\
\hline \multicolumn{3}{|l|}{ Age (Years) } \\
\hline $30-35$ & 5.3 & 2 \\
\hline $36-40$ & 5.3 & 2 \\
\hline $41-45$ & 5.3 & 2 \\
\hline $46-50$ & 10.5 & 4 \\
\hline $51-55$ & 7.9 & 3 \\
\hline $56-60$ & 5.3 & 2 \\
\hline $61-65$ & 5.3 & 2 \\
\hline $71-75$ & 5.3 & 2 \\
\hline \multicolumn{3}{|l|}{ Geographical Location } \\
\hline Rural & 52.6 & 10 \\
\hline Non-Rural & 47.4 & 9 \\
\hline \multicolumn{3}{|l|}{ Education } \\
\hline Less than High School Diploma & 10.5 & 2 \\
\hline General Education Diploma & 15.8 & 3 \\
\hline High School Diploma & 15.8 & 3 \\
\hline Some College & 31.6 & 6 \\
\hline Bachelor's Degree & 15.8 & 3 \\
\hline Graduate Degree & 10.5 & 2 \\
\hline
\end{tabular}

Note. $n=19$ 
Table 2

Participant Pain Demographics

\begin{tabular}{|c|c|c|c|}
\hline \multirow{2}{*}{\multicolumn{2}{|c|}{ Variable }} & \multicolumn{2}{|c|}{ Frequency } \\
\hline & & $\%$ & $n$ \\
\hline \multicolumn{4}{|l|}{ Duration of pain } \\
\hline & 6 months - 1 year & 5.3 & 1 \\
\hline & 2 - 5 years & 0 & 0 \\
\hline & $6-10$ years & 15.8 & 3 \\
\hline & 11 - 20 years & 42.1 & 8 \\
\hline & 21 - 30 years & 31.8 & 6 \\
\hline & $31-40$ years & 5.3 & 1 \\
\hline \multicolumn{4}{|l|}{ Location of Pain } \\
\hline & Lower Extremity Region & 52.6 & 10 \\
\hline & Lumbar Region & 47.4 & 9 \\
\hline & Thoracic Region & 42.1 & 8 \\
\hline & Upper Extremity Region & 26.3 & 5 \\
\hline & Groin Region & 26.3 & 5 \\
\hline & Cervical Region & 26.3 & 5 \\
\hline & Buttocks Region & 26.3 & 5 \\
\hline & Abdomen Region & 21.1 & 4 \\
\hline & Shoulder Region & 15.8 & 3 \\
\hline
\end{tabular}

Note. $n=19$

\section{Measures}

\section{Demographic Questionnaire}

A demographic questionnaire was administered to gain descriptive information on several categories including age, zip code, sex, level of education, duration of pain symptoms, and location of pain. The variable sex has been studied in regard to pain acceptance and pain catastrophizing (Keogh et al., 2005; Sullivan et al., 1995). Therefore, sex was considered during this study in order to properally assess treatment effects. Duration of pain and education are critical to understanding the participants' perception of the one-session ACT-intervention. Education levels determined the grade-level in which the material was taught to make sure the 
participants were able to understand the material. In a study conducted by Lanitis and colleagues (2015), they found that individuals with less education experienced higher levels of pain severity post-operatively versus individuals with higher education statuses. Therefore, information on these demographic variables produced additional information for exploratory analyses (See Chapter 3 Results: Exploratory Analysis).

\section{Chronic Pain Acceptance Questionnaire - Revised (CPAQ-R; McCracken et al., 2004)}

The CPAQ-R is adapted from the Chronic Pain Acceptance Questionnaire, which originally consisted of 34 items (McCracken, 1999). The CPAQ-R is adjusted to be a 20-item questionnaire that measures pain acceptance. The CPAQ-R has two sub-scales. First is activity engagement, which refers to the ability of an individual to continue to participate in life regardless of their current pain experience. Secondly is pain willingness, which refers to having knowledge of past maladaptive coping mechanisms such as avoidance and control as a way of living with chronic pain. The 20 questions on the CPAQ-R are rated on a 7-point Likert-type scale $(0=$ never true to $6=$ always true $)$. When scoring the CPAQ-R, the items related to the pain willingness and activity engagement subscales are added separately. A total score is also used to indicate overall pain acceptance. Higher total scores on the CPAQ-R are indicative of higher levels of pain acceptance.

Studies have supported the factoral stucture, internal consistency and validity of the CPAQ-R (McCracken et al., 2004; Vowles et al., 2008). McCracken and colleagues (2004) conducted a study utilizing the parent measure, the CPAQ, to determine which of the four subscales were predictive of pain intensity, which subsequently led to the development of the CPAQ-R. The CPAQ consisted of four subscales, including (1) activity engagement, (2) pain willingness, (3) thought control, and (4) chronicity. Two-hundred and thirty-five participants 
referred through a pain management program with an average pain duration of 119.5 months completed questionnaires such as the CPAQ, and scales related to pain severity, depression, anxiety, disability, catastrophizing, fear-avoidance, and self-efficacy.

After frequency distributions were assessed on each item to determine if any of the questions were skewed, an item-total correlation was calculated to designate if the items were suitable for the final draft of the CPAQ-R. McCracken et al. (2004) conducted a principal components analysis, in which they found four factors that accounted for $46.7 \%$ of the variability within the given items. The internal consistency reliability is acceptable, with Cronbach's $\alpha=$ .82 for the activity engagement subscale, Cronbach's $\alpha=.78$ for the pain willingness subscale, Cronbach's $\alpha=.64$ for the thought control subscale, and Cronbach's $\alpha=.62$ for the chronicity subscale (McCracken et al., 2004).

The CPAQ was then compared with other instruments that are regularly employed in pain evaluations. These measures were categorized into three groups, including medically oriented, physical disability and functioning, and psychosocial issues. After analyzing the subscales on the CPAQ for relationships with these measures, McCracken et al. (2004) discovered activity engagement and pain willingness were significant predictors of variables such as pain intensity (activity engagement, $r=-.17$; pain willingness, $r=-.25$ ), physical disability (activity engagement, $r=-19$; pain willingness, $r=-.33$ ), work status (activity engagement, $r=.33$; pain willingness, $r=.24$ ), depression (activity engagement, $r=-.51$; pain willingness, $r=-.49$ ), psychosocial disability (activity engagement, $r=-.34$; pain willingness, $r=-.46$ ), and pain-related anxiety (activity engagement, $r=-.51$; pain willingness, $r=-.63$ ). Therefore, the revised version only includes the activity engagement and pain willingness subscales, as there was more support for 
predictability regarding pain related variables over and above the other subscales (i.e., thought control and chronicity) on the CPAQ (McCracken et al., 2004).

For the purpose of this study, chronic pain acceptance, along with the two sub-scales (i.e., activity engagement and pain willingness) were considered outcome variables. Due to the evidence in literature on the respectable psychometric properties, the CPAQ-R was an appropriate measure to determine participants' chronic pain acceptance. Overall good internal consistency reliability ( $\alpha=.81$ ) was demonstrated for the current study and corresponded to the previously mentioned studies. Pre-and post-workshop data were split to determine if the measure held adequate internal consistency reliability pre- and post-test, the Cronbach's alphas for the CPAQ-R were .87 pre-test and .67 post-test, respectively. This change in internal consistency reliability pre- and post-test may be attributed to the nature in which the individuals were administered the questionnaire (i.e., paper versus telephone administration).

\section{Two-Item Pain Catastrophizing Questionnaire (2-PCQ; Jensen et al., 2003)}

For the purpose of this study, a two-item pain-catastrophizing questionnaire was used. This two-item scale is derived from the Coping Strategies Questionnaire (CSQ) (Rosenstiel \& Keefe, 1983). Jensen, Keefe, Lefebvre, Romano, and Turner (2003) developed a reliable twoitem catastrophizing questionnaire derived from the CSQ. The CSQ's purpose is to assess the occurrence of how individuals cope with their pain. The coping mechanisms encompassed within the CSQ include guarding behavior, interpretation of pain sensation, behavior activities, pain avoidance, spirituality, coping self-statements, activities, and pain catastrophizing (Rosenstiel \& Keefe, 1983). The six-item catastrophizing subscale on the CSQ has a good overall internal consistency reliability of $(\alpha)$.78) (Rosenstiel \& Keefe, 1983). 
However, the length of the CSQ is a limitation for the over-the-phone follow-up call with clients. Therefore, the two-item pain-catastrophizing measure (2-PCQ) derived from the CSQ was utilized. Jensen and colleagues (2003) first compared the one-item measures to their parent subscales when assessing their validity and sensitivity. They found that two-item versions of the catastrophizing scales have higher correlations than one item-measures when comparing to the parent measure on a sample of university participants (one-item pre-treatment $r=.81$, posttreatment $r=.83$; two-item pre-treatment $r=.90$, post-treatment $r=.92$ ). Therefore, Jensen et al. (2003) suggested that using the two-item measure when possible would yield better reliability and have more validity in future studies. The two catastrophizing items on the CSQ that were used for the current study included: (1) "It is terrible and I feel it is never going to get any better", and (2) "I feel I can't stand it anymore." These two items are rated on a 7-point Likerttype scale $(0=$ never do to $6=$ always do that $)$. An average of these two scales is taken to obtain a catastrophizing score, which was an outcome variable in the main analysis. Overall internal consistency reliability $(\alpha=.78)$ demonstrated for the current study was acceptable and corresponds to the previously mentioned studies. Once the data was split to determine if the measure held adequate internal consistency reliability pre- and post-test, the Cronbach's alpha for the 2-PCQ was .71 pre-test and .90 post-test, respectively.

\section{Two-Item Client Statisfaction Questionnaire}

An exploratory analysis was conducted to determine if there are any variables that contribute to the individual's unique experience of the group (i.e., demographic variables). Two questions were derived after discussion among members of the dissertation committee. These two questions include, "Please rate your level of satisfaction based on the group you attended," and "How likely are you to refer a friend or family member to the workshop you attended?" Both 
items were rated on a 7-point Likert-type scale. The overall internal consistency reliability $(\alpha=$ .97) for the Two-Item Client Satisfaction Questionnaire in this current study was excellent.

\section{Procedure}

All research procedures were first approved by the WVU Office of Research Integrity and Compliance's Institutional Review Board. Once approved, a pilot trial with a peer group took place employing a draft of the workshop outline to gauge any changes needed to be made prior to participant recruitment. After appropriate changes were made, such as the length of the workshop and administration of materials, participants were recruited.

To recruit participants, two convenience sampling procedures were conducted. First, the researcher provided current pain clinic patients with the option to participate in a free one-hour ACT-based workshop during the times they were present for other psychotherapy groups with the permission from the group leaders. These groups included suboxone groups $(n=13)$ and a professional women's chronic pain group $(n=3)$. Second, participants were referred to the ACT workshop on a waitlist $(n=3)$ and were given an educational workshop flyer by the referee (see Appendix F). Those in the referral ACT group were referred by other mental health professionals located in the clinic via an electronic medical record software EPIC-SYSTEMS. Once participants agreed to enroll in the study, they were given a packet containing informed consent, a demographic questionnaire, the CPAQ-R, and the 2-PCQ. These questionnaires were counterbalanced for each participant to minimize the possibility of order effects.

After participants consented, they attended a single-session, free-of-charge, one-hour ACT workshop. This workshop was developed from aspects from the "Therapist Guide and Patient Workbook: Life with Chronic Pain: An Acceptance-Based Approach" written by Vowles and Sorrell (2007), "Living Beyond Your Pain: Using Acceptance and Commitment Therapy to 
Ease Chronic Pain” workbooks developed by Dahl and Lundgren (2006), and ACT for Chronic Pain by McCracken (2015) (see Appendix G for a detailed overview of workshop interventions). Workshops took place within a six-month time-interval. Each workshop consisted of three to five participants.

All participants took home materials that were shared during the workshop, including a summary of the workshop, a copy of the informed consent, national and local psychological and pain resources, copies of the CPAQ-R, the 2-PCQ, and the two-item client satisfaction questionnaire. Additionally, participants were reminded of the opportunity to complete a followup phone call for a ten-dollar Walmart gift-card. Upon completion of the ACT-workshop, participants were followed-up via telephone communication for their four-week follow-up postassessment. The four-week follow-up time was chosen to align with Darnall et al.'s, (2014) single-session pain catastrophizing study.

The follow-up call was completed by a secondary researcher to minimize client bias towards the group leader. This follow-up phone call included questionnaires such as the CPAQ$\mathrm{R}$, the 2-PCQ, and the two-item client satisfaction questionnaire. The questionnaires were counterbalanced post-workshop to minimize the influence of order effects. At the end of each phone call the secondary researcher asked each participant, "Do you have any more comments about the group that you would like to tell us about?" to determine if there were areas of the workshop that could be improved from the client's perspective. Additionally, the researcher obtained an address from each participant for mailing purposes to receive their $\$ 10$ Walmart gift card. Each participant who participated in the follow-up phone call was sent a $\$ 10$ Walmart gift card to their mailing address (see Appendix H). All participants were thanked for their involvement with treatment. 


\section{Design and Analysis}

This prospective exploratory trial employed a quantitative, one-sample, pretest-posttest design (Heppner et al., 2016). Data sources included a demographic questionnaire, the Chronic Pain Acceptance Questionnaire - Revised (CPAQ-R), which includes activity engagement and pain willingness subscales (McCracken et al., 2004), and a two-item pain catastrophizing questionnaire derived from the Coping Strategies Questionnaire (2-PCQ) (Jensen et al., 2003; Rosenstiel \& Keefe, 1983). This study explored differences in (1) pain acceptance, (2) activity engagement, (3) pain willingness, and (4) pain catastrophizing pre- and four-weeks post-ACT workshop. The data was analyzed with the Statistical Package for Social Sciences (SPSS).

The researcher used a demographic questionnaire for referred participants to collect information regarding participant age, zip code, sex, level of education, duration of pain symptoms, and location of pain. The total and sub-scale scores for the CPAQ-R were calculated, as well as the average score of the 2-PCQ. Additionally, a scaled, two-item client satisfaction questionnaire was administered to better understand the experience of the individuals who attended the workshop. Finally, participants were asked their experience with the workshop at the end of the four-week post-workshop phone call. All but the client satisfaction questionnaire and the feedback question were calculated at two different time intervals; pre-workshop and 4weeks post-workshop.

A paired-samples $t$-test was conducted to analyze the hypotheses of this study. For the exploratory analysis, a single and multiple linear regression was conducted to determine the relationship between demographic variables, pain acceptance and pain catastrophizing. Client satisfaction was examined utilizing a bivariate correlation. The results of the exploratory analysis are investigated further in the discussion section. The major hypotheses were: 
Hypothesis 1: Individuals experiencing chronic pain who attend a brief ACT-workshop will report a significant improvement in overall pain acceptance post-workshop as compared to overall pain acceptance scores pre-workshop. To test this hypothesis, the CPAQ-R was administered pre-treatment and four-weeks post-treatment. This hypothesis was analyzed with a paired-samples $t$-test.

Hypothesis 2: Individuals experiencing chronic pain who attend a brief ACT-workshop will report a significant improvement in activity engagement post-workshop as compared to activity engagement scores pre-workshop. To test this hypothesis, the CPAQ-R was administered pre-treatment and four-weeks post-treatment. This hypothesis was analyzed with a pairedsamples $t$-test.

Hypothesis 3: Individuals experiencing chronic pain who attend a brief ACT-workshop will report a significant improvement in pain willingness post-workshop as compared to pain willingness scores pre-workshop. To test this hypothesis, the CPAQ-R will be administered pretreatment and four-weeks post-treatment. This hypothesis will be analyzed with a paired-samples $t$-test.

Hypothesis 4: Individuals experiencing chronic pain who attend a brief ACT-workshop will report a significant improvement in pain catastrophizing post-workshop as compared to pain catastrophizing scores pre-workshop. To test this hypothesis, the 2-PCQ was administered pretreatment and four-weeks post-treatment. This hypothesis was analyzed with a paired-samples $t$ test. 


\section{Chapter 3: Results}

The purpose of this study was to investigate if a brief one-session ACT workshop would improve adaptive pain-related coping mechanisms (i.e., pain acceptance, activity engagement, pain willingness) as well as improve maladaptive coping mechanisms (i.e., pain catastrophizing). The independent variables of this study are the two levels of the ACT work-shop, (1) preworkshop and (2) post-workshop. The dependent variables include total pain acceptance, activity engagement, pain willingness, and pain catastrophizing. Scores were taken pre-ACT workshop and four-weeks post-ACT workshop intervention.

\section{Tests of Assumptions: Paired-Samples $t$-Test}

To measure the interpretability of the results for the current study, tests of assumptions for a paired-samples $t$-test were applied. There are two assumptions to consider when employing a paired-samples $t$-test statistical analysis: (1) normality and (2) independence within groups (Privitera, 2015).

\section{Assumption One: Normality}

Normality refers to the spread of the data and its placement within a normal distribution. The assumption of normality is noted by Privitera (2015) as having increased importance when the sample size is small $(n<30)$ because the standard of error is larger. Due to the small sample size of this study $(n=19)$, it is crucial to determine the interpretability of the data. Normality was assessed utilizing the Shapiro-Wilk test (Shapiro \& Wilk, 1965) and skewness and kurtosis scores (Pearson, 1930). The Shapiro-Wilk test accepts the null hypothesis and assumes normality when $p>.05$ and rejects the null hypothesis and assumes non-normality when $p<.05$. In regard skewness and kurtosis statistics, Curran et al. (1996) suggested skewness statistics below two $(<|2.0|)$, and kurtosis statistics below seven $(<|7.0|)$ suggest the data is normally distributed. 
The pain acceptance pre-workshop total scores appear to meet the assumption of normality (Figure 1$)$ according to the Shapiro-Wilk test $(S W=.95, p=.33)$, and the skewness (.76) and kurtosis (1.07) tests. Additionally, the pain acceptance post-workshop total scores appear to meet the assumption of normality (Figure 2) $(S W=.90, p=.06)$, as well as the skewness (.79) and kurtosis (2.59) scores. Regarding activity engagement pre- and postworkshop, the Shapiro-Wilk test indicates the activity engagement pre-workshop scores (Figure 3) $(S W=.94, p=.21$, skewness $=.52$, kurtosis $=.54)$ and post-workshop scores (Figure 4$)(S W=$ $.97, p=.84$, skewness $=.06$, kurtosis $=-.43$ ) both meet the assumption of normality and fail to reject the null hypothesis. The pain willingness subscale of the CPAQ-R also met the assumption of normality for this current study for both the pre-workshop scores (Figure 5) $(S W=.97, p=$ .83 , skewness $=-.23$, kurtosis $=-.26)$ and post-workshop scores (Figure 6$)(S W=.98, p=.95$, skewness $=-.10$, kurtosis $=-.72)$. According to Shapiro and Wilk (1965), the pain catastrophizing scores pre-workshop (Figure 7) $(S W=.89, p=.03)$, and post-workshop scores (Figure 8) $(S W=.90, p=.06)$ did not meet the assumption of normality. However, the skewness and kurtosis scores for pain catastrophizing pre-workshop $($ skewness $=-.53$, kurtosis $=-1.11$ ) and post-workshop $($ skewness $=-.98$, kurtosis $=.81$ ) were acceptable. Due to the assumption of normality being met by all conditions, there were no changes made to the data set, nor were any variables excluded from the major findings. 


\section{Figure 1}

Histogram of Pre-Workshop Pain Acceptance Total Scores.

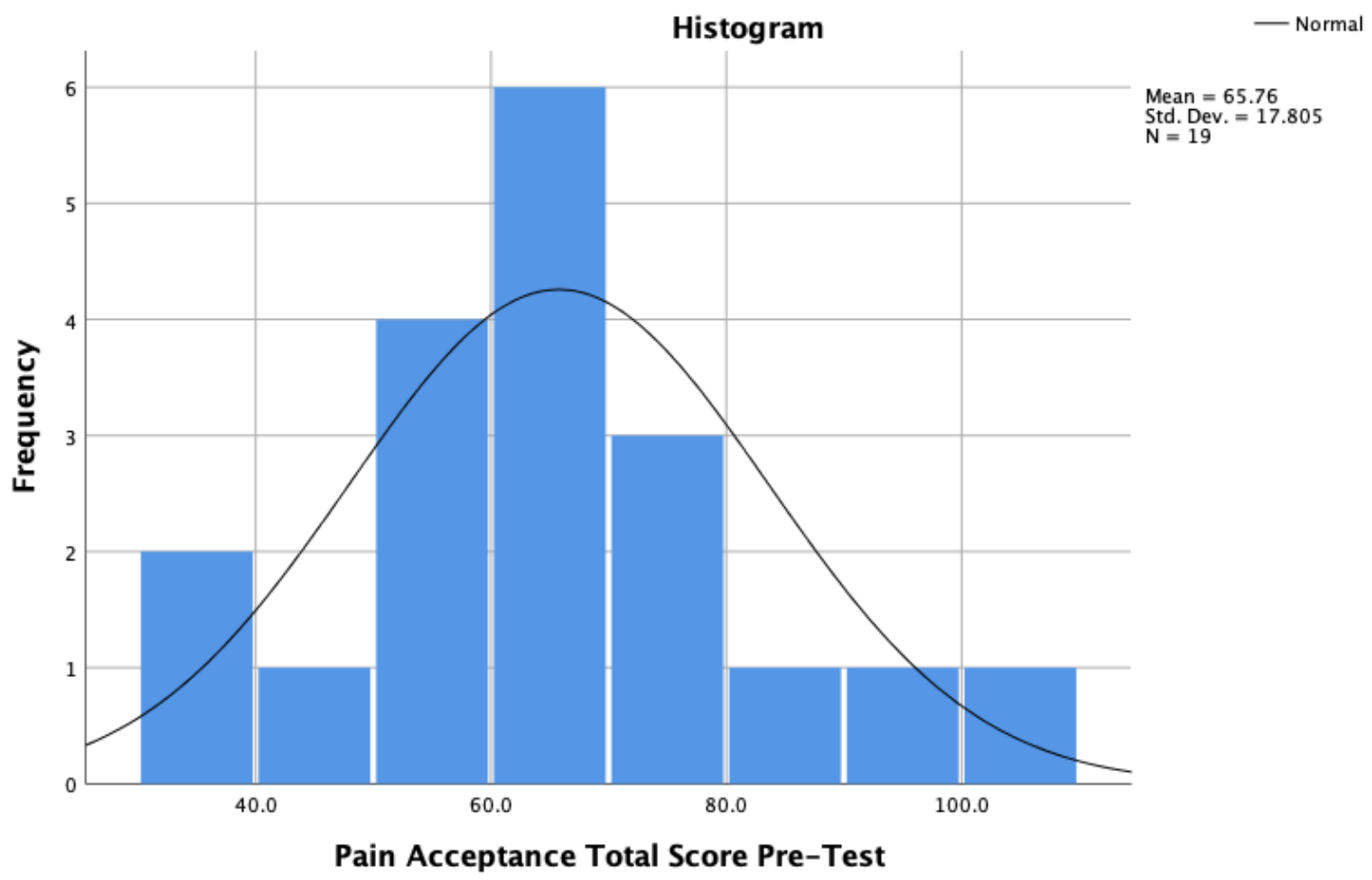

Figure 2

Histogram of Post-Workshop Pain Acceptance Total Scores.

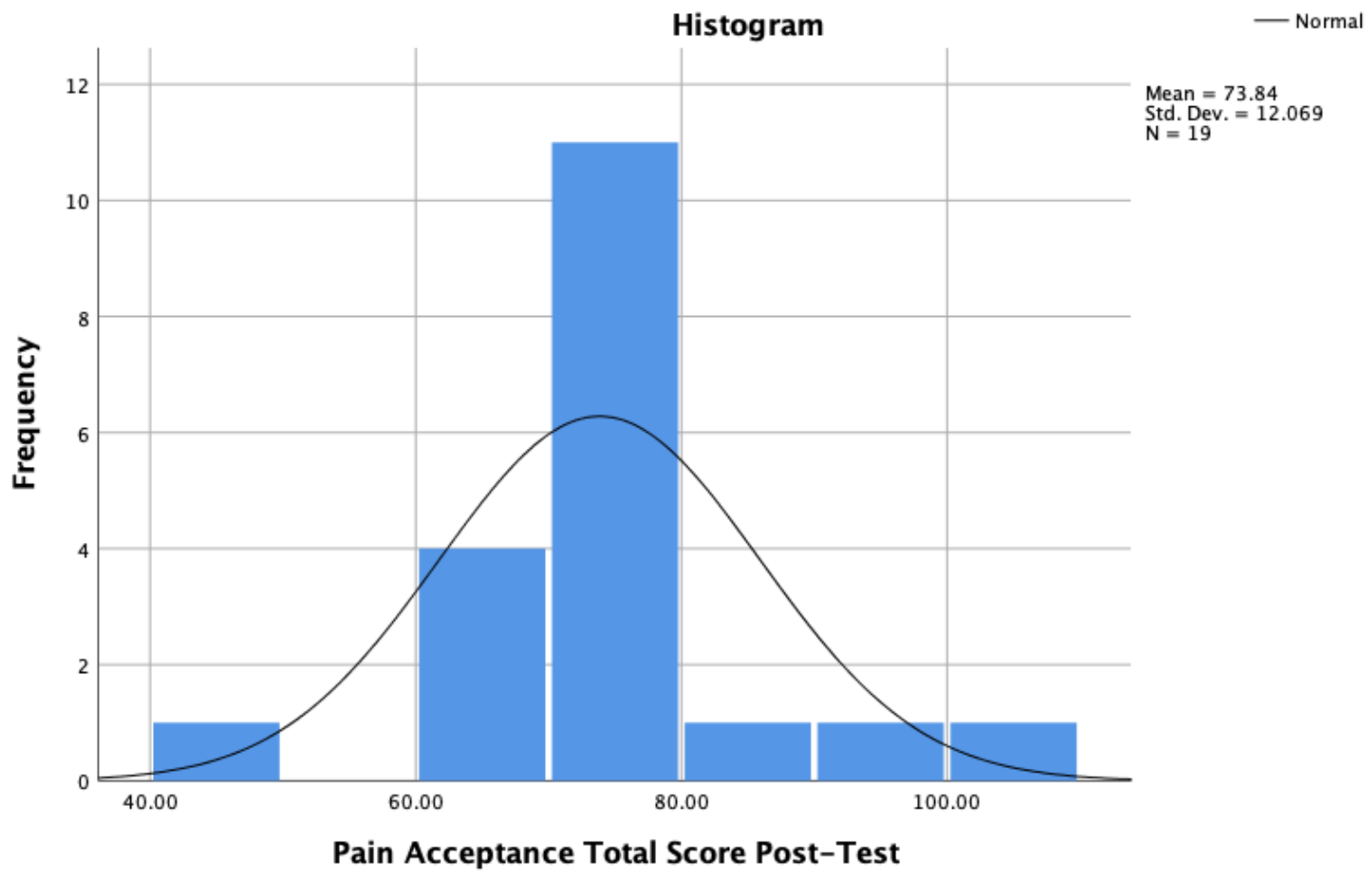




\section{Figure 3}

Histogram of Pre-Workshop Activity Engagement Subscale Scores.

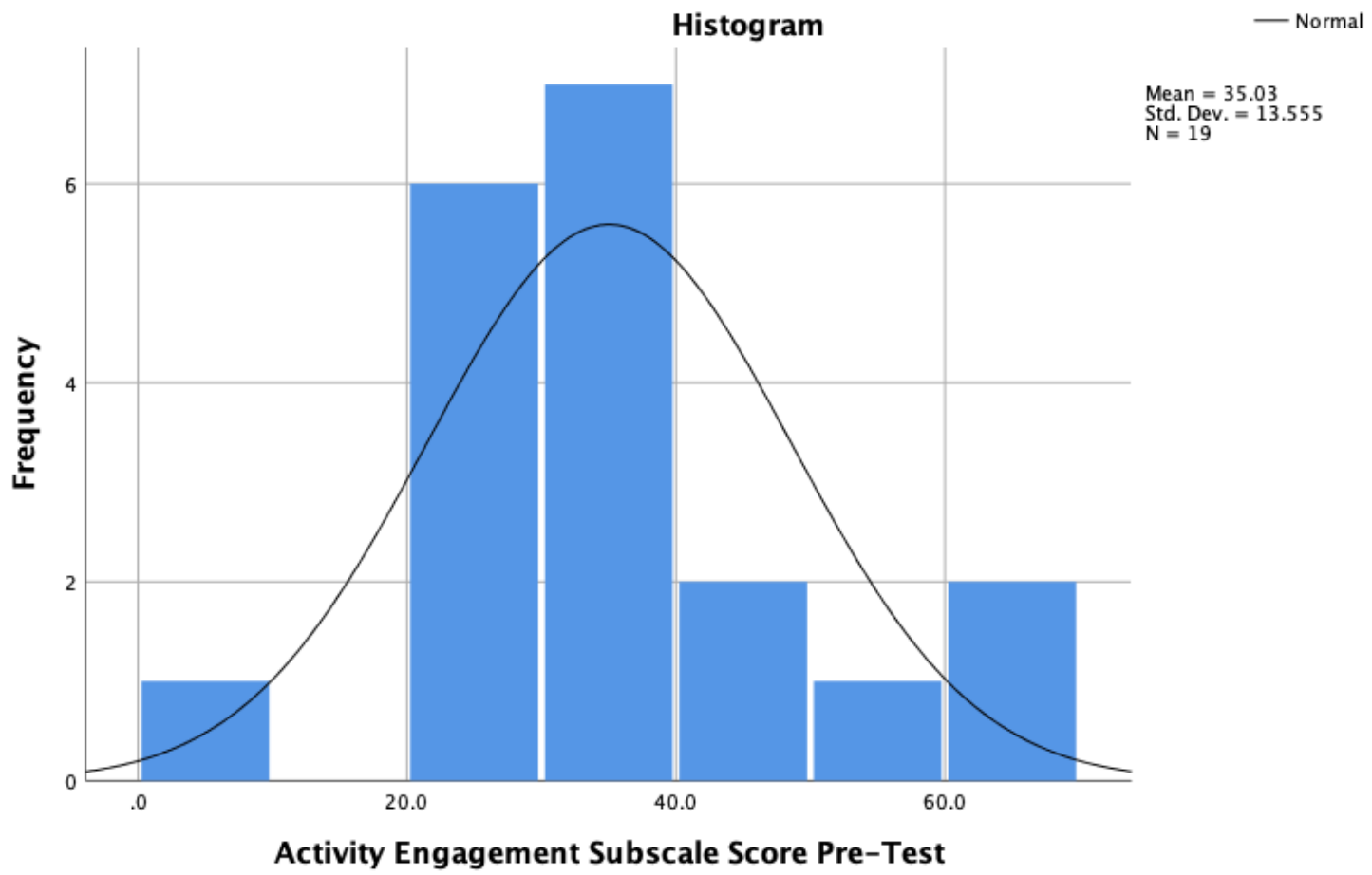

\section{Figure 4}

Histogram of Post-Workshop Activity Engagement Subscale Scores.

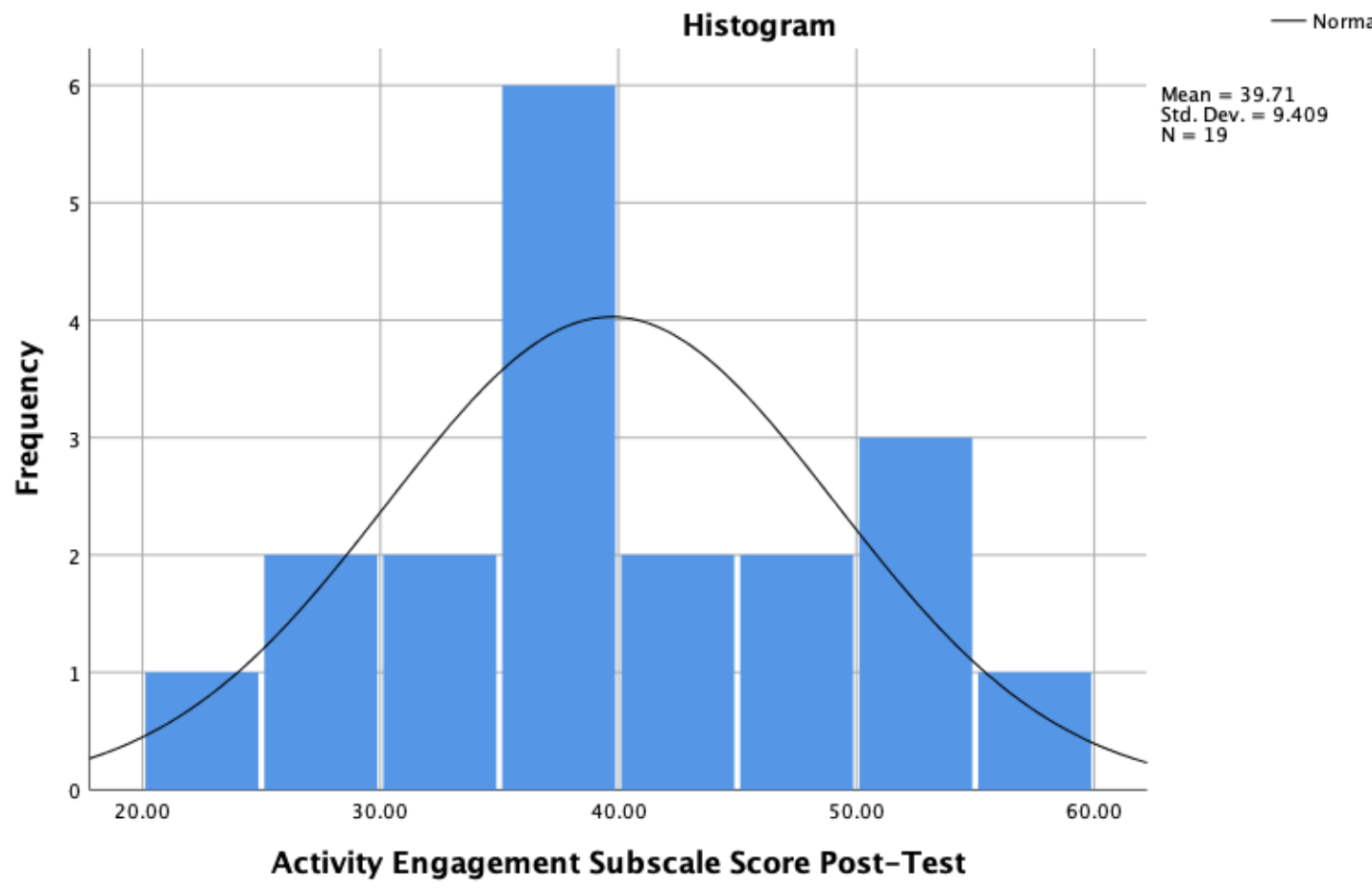


Figure 5

Histogram of Pre-Workshop Pain Willingness Subscale Scores.

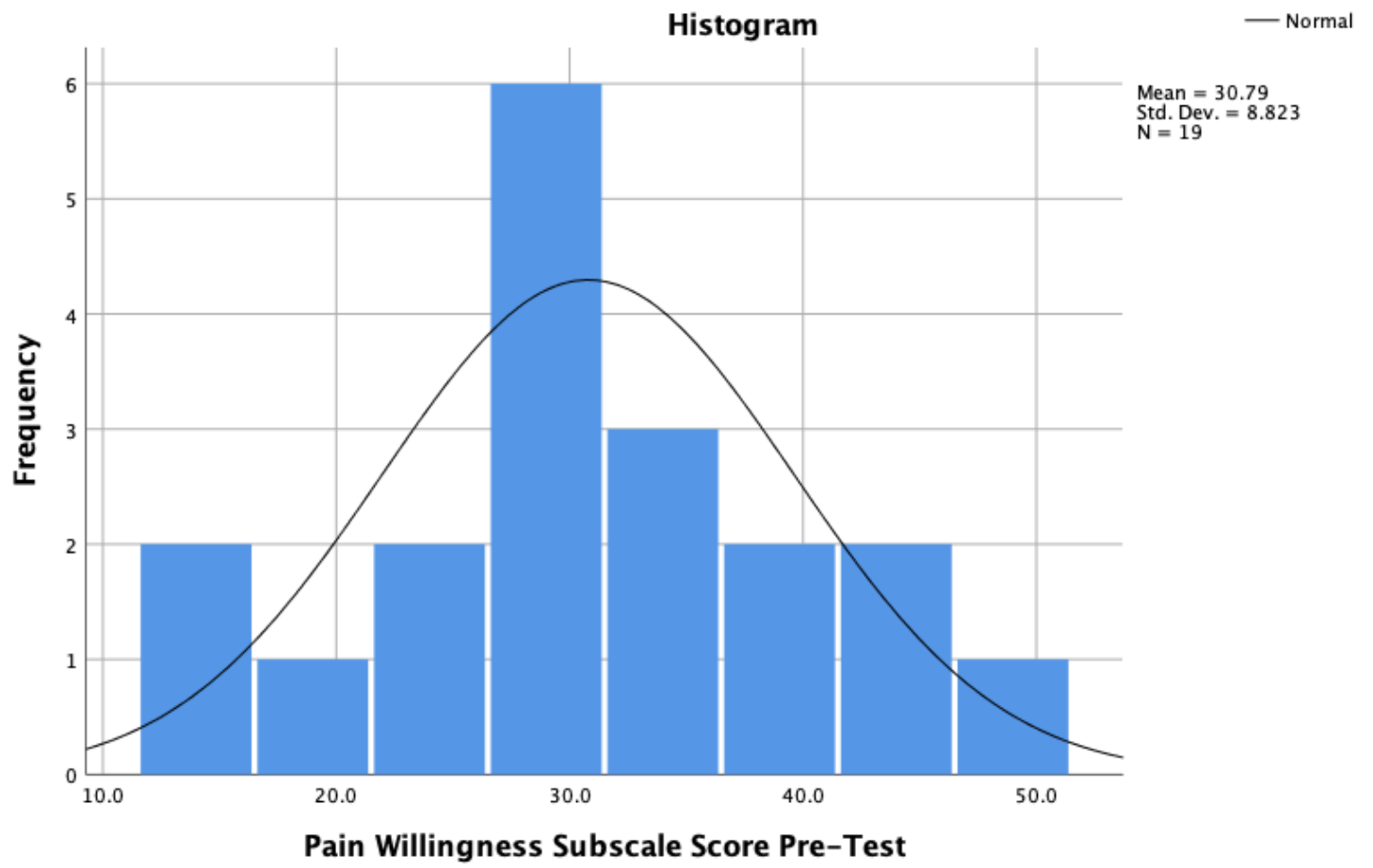

Figure 6

Histogram of Post-Workshop Pain Willingness Subscale Scores.

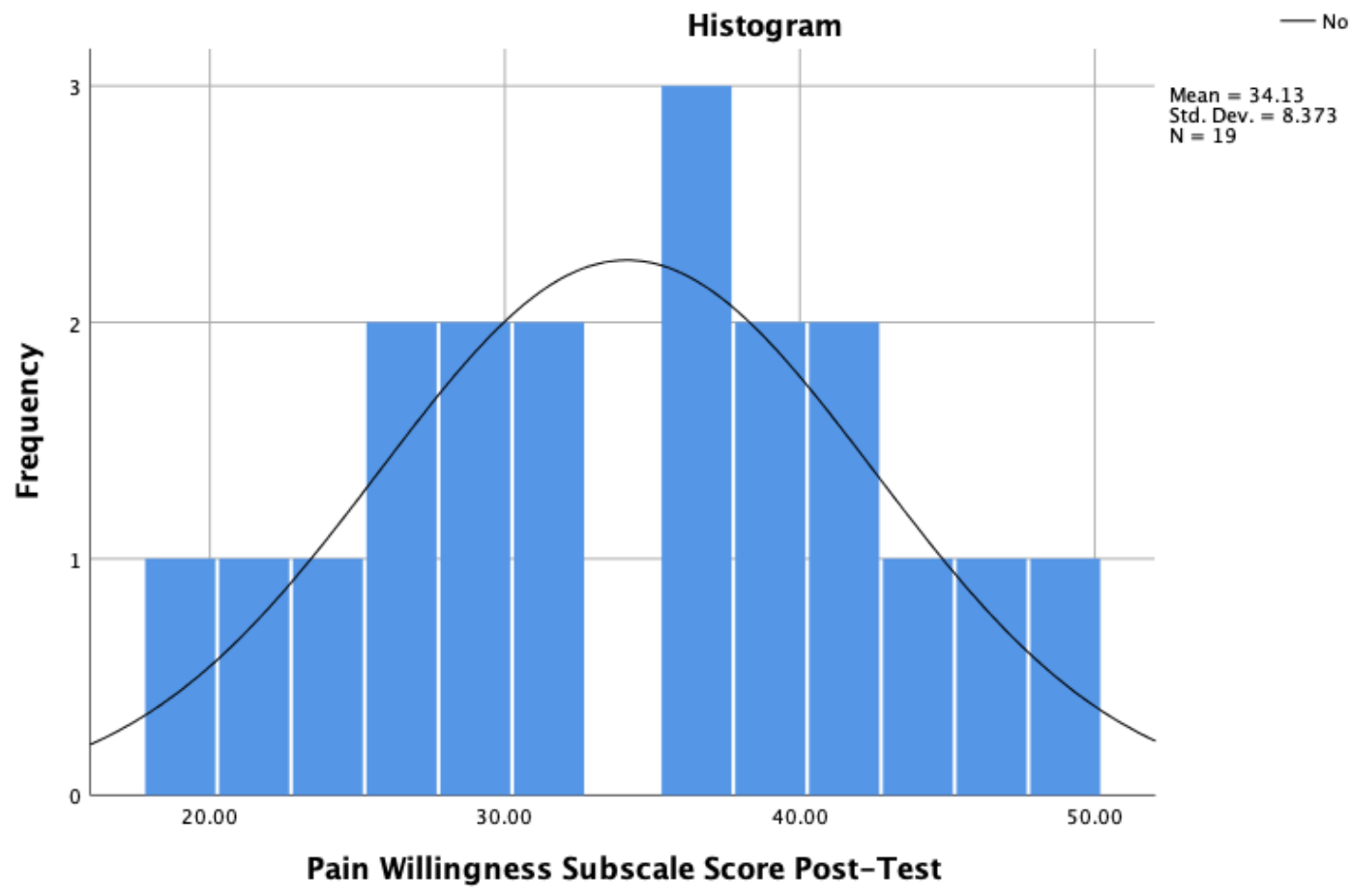


Figure 7

Histogram of Pre-Workshop Pain Catastrophizing Scores.

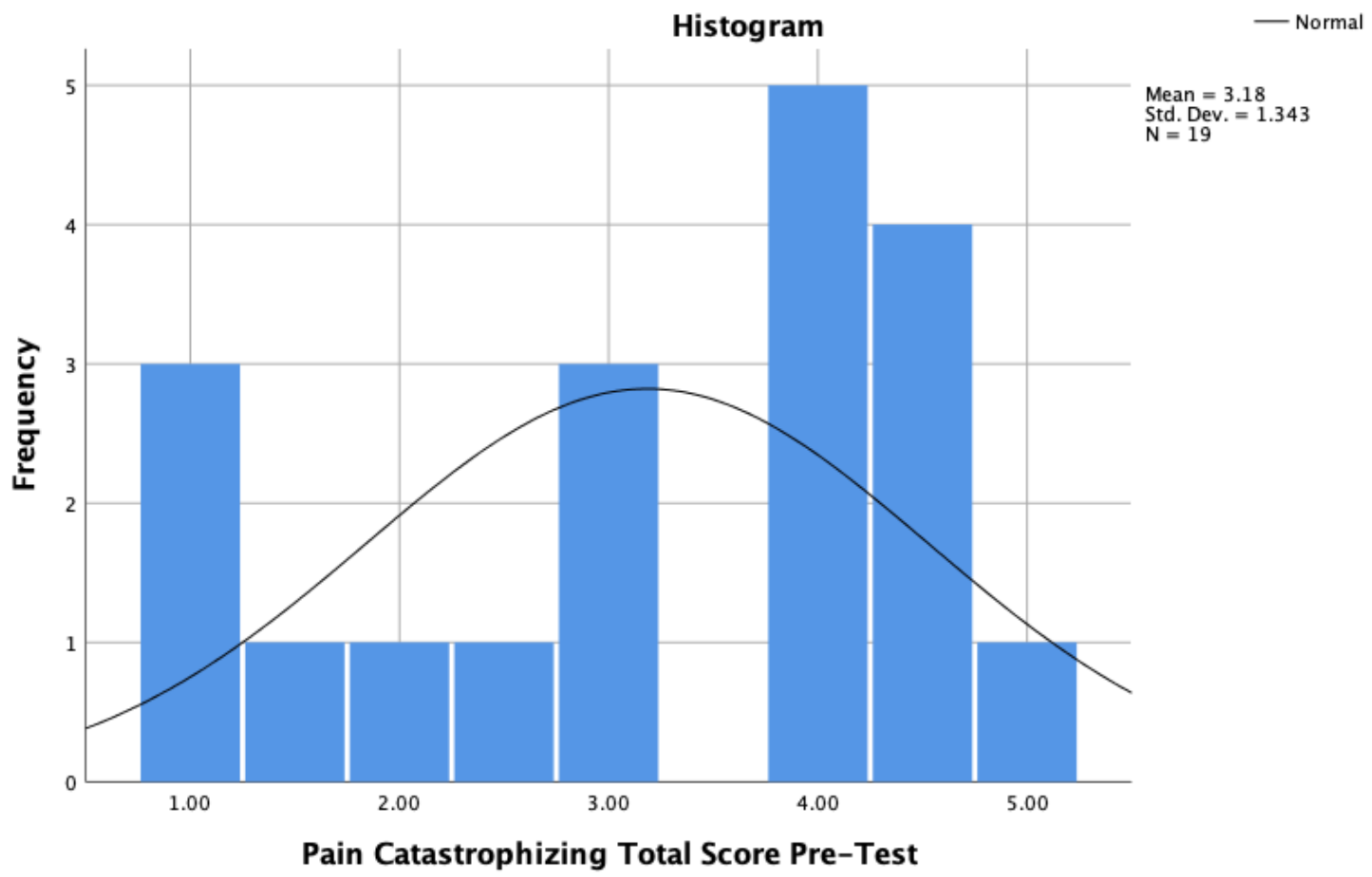

Figure 8

Histogram of Post-Workshop Pain Catastrophizing Scores.

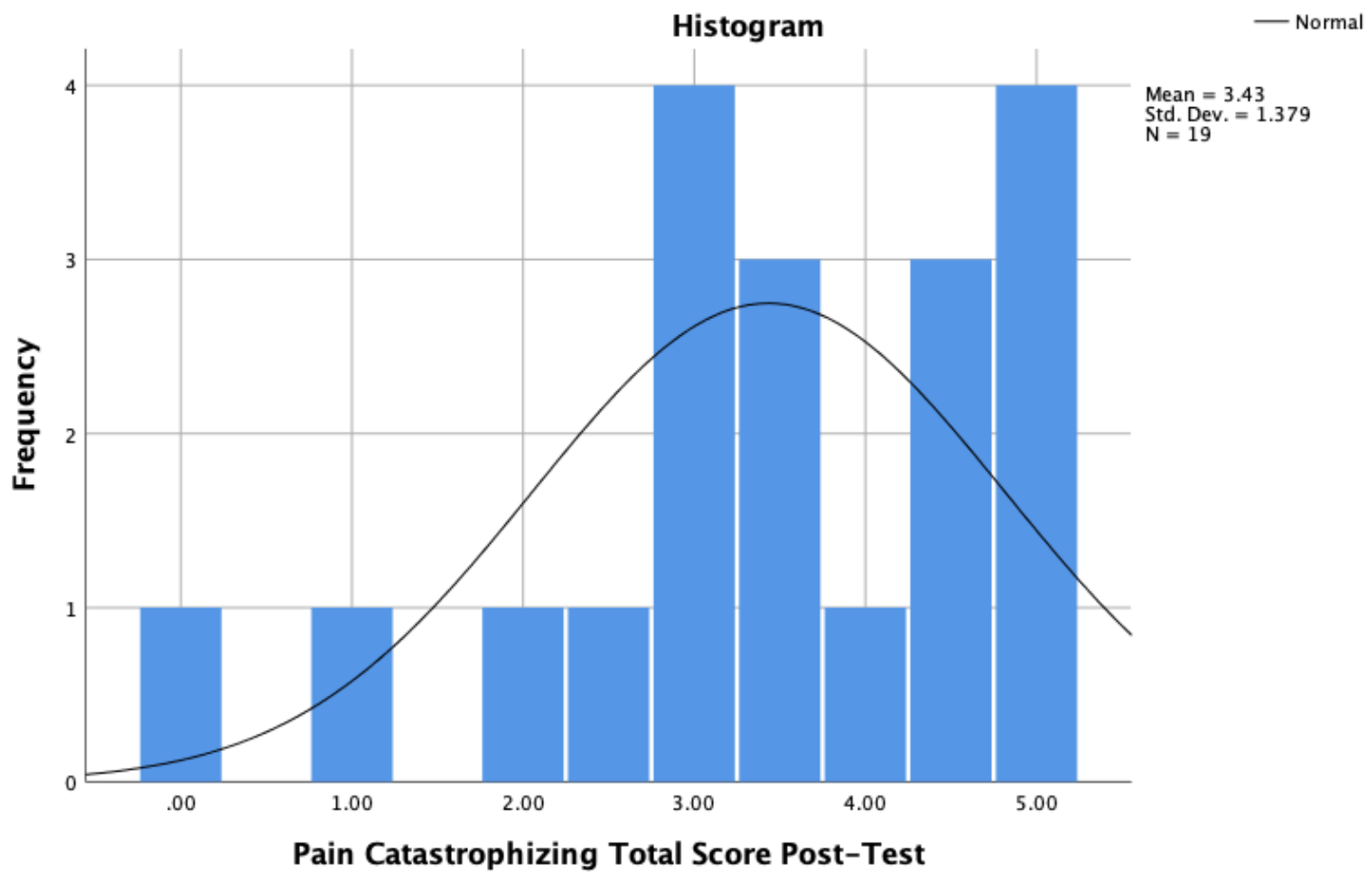




\section{Assumption Two: Independence within Groups}

Privitera (2015) noted the second assumption of independence within groups for a pairedsamples $t$-test is when the participants' scores are (1) related between the two groups, and (2) that the scores were obtained from different individuals within each group. For the purpose of this current study, data was collected and analyzed through procedures that would allow for this assumption to be met, such as collecting data from each participant at both pre-and postworkshop time-points, and utilizing SPSS, which assumes and analyses scores as if they were obtained from different individuals at both time-points.

\section{Descriptive Statistics of Study Variables}

The average scores and standard deviations for the full-scale pain acceptance measure (CPAQ-R) and the pain catastrophizing measure (2-PCQ) are presented in Table 3. Vowels et al. (2008) reported the average pain acceptance total score for a sample of 641 chronic pain individuals was $47.2(S D=18.8)$. The average pain acceptance total score for the current study was $65.7(S D=17.80)$ pre-workshop and $73.84(S D=12.07)$ post-workshop. These averages suggest higher total pain acceptance both pre and post-workshop as compared to a normed sample. Regarding activity engagement, the average score of 641 chronic pain individuals was $28.7(S D=12.4)$ (Vowels et al., 2008). For the current study, the mean activity engagement scores both pre-workshop $(M=35.03, S D=13.55)$ and post-workshop $(M=39.71, S D=9.41)$ were also higher than the normed sample. The mean pain willingness subscale score for the normed sample $(M=18.5, S D=10.3)$ was lower than the current study's average pain willingness scores at both the pre-workshop $(M=30.79, S D=8.82)$ and post-workshop $(M=$ 34.13, $S D=8.37$ ) time points. Overall the total and subscale scores of the current study were elevated compared to a normed sample (Vowels et al., 2008). 
Regarding the 2-PCQ, Jensen and colleagues (2003) created a version of the coping strategies questionnaire (Rosenstiel \& Keefe, 1983) that measures pain catastrophizing using only two-items. Normed means and standard deviations were not reported in their original study. However, a study validating the use of a two-item pain catastrophizing measure in a chronic pain veteran population was conducted (Tan et al., 2006). Five-hundred and sixty-three veterans involved in a multidisciplinary pain clinic were recruited. The average score within this population was $3.93(S D=2.44)$. The current study had similar findings both pre-workshop $(M=$ 3.18, $S D=1.34)$ and post-workshop $(M=3.43, S D=1.37)$.

\section{Table 3}

Descriptive Statistics of Study Variables Pre-ACT Workshop and Post-Act Workshop Pre-ACT workshop $\quad$ Post-ACT workshop

\begin{tabular}{lcccc}
\multicolumn{1}{c}{ Coping measure } & $M$ & $S D$ & $M$ & $S D$ \\
\hline 1. CPAQ- R Full Scale & 65.76 & 17.80 & 73.84 & 12.07 \\
2. CPAQ- R AE Subscale & 35.03 & 13.55 & 39.71 & 9.41 \\
3. CPAQ- R PW Subscale & 30.79 & 8.82 & 34.13 & 8.37 \\
4. 2-PCQ & 3.18 & 1.34 & 3.43 & 1.37 \\
\hline
\end{tabular}

Note. $n=19$; CPAQ-R= Chronic Pain Acceptance Questionnaire-Revised; CPAQ-R AE Subscale = Chronic Pain Acceptance Questionnaire - Revised Activity Engagement subscale; CPAQ-R PW Subscale $=$ Chronic Pain Acceptance Questionnaire - Revised Pain Willingness subscale; 2PCQ = Two-Item Pain Catastrophizing Questionnaire; Post-ACT workshop $=$ four-weeks postintervention.

\section{Major Findings}

Four hypotheses were tested utilizing paired samples $t$-tests to determine the treatment effect of a one-hour ACT-workshop on participants' level of adaptive and maladaptive coping. Nineteen participants were included in the final data analysis. Inclusion criteria for the participant data included: (1) must be 18 years or older, (2) have had a chronic pain condition for 
six or more months, (3) currently receiving treatment at a medical center specific to pain management, and (4) completed the follow-up phone call four-weeks post-ACT workshop.

\section{Hypothesis One}

It was hypothesized that individuals experiencing chronic pain who attend a brief ACTworkshop will report a significant improvement in overall pain acceptance scores post-workshop as compared to overall pain acceptance scores pre-workshop. . To test this hypothesis, the CPAQ-R was administered pre-treatment and four-weeks post-treatment. A paired-samples $t$-test indicated a significant difference in total pain acceptance scores pre-ACT workshop $(M=65.76$, $S D=17.80)$ and post-ACT workshop $(M=73.84, S D=12.07) ; t(18)=-2.44, p<.05,95 \%$ CI $[-$ 15.03, -1.13]. Thus, the post-workshop mean total pain acceptance scores were statistically significantly higher than the pre-workshop scores. Cohen's $d$ was -0.53 , which is a medium effect size based on Cohen's (1992) standards.

\section{Hypothesis Two}

It was hypothesized that individuals with chronic pain who attended a brief ACTworkshop would report a significant improvement in activity engagement scores post-workshop as compared to overall pain acceptance scores pre-workshop. To test this hypothesis, the CPAQ$\mathrm{R}$ was administered. The subscale activity engagement was calculated from this questionnaire at both pre-treatment and four-weeks post-treatment. A paired-samples $t$-test indicated that there was no statistically significant difference in activity engagement scores pre-ACT workshop $(M=$ 35.03, $S D=13.55)$ and post-ACT workshop $(M=39.71, S D=9.41) ; t(18)=-1.81, p=.087$, 95\% CI $[-10.12, .76]$. Cohen's $d$ was .40 , which is considered to be a medium effect size (Cohen, 1992). 


\section{Hypothesis Three}

It was hypothesized that individuals experiencing chronic pain who attended a brief ACT-workshop would report a significant improvement in pain willingness scores postworkshop as compared to pain willingness scores pre-workshop. To test this hypothesis, the CPAQ-R was administered at both pre-treatment and four-weeks post-treatment. The pain willingness subscale was calculated from the CRAQ-R at both time intervals. A paired-samples $t$-test indicated a significant difference in in pain willingness scores pre-ACT workshop $(M=$ $30.79, S D=8.82)$ and post-ACT workshop $(M=34.13, S D=8.37) ; t(18)=-2.78, p<.05,95 \% \mathrm{CI}$ $[-5.87,-.81]$. Cohen's $d$ for hypothesis three was .30 , which is considered to be a small to medium effect size (Cohen, 1992).

\section{Hypothesis Four}

It was hypothesized that individuals experiencing chronic pain who attended a brief ACT-workshop would report a significant improvement in pain catastrophizing scores postworkshop as compared to pain catastrophizing scores pre-workshop. To test this hypothesis, the 2-PCQ was administered pre-treatment and four-weeks post-treatment. A paired-samples $t$-test indicated no statistically significant difference in pain catastrophizing scores pre-ACT workshop $(M=3.18, S D=1.34)$ and post-ACT workshop $(M=3.43, S D=1.37) ; t(18)=-.920, p=.370$, $95 \%$ CI $[-.82, .32]$. The effect size for hypothesis four was .18, which is considered to be a small effect size based on Cohen's (1992) standards. 
Table 4

Paired-Samples t-Test for Pre-Workshop and Post-Workshop Comparison

\begin{tabular}{|c|c|c|c|c|c|c|c|c|}
\hline & \multicolumn{8}{|c|}{$\begin{array}{c}95 \% \\
\text { Confidence } \\
\text { Interval of the } \\
\text { Difference }\end{array}$} \\
\hline & Mean & SD & $\begin{array}{l}\text { Std. } \\
\text { Error } \\
\text { Mean } \\
\end{array}$ & Lower & Upper & $t(18)$ & $\mathrm{df}$ & $\begin{array}{l}\text { Sig. }(2- \\
\text { tailed })\end{array}$ \\
\hline $\begin{array}{l}\text { CPAQ-R Total Score } \\
\text { Pre-Test - CPAQ-R } \\
\text { Total Score Post-Test }\end{array}$ & -8.08 & 14.42 & 3.31 & -15.03 & -1.13 & -2.44 & 18 & .025 \\
\hline $\begin{array}{l}\text { CPAQ-R AE Subscale } \\
\text { Pre-Test - CPAQ-R AE } \\
\text { Subscale Score Post- } \\
\text { Test }\end{array}$ & -4.68 & 11.29 & 2.59 & -10.12 & .76 & -1.81 & 18 & .087 \\
\hline $\begin{array}{l}\text { CPAQ-R PW Subscale } \\
\text { Pre-Test - CPAQ-R } \\
\text { PW Subscale Score } \\
\text { Post-Test }\end{array}$ & -3.34 & 5.24 & 1.20 & -5.86 & -.81 & -2.78 & 18 & .012 \\
\hline $\begin{array}{l}\text { 2-PCQ Pre-Test - 2- } \\
\text { PCQ Score Post-Test }\end{array}$ & -.25 & 1.18 & .27 & -.82 & .32 & -.92 & 18 & .370 \\
\hline
\end{tabular}

Note. $n=19$; CPAQ-R= Chronic Pain Acceptance Questionnaire-Revised; CPAQ-R AE

Subscale $=$ Chronic Pain Acceptance Questionnaire - Revised Activity Engagement subscale; CPAQ-R PW Subscale $=$ Chronic Pain Acceptance Questionnaire - Revised Pain Willingness subscale; 2-PCQ = Two-Item Pain Catastrophizing Questionnaire; Post-ACT workshop = four-weeks post-intervention. $\mathrm{p}<.05$ is considered significant.

\section{Exploratory Analysis 1: Linear Regression}

A secondary intent of this current study is to provide clinicians with a one-session ACTworkshop to increase participants' coping mechanisms that is pertinent to their clientpopulation's needs. Therefore, an exploratory analysis was conducted to determine if there was influence by external variables on the results of this study. Additionally, the exploratory analysis was conducted to aid in recommendations for group composition. For these analyses, demographic information was compared to the outcome variables of this study. The demographic 
variables included age, duration of pain, sex, and education. A linear regression analysis was utilized and summarized in Tables 5 through 8 to show the influence that demographic variables had on the study outcome. A G*power analysis was calculated utilizing a G*Power software (Faul et al., 2008). Power (1- $\beta$ ) was set at 0.80 and $\alpha=0.05$. This analysis showed a need for $n=$ 270 to reach a significance level of .05 . Thus, it is likely that the negative findings in the below exploratory analysis is attributed to a low sample size $(n=19)$ in the current study.

\section{Age and Outcome}

The demographic variable age was tested as a predictor for outcome measures, including total pain acceptance, activity engagement, pain willingness, and pain catastrophizing. Age did not account for significant variance in pre-test outcome scores $\left(R^{2}=.07\right.$, adjusted $R^{2}=.02, F(1$, $17)=1.27, p=.28)$ or post-tests outcome scores $\left(R^{2}=.00\right.$, adjusted $R^{2}=-.05, F(1,17)=.06, p=$ .81). Age also did not account for significant variance for activity engagement $\left(R^{2}=.03\right.$, adjusted $\left.R^{2}=-.03, F(1,17)=.57, p=.46\right)$, pain willingness $\left(R^{2}=.07\right.$, adjusted $R^{2}=-.01, F(1,17)=1.21$, $p=.27)$, and pain catastrophizing $\left(R^{2}=.01\right.$, adjusted $\left.R^{2}=-.04, F(1,17)=.25, p=.62\right)$ preworkshop. The same was true for age and activity engagement $\left(R^{2}=.01\right.$, adjusted $R^{2}=-.05, F(1$, $17)=.10, p=.75)$, pain willingness $\left(R^{2}=.00\right.$, adjusted $\left.R^{2}=-.06, F(1,17)=.00, p=.99\right)$, and pain catastrophizing $\left(R^{2}=.05\right.$, adjusted $\left.R^{2}=-.01, F(1,17)=.88, p=.36\right)$ post-workshop.

\section{Table 5}

Summary of Age Tested as Predictor of Outcome Measures

\begin{tabular}{lccc|ccc}
\hline Variable & \multicolumn{3}{c}{ Pre-ACT Workshop } & \multicolumn{3}{c}{ Post-ACT Workshop } \\
\cline { 2 - 6 } & $B$ & $S E B$ & $\beta$ & $B$ & $S E B$ & $\beta$ \\
\hline Pain Acceptance & .38 & .34 & .26 & -.06 & .24 & -.06 \\
Activity Engagement & .20 & .26 & .18 & -.06 & .18 & -.08
\end{tabular}




\begin{tabular}{llll|lll} 
Pain Willingness & .18 & .17 & .26 & .00 & .16 & .00 \\
Pain Catastrophizing & .01 & .03 & .12 & -.03 & .03 & -.22
\end{tabular}

Note. $n=19$. The impact of demographic variable 'age' on outcome measures was examined pre and post-test. The demographic variables were used to predict pain acceptance pre-workshop and post-workshop.

\section{Pain Duration and Outcome}

The demographic variable pain duration was tested through a linear regression model as a predictor of outcome. Pain duration did not account significant variance for pain acceptance $\left(R^{2}\right.$ $=.09$, adjusted $\left.R^{2}=.04, F(1,17)=1.77, p=.20\right)$, activity engagement $\left(R^{2}=.14\right.$, adjusted $R^{2}=$ $.09, F(1,17)=2.81, p=.11)$, pain willingness $\left(R^{2}=.00\right.$, adjusted $R^{2}=-.06, F(1,17)=.02, p=$ $.87)$, and pain catastrophizing $\left(R^{2}=.01\right.$, adjusted $\left.R^{2}=-.05, F(1,17)=.13, p=.72\right)$ preworkshop. Additionally, pain duration did not account for significant variance for pain acceptance $\left(R^{2}=.10\right.$, adjusted $\left.R^{2}=.05, F(1,17)=1.93, p=.18\right)$, activity engagement $\left(R^{2}=.10\right.$, adjusted $\left.R^{2}=.05, F(1,17)=1.88, p=.19\right)$, pain willingness $\left(R^{2}=.01\right.$, adjusted $R^{2}=-.05, F(1$, $17)=.19, p=.67)$, and pain catastrophizing $\left(R^{2}=.02\right.$, adjusted $\left.R^{2}=-.04, F(1,17)=.28, p=.60\right)$ post-workshop.

\section{Table 6}

Summary of Pain Duration Tested as Predictor of Outcome Measures

\begin{tabular}{lccc|ccc}
\hline Variable & \multicolumn{3}{c}{ Pre-ACT Workshop } & \multicolumn{3}{c}{ Post-ACT Workshop } \\
\cline { 2 - 6 } & $B$ & $S E B$ & $\beta$ & $B$ & $S E B$ & $\beta$ \\
\hline Pain Acceptance & -.63 & .47 & -.31 & -.44 & .32 & .32 \\
Activity Engagement & -.59 & .35 & -.38 & -.34 & .25 & -.32 \\
Pain Willingness & -.04 & .25 & -.04 & -.10 & .23 & -.11 \\
Pain Catastrophizing & -.01 & .04 & -.09 & -02 & .04 & -.13 \\
\end{tabular}


Note. $n=19$. The impact of demographic variable 'pain duration' on outcome measures was examined pre and post-test. The demographic variables were used to predict pain acceptance preworkshop and post-workshop.

\section{Sex and Outcome}

The demographic variable sex was tested utilizing a linear regression model as a predictor of outcome. The variable sex was dummy coded into groups ( 0 -male; 1 -female). Pain duration did not account significant variance for pain acceptance $\left(R^{2}=.02\right.$, adjusted $R^{2}=-.04$, $F(1,17)=.27, p=.61)$, activity engagement $\left(R^{2}=.01\right.$, adjusted $R^{2}=-.05, F(1,17)=.18, p=$ $.68)$, pain willingness $\left(R^{2}=.01\right.$, adjusted $\left.R^{2}=-.05, F(1,17)=.17, p=.69\right)$, and pain catastrophizing $\left(R^{2}=.00\right.$, adjusted $\left.R^{2}=-.01, F(1,17)=.78, p=.39\right)$ pre-workshop. Additionally, sex did not account for significant variance for pain acceptance $\left(R^{2}=.16\right.$, adjusted $R^{2}=.11, F(1$, $17)=3.33, p=.09)$, activity engagement $\left(R^{2}=.11\right.$, adjusted $\left.R^{2}=.058, F(1,17)=2.11, p=.16\right)$, pain willingness $\left(R^{2}=.04\right.$, adjusted $\left.R^{2}=-.01, F(1,17)=.78, p=.39\right)$, and pain catastrophizing $\left(R^{2}=.00\right.$, adjusted $\left.R^{2}=-.05, F(1,17)=.08, p=.79\right)$ post-workshop.

\section{Table 7}

Summary of Sex Tested as Predictor of Outcome Measures

\begin{tabular}{lccc|ccc}
\hline Variable & \multicolumn{3}{c}{ Pre-ACT Workshop } & \multicolumn{3}{c}{ Post-ACT Workshop } \\
\cline { 2 - 7 } & $B$ & $S E B$ & $\beta$ & $B$ & $S E B$ & $\beta$ \\
\hline Pain Acceptance & -4.30 & 8.35 & -.12 & -9.52 & 5.22 & -.40 \\
Activity Engagement & -2.69 & 6.38 & -.10 & -6.10 & 4.20 & -.33 \\
Pain Willingness & -1.71 & 4.15 & -.10 & -3.41 & 3.87 & -.21 \\
Pain Catastrophizing & .55 & .62 & .21 & .18 & .65 & .07 \\
\hline
\end{tabular}

Note. $n=19$. The impact of demographic variable 'sex' on outcome measures was examined pre and post-test. The demographic variables were used to predict pain acceptance pre-workshop and post-workshop. 


\section{Education and Outcome}

The demographic variable education was tested through a linear regression model as a predictor of pre-and post-workshop outcome. Education did not account for significant variance for pain acceptance $\left(R^{2}=.02\right.$, adjusted $\left.R^{2}=-.03, F(1,17)=.40, p=.54\right)$, activity engagement $\left(R^{2}=.00\right)$, adjusted $\left.R^{2}=-.05, F(1,17)=.07, p=.79\right)$, pain willingness $\left(R^{2}=.04\right.$, adjusted $R^{2}=-$ $.01, F(1,17)=.79, p=.39)$, and pain catastrophizing $\left(R^{2}=.02\right.$, adjusted $R^{2}=-.04, F(1,17)=$ $.33, p=.58)$ pre-workshop. Additionally, education did not account for significant variance for pain acceptance $\left(R^{2}=.01\right.$, adjusted $\left.R^{2}=-.05, F(1,17)=.13, p=.73\right)$, activity engagement $\left(R^{2}=\right.$ .00 , adjusted $\left.R^{2}=-.06, F(1,17)=.01, p=.92\right)$, pain willingness $\left(R^{2}=.01\right.$, adjusted $R^{2}=-.05$, $F(1,17)=.16, p=.69)$, and pain catastrophizing $\left(R^{2}=.01\right.$, adjusted $R^{2}=-.05, F(1,17)=.22, p=$ .64) post-workshop.

\section{Table 8}

Summary of Education Tested as Predictor of Outcome Measures

\begin{tabular}{lccc|ccc}
\hline Variable & \multicolumn{3}{c}{ Pre-ACT Workshop } & \multicolumn{3}{c}{ Post-ACT Workshop } \\
\cline { 2 - 7 } & $B$ & SE B & $\beta$ & $B$ & $S E B$ & $\beta$ \\
\hline Pain Acceptance & 1.78 & 2.84 & .15 & .70 & 1.94 & .09 \\
Activity Engagement & .60 & 2.18 & .66 & .15 & 1.52 & .02 \\
Pain Willingness & 1.24 & 1.38 & .21 & .54 & 1.35 & .10 \\
Pain Catastrophizing & .12 & .22 & .14 & .10 & .22 & .11 \\
\end{tabular}

Note. $n=19$. The impact of demographic variable 'education' on outcome measures was examined pre and post-test. The demographic variables were used to predict pain acceptance preworkshop and post-workshop. 


\section{Exploratory Analysis 2: Multiple Linear Regression}

Privitera (2015) described multiple regression as a more comprehensive approach to predicting behaviors compared to a linear regression. Additionally, he reports that multiple regression analyses are helpful in indicating interactions between multiple variables (Privitera, 2015). To even further explore the influence of demographic variables on the outcome of the study, Allison (1990) suggests utilizing a change score from pre-and post- test data when employing a regression analysis so that the pre-workshop scores are controlled for. Additionally, by using a change score between pre-and post-workshop means, the influence of demographic variables on the outcome variables (i.e., pain acceptance, activity engagement, pain willingness, and pain catastrophizing) are presented together rather than separately; showing an overall trend in the data (Allison, 1990). Therefore, a multiple regression analysis was utilized to show interactions between the demographic variables and the change scores of the dependent variables of this study.

The analysis is summarized in Tables 9 through 12 to show the influence that demographic variables had on the change scores of the study outcome. A G*power analysis was calculated utilizing $\mathrm{G}^{*}$ Power software (Faul et al., 2008). Power (1- $\beta$ ) was set at 0.80 and $\alpha=$ 0.05. This analysis showed a need for $n=85$ to reach a significance level of .05 . Thus, it may be that the negative findings presented in the below exploratory analysis is attributed to a low sample size $(n=19)$ in the current study.

\section{Pain Acceptance}

A change score was calculated utilizing SPSS software, in which the post-workshop pain acceptance mean was subtracted by the pre-workshop pain acceptance mean. A multiple linear 
regression analysis indicates no significant influence of the demographic variables on the pain acceptance change score $\left(R^{2}=.308\right.$, adjusted $\left.R^{2}=.111, F(4,14)=1.56, p=.239\right)$.

\section{Table 9}

Summary of Demographic Variables Influence on Pain Acceptance Change Score

\begin{tabular}{lccccc}
\hline Total Pain Acceptance & $B$ & $S E B$ & $\beta$ & $t$ & $p$ \\
\hline Age & -.55 & .28 & -.47 & -1.95 & .072 \\
Duration of Pain & .70 & .45 & .43 & 1.57 & .140 \\
Sex & -11.44 & 7.15 & -.41 & 1.60 & .132 \\
Education & -.73 & 2.39 & -.08 & -.31 & .765 \\
\end{tabular}

Note. $n=19$. The impact of demographic variables on pain acceptance change score (postworkshop pain acceptance mean - pre-workshop pain acceptance mean).

\section{Activity Engagement}

A change score was calculated by subtracting the activity engagement post-workshop mean from the activity engagement pre-workshop mean. A multiple linear regression analysis indicated no significant influence of the demographic variables on the activity engagement change score $\left(R^{2}=.265\right.$, adjusted $\left.R^{2}=.055, F(4,14)=1.261, p=.331\right)$.

\section{Table 10}

Summary of Demographic Variables Influence on Activity Engagement Change Score

\begin{tabular}{lccccc}
\hline Activity Engagement & $B$ & $S E B$ & $\beta$ & $t$ & $p$ \\
\hline Age & -.36 & .23 & -.39 & -1.57 & .140 \\
Duration of Pain & .62 & .36 & .48 & 1.70 & .111 \\
Sex & -8.68 & 5.78 & -.40 & -1.50 & .155 \\
Education & -.50 & 1.93 & -.07 & -.26 & .799 \\
& & & & & \\
\hline
\end{tabular}


Note. $n=19$. The impact of demographic variables on activity engagement change score (postworkshop activity engagement mean - pre-workshop activity engagement mean).

\section{Pain Willingness}

The pain willingness post-workshop mean was subtracted from the pain willingness preworkshop mean to calculate a change score. A multiple linear regression analysis indicated no significant influence of the demographic variables on the pain willingness change score $\left(R^{2}=\right.$ .236 , adjusted $\left.R^{2}=.018, F(4,14)=1.082, p=.403\right)$.

\section{Table 11}

Summary of Demographic Variables Influence on Pain Willingness Change Score

\begin{tabular}{lccccc}
\hline Pain Willingness & $B$ & $S E B$ & $\beta$ & $t$ & $p$ \\
\hline Age & -.19 & .11 & -.45 & -1.78 & .098 \\
Duration of Pain & .08 & .17 & .13 & .45 & .660 \\
Sex & -2.60 & 2.73 & -.25 & -.95 & .360 \\
Education & -.26 & .91 & -.07 & -.28 & .783 \\
& & & & &
\end{tabular}

Note. $n=19$. The impact of demographic variables on pain willingness change score (postworkshop pain willingness mean - pre-workshop pain willingness mean).

\section{Pain Catastrophizing}

A change score was calculated in SPSS by subtracting the pain catastrophizing postworkshop mean from the pain catastrophizing pre-workshop mean. A multiple linear regression indicated no significant influence of the demographic variables on the pain catastrophizing change score $\left(R^{2}=.224\right.$, adjusted $\left.R^{2}=.002, F(4,14)=1.011, p=.435\right)$.

\section{Table 12}

Summary of Demographic Variables Influence on Pain Catastrophizing Change Score 


\begin{tabular}{lccccc}
\cline { 2 - 5 } Pain Catastrophizing & $B$ & $S E B$ & $\beta$ & $t$ & $p$ \\
\hline Age & -.05 & .02 & -.48 & -1.89 & .080 \\
Duration of Pain & .02 & .04 & .14 & .48 & .64 \\
Sex & -.61 & .62 & -.26 & -.98 & .344 \\
Education & .09 & .21 & .11 & .42 & .679
\end{tabular}

Note. $n=19$. The impact of demographic variables on pain catastrophizing change score (postworkshop pain catastrophizing mean - pre-workshop pain catastrophizing mean).

\section{Exploratory Analysis 3: Client Satisfaction}

Descriptive statistics on client satisfaction are presented below. A bivariate correlation analysis was utilized to determine the relationship among client satisfaction and age, pain duration, sex, and education. Additionally, a bivariate correlation analysis on client satisfaction and dependent variables was conducted to determine if any relationship was present pre-and post-workshop. A G*power analysis was calculated utilizing a $\mathrm{G}^{*}$ Power software (Faul et al., 2008). Power (1- $\beta$ ) was set at 0.80 and $\alpha=0.05$. This analysis showed a need for $n=84$ to reach a significance level of $(\alpha)$.05. Thus, the negative findings in the below exploratory analysis could be attributed to a low sample size $(n=19)$ in the current study.

Two questions were asked of the participants to determine their satisfaction with the ACT-workshop four-weeks post-workshop. These two questions include, (Q1) "Please rate your level of satisfaction based on the group you attended," and (Q2) "How likely are you to refer a friend or family member to the workshop you attended?". Scores for question one could range from $0=$ Very Dissatisfied to $6=$ Very Satisfied. For question two, scores could range from $0=$ Very Unlikely to $6=$ Very Likely. Descriptive statistics and threshold percentages for Q1 and Q2 are presented in Table 13. Mean ratings exceeded an a priori threshold of $\geq 80 \%$; suggesting 
$83 \%$ of participants were satisfied with the workshop, and $83 \%$ of participants would refer the workshop to a friend or family member. A summary of the relationship between client satisfaction and demographic variables are presented in Table 14. Overall, there were no significant relationships between demographic variables and client satisfaction. A separate bivariate correlation analysis was conducted to determine any relationships between outcome variables both pre-and post-workshop and client satisfaction. Again, there were no significant relationships between outcome variables pain acceptance, activity engagement, pain willingness, and pain catastrophizing at both data collection points. Please reference Table 15 and Table 16 for Pearson correlations between client satisfaction and outcome variables at both pre-workshop and post-workshop time points.

To further examine client satisfaction, a secondary researcher asked the participants at the end of the four-week follow-up phone conversation, "Do you have any more comments about the group that you would like to tell us about?". Participant comments included: "Good the way it is," "Safe and relaxed," "Listening to others is helpful," "Reframing was helpful and brought things to my attention," and "Liked the style of the group." Examples of constructive feedback included: "Wish there was more time to talk," "Didn't get much from it," and "Physical interventions like meds seem to be the only relief."

\section{Table 13}

Descriptive Statistics for Q1 and Q2 on the Two-Item Client Satisfaction Questionnaire.

\begin{tabular}{cccccc}
\hline & Mean & SD & Minimum & Maximum & $\begin{array}{c}\text { Percentage } \\
\text { above } \geq 80 \% \\
\text { threshold }\end{array}$ \\
\cline { 2 - 6 } CS Question 1 & 4.89 & 1.20 & 3.00 & 6.00 & $83 \%$ \\
CS Question 2 & 5.00 & 1.37 & 2.00 & 6.00 & $83 \%$ \\
\hline
\end{tabular}


Note. $n=19$; Question 1 = "Please rate your level of satisfaction based on the group you attended"; Question 2 = "How likely are you to refer a friend of family member to the workshop you attended.

\section{Table 14}

Bivariate Correlation Analysis for Client Satisfaction and Demographic Variables

\begin{tabular}{lllllll}
\hline Measure & 1 & 2 & 3 & 4 & 5 & 6
\end{tabular}

1. Age

2. Duration of Pain Sx

.22

3. Sex

$-.07$

.45

4. Education

.35

.35

.06

5. Client Satisfaction Q1

.02

.40

.09

.01

6. Client Satisfaction Q2

.17

.45

.08

.08

$.95 * *$

Note. $n=19 ; \mathrm{CS}=$ Client satisfaction; Question $1=$ "Please rate your level of satisfaction based on the group you attended"; Question 2 = "How likely are you to refer a friend of family member to the workshop you attended; $* * p<.01$ (2-tailed).

\section{Table 15}

Bivariate Correlation Analysis for Client Satisfaction and Outcome Variables Pre-Workshop

\begin{tabular}{lllllll}
\hline Measure & 1 & 2 & 3 & 4 & 5 & 6
\end{tabular}

1. Total Pain Acceptance

2. Activity Engagement

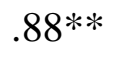

3. Pain Willingness

$.66^{* *} \quad .22$

4. Pain Catastrophizing

.24

$-.07 \quad .59 * *$

5. Client Satisfaction Q1

.24

.12

.30

.04 

6. Client Satisfaction Q2
.27
.15
.31
.08
$.95^{* *}$

Note. $n=19 ; \mathrm{CS}=$ Client satisfaction; Question $1=$ "Please rate your level of satisfaction based on the group you attended"; Question 2 = "How likely are you to refer a friend of family member to the workshop you attended; $* * p<.01$ (2-tailed).

\section{Table 16}

Bivariate Correlation Analysis for Client Satisfaction and Outcome Variables Post-Workshop

\begin{tabular}{lllllll}
\hline Measure & 1 & 2 & 3 & 4 & 5 & 6
\end{tabular}

1. Total Pain Acceptance

2. Activity Engagement

$.72 * *$

3. Pain Willingness

$.63 * * \quad-.08$

4. Pain Catastrophizing

$.59 * * \quad .07 \quad .77 * *$

5. Client Satisfaction Q1

$-.08$

$-.13$

.04

.02

6. Client Satisfaction Q2

$\begin{array}{lll}-.06 & -.14 \quad .08\end{array}$

.04

$.95 * *$

Note. $n=19 ; \mathrm{CS}=$ Client satisfaction; Question $1=$ "Please rate your level of satisfaction based on the group you attended"; Question 2 = "How likely are you to refer a friend of family member to the workshop you attended; $* * p<.01$ (2-tailed).

\section{Summary}

The purpose of this study was to investigate if a brief one-session ACT workshop would increase adaptive pain-related coping mechanisms, such as pain acceptance, as well as decrease maladaptive coping mechanisms such as pain catastrophizing. The first and third hypotheses were supported. Therefore, individuals who participated in a one-session ACT workshop had statistically significantly higher overall pain acceptance and pain willingness. However, the second and fourth hypotheses were not supported, meaning there was no significant change in the participants' activity engagement and pain catastrophizing between both data collection 
points. The first exploratory analysis utilized a linear regression, which indicated that demographic variables such as age, duration of pain, sex, and education were not predictive of the outcome variables (CPAQ-R Total Score, CPAQ-R AE Subscale, CPAQ-R PW Subscale, 2PCQ) both pre-and four-weeks post-workshop. The second exploratory analysis indicated that demographic variables did not impact the outcomes of this study through the utilization of a multiple regression. The third exploratory analysis reviewed client satisfaction by using a bivariate correlation analysis. Overall, clients reported they were generally satisfied with the workshop and would recommend the workshop to a friend or family member. 


\section{Chapter 4: Discussion}

The literature on chronic pain is vast. However, little is known about the best psychological practices for chronic pain patients compared to the current gold standard, cognitive behavioral therapy (CBT) (Seminowicz et al., 2013). There has been a call to the chronic pain research community to develop evidence-based, brief psychological interventions for chronic pain (Society of Clinical Psychology, 2016). Additionally, one-session workshop interventions for chronic pain are a relatively new treatment modality that needs more research. Therefore, this study adds to the body of literature supporting acceptance and commitment therapy (ACT) for chronic pain as a brief intervention.

The overall purpose of this study was to develop a one-session, ACT workshop that would provide chronic pain patients who may have difficulties accessing or affording mental health care with adaptive coping mechanisms. More specifically, this study sought to increase adaptive coping mechanisms such as chronic pain acceptance, activity engagement, and willingness to experience pain. Additionally, it was hypothesized that the workshop would decrease maladaptive coping mechanisms such as pain catastrophizing.

Supplemental information on the development and implementation of the ACT-workshop are reviewed and discussed in this section so that future clinicians can apply the workshop in new settings and improve the current workshop format. Second, the major and exploratory findings from the present study will be reviewed and discussed. Third, data on client satisfaction from the exploratory analyses is interpreted to deliver future clinicians with information on group construction and recommendations. Finally, the strengths and limitations of the study as well as recommendations for future clinicians and researchers are provided. 


\section{Development of One-Session ACT-Based Chronic Pain Workshop}

To the current researcher's knowledge, few workshops are developed for chronic pain utilizing an ACT modality. This current study was a reflection of Darnall et al's. (2014) study which indicated that a one-session 120-minute CBT-based workshop was able to improve pain catastrophizing in chronic pain patients post-workshop. The current study utilized similar methodology, but employed an ACT invention with the purpose of increasing pain acceptance and decreasing pain catastrophizing. Prior to Darnall's et al's. (2014) study, no ACT-workshops were created for chronic pain until Dindo and colleagues (2018) created a preventative ACTworkshop for chronic pain veterans who were for at-risk for opioid misuse. Due to the limited resources available on single-session treatment modalities, the current researcher utilized intervention and language from the "Therapist Guide and Patient Workbook: Life with Chronic Pain: An Acceptance-Based Approach" (Vowles \& Sorrell, 2007), “Living Beyond Your Pain: Using Acceptance and Commitment Therapy to Ease Chronic Pain” (Dahl \& Lundgren, 2006), and ACT for Chronic Pain (McCracken, 2015).

LaChapelle et al. (2008) reported variables associated with high pain acceptance included educating themselves and others about pain, self-care, and a strong social support network. Therefore, the current researcher developed the workshop to be informative about the difference between pain and suffering, examined the participants' values and barriers for self-care strategies, and provided the participants with a social support network through a group-workshop environment. Additionally, Bor and colleagues (2004) discussed four themes that make brief therapies more effective; including (1) moving towards a goal, (2) building rapport and therapeutic alliance, (3) creating cognitive flexibility, and (4) introducing the intervention early. Therefore, the current researcher implemented the characteristics of effective brief therapies into 
the ACT-based workshop by offering an "ice breaker" session at the beginning to build rapport, utilizing ACT-interventions to develop cognitive flexibility, and providing the clients with the overview of the workshop.

ACT interventions for the workshop corresponded with the six core processes of the psychological flexibility model. These core processes include (1) acceptance, (2) cognitive defusion, (3) flexible attention to the present moment, (4) perspective-taking, (5) values, and (6) committed action (Hayes \& Lillis, 2012). More literature on the core processes of acceptance, values, and committed action have been explored, while less is known about the processes of cognitive defusion, flexible attention to the present moment, and perspective-taking (Liu \& McCracken, 2016). Therefore, the current researcher focused more broadly on acceptance, values, and committed action during the workshop in efforts to make the intervention brief. The other processes were still present in the workshop, although less of a focus. An outline that the workshop leader utilized along with the handout given to participants during the workshop are available (see Appendix G).

The findings of this study are preliminary and supplement the literature on chronic pain, ACT for chronic pain, and one-session workshop intervention formats. Due to the results that a one-hour, ACT-based workshop for individuals with chronic pain elevated levels of overall pain acceptance and pain willingness, it is hopeful that this study will increase the drive for more clinicians and researchers to further this research.

\section{A Review of the Major Findings}

Nineteen participants with chronic pain attended the workshop and completed the fourweek follow-up phone call. There were four hypotheses tested in this study. The first hypothesis examined if total pain acceptance would improve post-workshop as measured by the CPAQ-R 
(McCracken et al., 2004). The data revealed a significant difference in total pain acceptance preworkshop and four-weeks post-workshop, in which total pain acceptance improved postworkshop. Further insight was gained by examining the two subscales within the CPAQ-R; activity engagement and pain willingness. Therefore, hypotheses two and three tested changes in the variable means pre-and four-weeks post-workshop. Results indicated that there was no significant difference in activity engagement scores pre-and post-workshop. However, there was a significant difference in pain willingness between both time points. Finally, the fourth hypothesis examined differences in pain catastrophizing. Results indicated there was no significant difference pre-and post-ACT workshop.

Several additional analyses were conducted to ensure that the findings were interpretable. First, the assumptions for a paired-samples $t$-test were assessed. Privtera (2015) stated the two assumptions of (1) normality and (2) independence within groups should be considered when utilizing a paired-samples $t$-test. After employing both a Shapiro-Wilk test (Shapiro \& Wilk, 1965) and a skewness and kurtosis analysis (Person, 1930), it was determined that all four dependent variables met the Shapiro and Wilk (1965) test of normality. However, while three of the four variables (i.e., pain acceptance, activity engagement, and pain willingness) met the guidelines of the skewness and kurtosis test, pain catastrophizing did not (Person, 1930). An internal consistency reliability analysis was conducted pre-and post-workshop for all three outcome measures (CPAQ-R, 2-PCQ, 2-Item Client Satisfaction Questionnaire). All measures had adequate to good internal consistency reliability for the current study, ensuring the questionnaires measured the corresponding outcome variables at both pre-and post-workshop. 


\section{Pain Acceptance}

The variable pain acceptance and was at the forefront of this study. The term pain acceptance is defined as a willingness to engage in a pain experience without attempting to reduce or change it (McCracken, 1999). Previous literature stated low pain acceptance is often associated with a disabled identity, unsatisfactory relationships, and difficulty accepting negative personal pain experiences (LaChapelle et al., 2008). Additionally, pain acceptance has been associated with lower levels of pain distress and positively correlates to daily activity levels (McCracken, 1998; McCracken et al., 2004).

Despite the current research on pain acceptance, little is known on new and effective brief one-session treatment modalities that have both pre-and post-test data. In this present study, the CPAQ-R was used to measure total pain acceptance, activity engagement, and pain willingness. The results indicated a change in total pain acceptance and pain willingness through the use of a brief ACT modality. However, there was no change in activity engagement scores post-workshop. Results of the current study were similar to Dindo et al.'s, (2018) pilot randomized controlled study, in which clinicians designed an ACT workshop to decrease opioid use post-surgery. Specifically, researchers observed higher pain acceptance post-workshop, among other noteworthy findings.

The first exploratory analysis for the current study investigated if outcome variables were associated with demographic variables. A linear regression analysis indicated that demographic variables such as age, pain duration, sex, and education did not account for significant variance in the dependent variables pain acceptance, activity engagement, or pain willingness both pre and post-workshop. In the second exploratory analysis, a multiple regression was calculated to determine any influence that demographic variables had on the pain acceptance change scores. 
Results from the multiple regression analysis indicated no significant findings. This lack of shared variance between demographic and outcome variables indicated that interior features did not confound the results of this study. However, of significant note, the negative findings of the exploratory analysis may be attributed to small sample size $(n=19)$.

\section{Pain Catastrophizing}

Pain catastrophizing is defined as a maladaptive belief that amplifies the negative orientation toward actual pain experiences (Gatchel et al., 2007). In previous literature, pain catastrophizing has been associated with elevated levels of disability, pain intensity, and poor surgical outcomes (McCracken, 2005; McCracken \& Turk, 2002; Sullivan, 2001). Additionally, those with higher pain acceptance report lower pain catastrophizing (De Boer et al., 2014).

Previous studies have used an ACT treatment modality to examine reductions in pain catastrophizing (De Boer, 2014; Vowles \& McCracken, 2008). Additionally, Darnall et al. (2014) investigated pain catastrophizing as an outcome measure for a CBT-based chronic pain workshop. Therefore, for the current study, pain catastrophizing was measured with the 2-PCQ developed by Jensen et al. (2003). Pain catastrophizing was hypothesized to improve after the administration of an ACT workshop. Results indicated no significant change in pain catastrophizing between pre-and four-weeks post-workshop time points.

An exploratory analysis was conducted to determine if demographic variables contributed to the nonsignificant finding. A linear regression analysis was performed for pain catastrophizing and the demographic variables of age, duration of pain, sex, and education. Additionally, a multiple regression was calculated to determine any influence that demographic variables had on pain catastrophizing change scores. Results from the first and second exploratory analysis suggested that demographic variables did not account for significant variance, and therefore did 
not contribute to the negative findings. Of important note, McCracken (2005) suggested that contextual-behavioral approaches are different from traditional treatments for chronic pain because the goal is not to reduce pain intensity or pain catastrophizing. Instead, the aim is to clarify the patients' values and ultimately improve their quality of life.

\section{Client Satisfaction}

The workshop created for this project has never been implemented in a clinical setting prior to this research. Therefore, data collection techniques reflected past studies, such as Darnall et al.'s (2014) one-session CBT workshop, in which a client satisfaction questionnaire was administered post-workshop. Thus, it was critical that this study also follow-up with the participants' satisfaction with the ACT workshop intervention, as well as collect qualitative data by asking for feedback from the clients. A post-workshop client satisfaction survey was conducted by a secondary researcher to determine the perceptions of the workshop. Client satisfaction was satisfactory, in that $83 \%$ of clients reported they would refer a friend or family member to the group and that they were satisfied with the content of the group, meeting an a priori value of $\geq 80 \%$.

An exploratory analysis was conducted to determine if there was a relationship between client satisfaction and demographic variables. The analysis determined no statistically significant relationship between client satisfaction and demographic variables. Additionally, there was no significant relationship between client satisfaction and outcome variables (total pain acceptance, activity engagement, pain willingness, pain catastrophizing). The results of the bivariate correlation indicated that participants' demographic features did not relate to how they perceived the group. Furthermore, the correlation analyses signified that outcome variables did not relate to 
client satisfaction, demonstrating that those with clinical features, such as high pain catastrophizing, still felt as though the group was satisfactory.

\section{Strengths, Limitations and Recommendations for Future Research}

There were many strengths of this study. First, this study adds to the literature and intervention repertoire on ACT, ACT for chronic pain, and one-session workshops. Additionally, more than half $(52.6 \%)$ of the participants in this study reside in a rural environment, providing mental health professionals with a timely, accessible, and cost-effective intervention for chronic pain patients who may not have had the opportunity to receive mental health care otherwise. The results of this study demonstrates the utility of brief therapeutic techniques, in that they are capable of having positive systemic impacts. Furthermore, this current study utilized a repeated measure and within-subject design, which presents both strengths and limitations. Howitt and Cramer (2011) state that repeated measures designs exclude individual differences pre-and posttest by using the same participants at both time points. Howitt and Cramer (2011) also report that repeated measure designs require a fewer number of participants, which improves the overall efficiency of the study.

However, this one-sample pretest-posttest prospective exploratory study was not without its limitations. One of the most significant limitations of the study was the limited number of participants. Data collection took place within a six-month period, which allowed the recruitment of participants. A total of 45 patients at a mid-Atlantic integrative pain clinic were asked to participate. However, only 24 of these patients agreed to complete the pre-workshop forms and engage in the ACT-workshop. Only 19 of the 24 participants completed the follow-up phone call after several attempts to reach out. Therefore, the total number of participants did not meet the ideal sample size of 27 to achieve an appropriate effect size for a paired-samples $t$-test. Due to 
this limitation, there is an increased risk that the findings presented in this study are incorrectly interpreted by the current researcher (Faber \& Fonseca, 2014). This limitation is increasingly pertinent in the exploratory analysis, in which the sample size needed to reach an appropriate effect size was significantly larger than the total number of participants.

To combat this limitation, several analyses were conducted to ensure the assumptions for paired-samples $t$-tests were met, even with a smaller sample size. Of important note, the assumption of normality for both pre-and post-workshop outcome measures was met in all cases except for pain catastrophizing. Pain catastrophizing did not meet the assumption of normality using the Shapiro-Wilk (1965) test but did meet the assumption of normality once conducting a skewness and kurtosis test. Therefore, the variable pain catastrophizing is at a higher risk of misinterpretation, threatening internal validity. Additionally, a small sample size threatens external validity, in that the participants in this study may not be representative of a chronic pain population. It is recommended that this study be replicated with a larger sample size in the future to ensure that the results are accurate.

The second limitation of this study is the recruitment methods used to obtain participants. Participants were recruited through convenience sampling procedures, which increases the risk of selection bias and limitations to generalizability. The characteristics of the patients who decided to participate may be different than the population that did not choose to participate. Specifically, there may have been differences in motivation and personality, further threatening internal validity. For example, those who did not agree to participate in the study may not have been motivated by the Walmart gift card compared to the group that did participate. Additionally, those who chose to participate may have been primed to possess a prior willingness to engage in an intervention, which could contribute to outcome variable scores (e.g., pain 
willingness). A future randomized controlled study would ensure changes pre-and postworkshop were due to treatment effects rather than an external source. Therefore, it is recommended that future research provide the workshop as part of a randomized controlled study to limit threats to external and internal validity.

A third limitation threatens external validity, in that the population of the study was $52.6 \%$ rural, and $47.4 \%$ of the population was non-rural (FORHP, 2018). Therefore, this study may not apply to others with chronic pain. However, this limitation could also be interpreted as a strength, in that more research and interventions are needed for rural populations. Specifically, rural communities are likely to have lower SES levels, difficulties accessing medical care, and usually have longer travel times to medical appointments (Artnak et al., 2011). In future research, the population of study should primarily be concentrated on a rural community or should utilize practices to increase generalizability to a general chronic pain population.

Another limitation is that this study relied on the participants' self-report of their chronic pain experience. This limitation poses several threats to internal and external validity. First, the chronic pain experience is subjective, in that no one person experiences pain in the same way. Therefore, chronic pain research has primarily been conducted through the use of self-report measures. However, the difficulty with self-report measures is that they rely on the participants' perception of the variables and their own past experiences, and therefore may be inaccurate (Heppner et al., 2016). Additionally, these self-report measures were given in two different formats for data collection. First, the pre-workshop self-report measures utilized a paper format, and the post-workshop data collection method was delivered through a verbal version of the questionnaires over the telephone. It is unknown if the environment they were in at the time of the phone call was in a controlled environment. However, many methods were used to minimize 
these threats to internal and external validity, such as counterbalancing the questionnaires, utilizing a secondary researcher to minimize biases towards the primary researcher/workshop leader, and providing the participants with a paper copy of the surveys for reference during the call. It is recommended that future researchers reduce this limitation by offering the questionnaires using the same method (i.e., paper copy only) in a controlled environment.

Finally, the last limitation of this study is that the primary researcher for this project contributed by developing the workshop in its current form and provided the intervention to the participants. Due to this overlap in various aspects of the project, external validity may be threatened due to the training and clinical characteristics that may differ from one clinician to another. Additionally, the primary researcher may have implicit biases towards the project, thus creating a threat to internal validity. To lower threats to validity, the primary researcher received training in ACT and in group process. Additionally, the primary researcher received supervision by a licensed clinical pain management psychologist to reduce clinician bias and aid in the construction of the workshop. It is recommended that clinicians interested in providing this workshop have sufficient training in ACT, chronic pain, and group process.

\section{Clinical Applications and Recommendations}

This study holds promise that a one-hour ACT workshop has utility in increasing levels of pain acceptance and pain willingness. Consequently, the systemic impacts for the 76 million individuals (NIH, 2010) suffering from chronic pain could be heavily influenced by an accessible ACT intervention specifically catered for chronic pain patients. Therefore, a follow-up study specifically identifying the systemic impacts (e.g., sociological, economical, etc.) of this workshop should be completed in the future. At the individual level, participating in this 
workshop may influence ones' perception of their disabled identity, relationships with others, and acceptance of personal pain experience (LaChapelle et al., 2008).

It is likely that chronic pain patients will present to medical settings for answers to their questions. This workshop may have good application in community care settings, hospital settings, rural medical settings, or primary care settings. These various settings often prefer brief psychological interventions to address the psychological impacts of medical diagnoses.

Therefore, it is recommended that follow-up studies continue to implement this workshop within these settings to determine broad usefulness.

For medical professionals, it may be difficult to continue to treat chronic pain patients who report no reductions in their pain severity over the course of months to years. Often, patients with chronic pain will endure several treatment modalities, such as pharmacological treatment, injections, and surgery to reduce their pain. However, ACT for chronic pain is aimed at increasing psychological flexibility in patients that have seen little success from previous treatments. Therefore, if a clinician begins to experience frustration with the progress of medical treatment, referring the patient to an ACT-based therapist, or finding a way to implement this workshop in a medical setting could provide medical professionals with relief.

Although this workshop was performed within a group modality, one participant reported during their follow-up phone call that they wished they had more opportunities for group process. Therefore, there may be many advantages in providing a similar intervention for individual treatment, or increasing the time of the intervention to allow for group process. When working with these individuals, the exploratory analysis indicated that demographic variables had no relation to outcome variables. Therefore, it is recommended that the composition of the 
workshop be aimed at individuals who are motivated to receive psychological care, and should not be based on demographic criteria such as sex, pain duration, education, or age.

Hayes and Lillis (2012) noted the role of the therapist in an ACT modality is to be accepting, active, based in values, and nonjudgmental. Additionally, they note a major role of ACT interventions is to increase the patient's psychological flexibility. It may be difficult for a mental health professional to keep in mind all of these underlying processes while also constrained by the briefness of this intervention. Since ACT is a client centered approach, it is critically important that patients have the opportunity to build rapport with you as a therapist prior to or during the administration of this workshop. Therefore, it is recommended that mental health professionals who provide this workshop have sufficient training and experience in delivering and implementing ACT interventions, workshop interventions, and have experience working with a chronic pain population. Additionally, if the clinic allows for additional time to be added to the workshop to provide clinicians with the opportunity to engage in these processes at a deeper level, the patients may have a more impactful experience.

\section{Conclusion}

In conclusion, the results of this study have promise in providing mental health professionals and their chronic pain patients with an efficient, non-pharmacological treatment for chronic pain. Additionally, this study illuminates the importance of a one-session ACT workshop for chronic pain patients who live in rural communities or do not have the resources to complete a four-to ten-week psychological intervention. Although strengths and limitations were both present, the major findings of this research indicated that a one-hour ACT workshop, can increase pain acceptance and pain willingness. The implications of this study could affect how individuals receive an intervention or manage their chronic pain. Additionally, there may be 
more substantial systemic impacts, in that the economic impact of chronic pain and disability could be reduced. In the future, it is recommended that this study will be revised and implemented in other medical and community health clinics as well as replicated in the literature. It is hoped that this project provides chronic pain patients with adaptive coping mechanisms that are brief and accessible, especially to those who may not otherwise have received care. 


\section{References}

Allison, P. D. (1990). Change scores as dependent variables in regression analysis. Sociological Methodology, 20, 93-114. https://doi.org/10.2307/271083

American Academy of Pain Medicine (n.d.). AAMPM facts and figures on pain. http://www.painmed.org/files/facts-and-figures-on-pain.pdf

American Psychiatric Association (2013). Diagnostic and statistical manual of mental disorders (5th ed.). American Psychiatric Publishing.

American Society of Regional Anesthesia and Pain Medicine, (n.d.). Types of chronic pain. https://www.asra.com/page/45/types-of-chronic-pain

Artnak, K. E., McGraw, R. M., \& Stanley, V. F. (2011). Health care accessibility for chronic illness management and end-of-life- care: A view from rural America. Journal of Law, Medicine, and Ethics, 39(2), 140-155. https://doi.org/10.1111/j.1748-720X.2011.00584.x

Association for Contextual Behavioral Science. (n.d.). The psychological flexibility model. https://contextualscience.org/the_six_core_processes_of_act

Beck Cognitive Behavior Therapy (2016). What is cognitive behavior therapy (CBT)? https://beckinstitute.org/get-informed/what-is-cognitive-therapy/

Beissener, K., Henderson, C. R., Popaleontiou, M., Olkhovskaya, Y., Wigglesworth, J., \& Reid, M. C. (2009). Physical therapists' use of cognitive-behavioral therapy for older adults with chronic pain: A nationwide survey. Physical Therapy, 89(5), 456-469. https://doi.org/10.2522/ptj.20080163

Bernabei, R., Gambassi, G., Lapane, K., Landi, F., Gatsonis, C., Dunlop, R., Lipsitz, L., Steel, K., \& Mor, V. (1998). Management of pain in elderly patients with cancer. SAGE study group. Systematic assessment of geriatric drug use via epidemiology. Journal of the 
American Medical Association, 279(23), 1877-1883.

https://doi.org/10.1001/jama.279.23.1877

Bor, R., Gill, S., Miller, R., \& Parrott, C. (2004). Doing therapy briefly. Palgrave Macmillan.

Campbell, L. C., Robinson, K., Meghani, S. H., Vallerand, A., Schatman, M., \& Sonty, N.

(2012). Challenges and opportunities in pain management dispartities research:

Implications for clinical practice, advocacy, and policy. Journal of Pain, 13(7), 611-619. https://doi.org/10.1016/j.jpain.2012.02.004

Carr, D. B., \& Bradshaw, Y. S. (2012). Time to flip the pain curriculum? Anesthesiology, 120(1), 12-14. https://doi.org/10.1097/ALN.0000000000000054

Chambless, D. L., \& Hollon, S. D. (1998). Defining empirically supported therapies. Journal of Counseling and Clinical Psychology, 66(1), 7-18. https://doi.org/10.1037//0022006x.66.1.7

Chaparro, L., Furlan, A. D., Deshpande, A., Mailis-Gagnon, A., Atlas, S., \& Turk, D. C. (2013). Opioids compared to placebo or other treatments for chronic low-back pain. Cochrane Database of Systematic Reviews, 8(CD004959). https://doi.org/10.1002/14651858.CD004959.pub4

Cohen, J. (1992). A power primer. Psychological Bulletin, 112(1), 155-159. https://doi.org/10.1037//0033-2909.112.1.155

Cucciare, M. A., Sorrell, J. T., \& Trafton, J. A. (2009). Predicting response to cognitivebehavioral therapy in a sample of HIV-positive patients with chronic pain. Journal of Behavioral Medicine, 32(4), 340-348. https://doi.org/10.1007/s10865-009-9208-5 
Curran, P. J., West, S. G., \& Finch, J. F. (1996). The robustness of test statistics to nonnormality and specification error in confirmatory factor analysis. Psychological Methods, 1(1), 1629. https://doi.org/10.1037/1082-989x.1.1.16

Dahl, J., \& Lundgren, T. (2006). Living beyond your pain: Using Acceptance and Commitment Therapy to ease chronic pain. New Harbinger Publications Inc.

Dallenbach, K. M. (1939). Pain: History and present status. American Journal of Psychology, 52(1), 331-347. doi:10.2307/1416740

Dansie, E. J., \& Turk, D. C. (2013). Assessment of patients with chronic pain. British Journal of Anaesthesia, 111(1), 19-25. https://doi.org/10.1093/bja/aet124

Darnall, B. D., Sturgeon, J. A., Kao, M-C., Hah, J. M., \& Mackey, S. C. (2014). From catastrophizing to recovery: A pilot study of a single-session treatment for pain catastrophizing. Journal of Pain Research, 7(1), 219-226. https://doi.org/10.2147/JPR.S62329

Darnall, B. D., Ziadni, M. S., Roy, A., Kao, M-C., Sturgeon J. A., Cook. K. R., Lorig, K., Burns, J. W., \& Mackey, S. C. (2018) Comparative efficacy and mechanisms of a single-session pain psychology class in chronic low back pain: Study protocol for a randomized controlled trial. BioMed Central, 19(165), 1-15. https://doi.org/10.1186/s13063-0182537-3

de Boer, M. J., Steinhagen, H. E., Versteegen, G. J., Struys, M. M. R. F., \& Sanderman, R. (2014). Mindfulness, acceptance and catastrophizing in chronic pain. PLos One, 9(1). e87445. https://doi.org/10.1371/journal.pone.0087445

Demyttenaere, K., Bruffaerts, R., Lee, S., Posada-Villa, J., Kovess, V., Angermeyer, M. C., Levinson, D., de Girolamo, G., Nakane, H., Mneimneh, Z., Lara, C., de Graaf, R., Scott, 
K., Gureje, O., Stein, D., Haro, J., Bromet, E., Kessler, R., Alonso, J., \& Von Korff, M. (2007). Mental disorders among persons with chronic back or neck pain: Results from the World Mental Health Surveys. Pain, 129(3), 332-342.

https://doi.org/10.1016/j.pain.2007.01.022

Dietrich, J. K. (2010). Psychology and chronic pain. Anaesthesia and Intensive Care Medicine, 12(2), 42-43. https://doi.org/10.1016/j.mpaic.2010.10.021

Dindo, L., Zimmerman, M. B., Hadlandsmyth, K., StMarie, B., Embree, J., Marchman, J., TrippReimer, \& Rakel, B. (2018). Acceptance and Commitment Therapy for prevention of chronic postsurgical pain and opioid use in at-risk Veterans: A pilot randomized controlled study. Journal of Pain, 19(10), 1211-1221. https://doi.org/10.1016/j.pain.2018.04.016

Dvorak, J., Gauchat, M. H., \& Valach, L. (1988). The outcome of surgery for lumbar disc herniation. I. A 4-17 years' follow-up with emphasis on somatic aspects. Spine, 13(12), 1418-1422. https://doi.org/10.1097/00007632-198812000-00015

Ehde, D. M., Dillworth, T. M., \& Turner, J. A. (2014). Cognitive-behavioral therapy for individuals with chronic pain: Efficacy, innovations, and directions for research. American Psychologist, 69(2), 153-166. https://doi.org/10.1037/a0035747

Eisenberg, D. M., Buring, J. E., Hrbek, A. L., Davis, R. B., Connelly, M. T., Cherkin, D. C., Levy, D. B., Cunningham, M., O’Connor, B., \& Post, D. E. (2012). A model of integrative care for low-back pain. The Journal of Alternative and Complementary Medicine, 18(4), 354-362. https://doi.org/10.1089/acm.2011.0408

Engle, G. L. (1977). The need for new medical model: A challenge for biomedicine. Science, 196(4286), 129-136. doi:10.1126/science.847460 
Epping-Jordan, J. E., Wahlgren, D. R., Williams, R. A., Pruitt, S. D., Slater, M.A., Patterson, T. L., Grant, I., Webster, J., Atkinson, J. H. (1998). Transition to chronic pain in men with low back pain: predictive relationships among pain intensity, disability, and depressive symptoms. Health Psychology, 17(5), 421-427. https://doi.org/10.1037//0278-

6133.17 .5 .421

Faber, J., \& Fonseca, L. M. (2014). How sample size influences research outcomes. Dental Press Journal of Orthodontics, 19(4), 27-29. https://doi.org/10.1590/2176-9451.19.4.027029.ebo

Faul, F., Erdfelder, E., Buchner, A., \& Lang, A.-G. (2008). G*Power Version 3.1.2 [computer software]. Uiversität Kiel, Germany. http://www.psycho.uniduesseldorf.de/abteilungen/aap/gpower3/download-and-register

Fillingim, R. B., King, C. D., Riberio-Dasilva M. C., Rahim-Williams, B., \& Riley J. L. (2009). Sex, gender, and pain: A review of recent clinical and experimental findings. Journal of Pain, 10(5), 447-485. https://doi.org/10.1016/j.jpain.2008.12.001

Fliesser, M., De Witt Huberts, J. D., \& Wippert, P-A. (2014). The choice that matters: The relative influence of socioeconomic status indicators on chronic back pain- a longitudinal study. BioMedCentral Health Services Research, 17(800), 2-8. https://doi.org/10.1186/s12913-017-2735-9

Fordyce, W. E. (1995), Back Pain in the workplace: Management of disability in nonspecific conditions. IASP Press.

Frances, A., \& Chapman, S. (2013). DSM-5 somatic symptom disorder mislabels medical illness as mental disorder. Australian \& New Zealand Journal of Psychiatry, 47(5), 483-484. https://doi.org/10.1177/0004867413484525. 
Gaskin, D. J., \& Richard, P. (2012). The economic costs of pain in the United States. The Journal of Pain, 13(8), 715. https://doi.org/10.1016/j.jpain.2012.03.009

Gatchel, R. J., \& Baum, A. (1983). An introduction to health psychology. Addison-Wesley.

Gatchel, R. J., Peng, Y. B., Peters, M. L., Fuchs, P. N., Turk, D. C. (2007). The biopsychosocial approach to chronic pain: Scientific advances and future directions. Psychological Bulletin, 133(4), 581-624. https://doi.org/10.1037/0033-2909.133.4.581

Gatchel, R. J., \& Rollings, K. H. (2008). Evidence-informed management of chronic low back pain with cognitive behavioral therapy. The Spine Journal, 8(1), 40-44. https://doi.org/10.1016/j.spinee.2007.10.007

Gaudiano, B. A. (2009). Öst's (2008) methodological comparison of clinical trials of acceptance and commitment therapy versus cogntive behavior therapy: Matching apples with oranges? Behaviour Research and Therapy, 47(12), 1066-1070. https://doi.org/10.1016/j.brat.2009.07.020

Gauntlett-Gilbert, J., Connell, H., Clinch, J., \& McCracken, L. M. (2012). Acceptance and values-based treatment of adolescents with chronic pain: Outcomes and their relationship to acceptance. Journal of Pediatric Psychology, 38(1), 72-81. https://doi.org/10.1093/jpepsy/jss098

Gerdle, B., Björk, J., Cöster, L., Henriksson, K. G., Henriksoon, C., \& Bengtsson, A. (2008). Prevalence of widespread pain and associations with work status: a population study. BMC Musculoskeletal Disorders, 9(1), 102-102. https://doi.org/10.1186/1471-2474-9102 
Glover-Graf, N. M., Marini, I., Baker, J., \& Buck, T. (2007). Religious and spiritual beliefs and practices of persons with chronic pain. Rehabilitation Counseling Bulletin, 51(1), 21-33. https://doi.org/10.1177/00343552070510010501

Green, C. R., Anderson, K. O., Baker, R. A., Campbell, L. C., Decker, S., Fillingim, R. B., Kaloukalani, D. A., Lasch, K. E., Myers, C., Tait, R. C., Todd, K. H., \& Vallerand, A. H. (2003). The unequal burden of pain: Confronting racial and ethnic disparities in pain. Pain Medicine, 4(3), 277-294. https://doi.org/10.1046/j.1526-4637.2003.03034.x

Hann, K. E. J., \& McCracken, L. M. (2014). A systematic review of randomized controlled trials of Acceptance and Commitment Therapy for adults with chronic pain: Outcome domains, design quality, and efficacy. Journal of Contextual Behavioral Science, 3(4), 217-227. https://doi.org/10.1016/j.jcbs.2014

Hardt, J., Jacobsen, C., Goldberg, J., Nickel, R., \& Buchwald, D. (2008). Prevalence of chronic pain in a representative sample in the United States. Pain Medicine 9(7), 803-812. https://doi.org/10.1111/j.1526-4637.2008.00425.x

Haskell, S. G., Brandt, C. A., Krebs, E. E., Shanderson, M., Kerns, R. B., \& Goulet, J. L. (2009). Pain among veterans of Operations Enduring Freedom and Iraqi Freedom: Do women and men differ? Pain Medicine, 10(7), 1167-1173. https://doi.org/10.1111/j.15264637.2009.00714.x.10.001

Hayes, S. C. (2004). Acceptance and commitment therapy, relational frame theory, and the third wave of behavioral and cognitive therapies. Behavior Therapy, 35(4), 39-665. https://doi.org/10.1016/s0005-7894(04)80013-3

Hayes, S. C., \& Lillis, J. (2012). Acceptance and Commitment Therapy. American Psychological Association. 
Hayes, S. C., Luoma, J. B., Bond, F. W., Masuda, A., \& Lillis, J. (2006). Acceptance and commitment therapy: Model, process and outcomes. Behaviour Research and Therapy, 44(1), 1-25. https://doi.org/10.1016/j.brat.2005.06.006

Health Resources \& Services Administration. (2018). Federal Office of Rural Health Policy (FORHP) Data Files. https://www.hrsa.gov/rural-health/aboutus/definition/datafiles.html

Heppner, P. P., Wampold, B. E., Owen, J., Thompson, M. N., \& Wang, K. T. (2016). Research design in counseling (4th ed.). Cengage Learning.

Howitt, D., \& Cramer, D. (2011). Introduction to Research Methods in Psychology (3rd ed.). Pearson Education Limited.

Institute of Pain Medicine. (2011). Relieving pain in America: A blueprint for transforming prevention, care, education, and research. National Academies Press.

International Association for the Study of Pain. (2017). IASP Terminology. https://www.iasppain.org/Education/Content.aspx?ItemNumber $=1698$

International Association for the Study of Pain. (2018). Descriptions of chronic pain syndromes and definitions of pain terms. Classification of Chronic Pain, (2nd ed.). http://www.iasppain.org/PublicationsNews/Content.aspx?ItemNumber=1673

Jensen, M. P., Keefe, F. J., Lefebvre, J. C., Romano, J. M., \& Turner, J. A. (2003). One- and two-item measures of pain beliefs and coping strategies. Pain, 104(3), 453-469. https://doi.org/10.1016/S0304-3959(03)00076-9

Jones-Smtih, E. (2012). Counseling and psychotherapy: An integrative approach. SAGE Publications, Inc. 
Katz, J. Rosenbloom, B. N., \& Fashler, S. (2015). Chronic pain, psychopathology, and DSM-5 Somatic Symptom disorder. Canadian Journal of Psychiatry, 60(4), 160-167. https://doi.org/10.1177\%2F070674371506000402

Kehlet, H., Jensen, T., \& Woolf, C. (2006). Persistent postsurgical pain: Risk factors and prevention. The Lancet, 367(9522), 1618-1625. https://doi.org/10.1016/S01406736(06)68700-X

Keogh, E., Bond, F. W., Hanmer, R., \& Tilston, J. (2005). Comparing acceptance- and controlbased coping instructions on the cold pressor pain experiences of healthy men and women. European Journal of Pain, 9(5), 591-598.

https://doi.org/10.1016/j.ejpain.2004.12.005

Khadilkar, A., Odebiyi, D. O., Brosseau, L., \& Wells, G. A. (2008). Transcutaneous electrical nerve stimulation (TENS) versus placebo for chronic low-back pain. Cochrane Database of Systematic Reviews, 4(CD003008). https://doi.org/10.1002/14651858.CD003008.pub3

Knoerl, R., Lavoie Smith, E. M., \& Weisberg, J. (2016). Chronic pain and cognitive behavioral therapy: An integrative review. Western Journal of Nursing Research, 38(5), 596-628. https://doi.org/:10.1177/0193945915615869

Krames, E. S., Oakley, J. C., Foster, A. M., Henderson, J., Prager, J. P., Rashbaum, R. R., Stamatos, J., \& Weiner, R. L. (2008). Spinal cord stimulation has comparable efficacy in common pain etiologies. Neuromodulation Technology at the Neural Interface, 11(3), 171-181. https://doi.org/10.1111/j.1525-1403.2008.00163.x

LaChapelle, D. L., Lavoie, S., \& Boudreau, A. (2008). The meaning and process of pain acceptance. Perceptions of women living with arthritis and fibromyalgia. Pain Research \& Management, 13(3), 201-210. https://doi.org/10.1155/2008/258542 
Lanitis, S. Mimigianni, C., Raptis, D., Sourtse, G., Sgourakis, G., \& Karaliotas. (2015). The impact of educational status on the postoperative perception of pain. Korean Journal of Pain, 38(4), 265-274. https://doi.org/10.3344/kjp.2015.28.4.265

Larsen, D. L., Attkisson, C. C., Hargreaves, W. A., \& Nguyen, T. D. (1979). Assessment of client/patient satisfaction: development of a general scale. Evaluation and Program Planning, 2(3), 197-207. https://doi.org/10.1016/0149-7189(79)90094-6

Lethem, J., Slade, P. D., Troup, J. D., \& Bently, G. (1983). Outline of a fear-avoidance model of exaggerated pain perception-I. Behavior Research and Therapy, 21(4), 401-408. https://doi.org/10.1016/0005-7967(83)90009-8

Lillis, J., Hayes, S. C., Bunting, K., \& Masuda, A. (2009). Teaching acceptance and mindfulness to improve the lives of the obese: A preliminary test of a theoretical model. Annual Behavior Medicine, 37(1), 58-69. https://doi.org/10.1007/s12160-009-9083-x

Linton, S. J. (2000). A review of psychological risk factors in back and neck pain. Spine, 25(9), 1148-1156. https://doi.org/10.1097/00007632-200005010-00017

Liu, L., \& McCracken, L. M. (2016). Model and processes of acceptance and commitment therapy (ACT) for chronic pain including a closer look at the self. Current Pain and Headache Reports, 20(12), 1-7. https://doi.org/10.1007/s11916-016-0541-4

Maas, E. T., Ostelo, R. W. J. G., Niemisto, L., Jousimaa, J., Hurri, H., Malmivaara, A. .. van Tulder, M. W. (2015). Radiofrequency denervation for chronic low back pain. Cochrane Database of Systematic Reviews, 10(CD008572). https://doi.org/10.1002/14651858.CD008572.pub2

Manchikanti, L., Fellos, B., \& Singh, V. (2002). Understanding psychological aspects of chronic pain in interventional pain management. Pain Physician, 5(1), 57-82. PMID: 16896359. 
Maniadakis, N. \& Gray, A. (2000). The economic burden of back pain in the UK. Pain, 84(1), 95-103. https://doi.org/10.1016/S0304-3959(99)00187-6

Meints, S. M., Wang, V., \& Edwards, R. R. (2018). Sex and race differences in pain sensitization among patients with chronic low back pain. Journal of Pain, 19(12), 1461-1470. https://doi.org/10.1016/j.pain.2018.07.001

Melzack, R. (1999). From the gate to the neuromatrix. Pain, 82, S121-S126. https://doi.org/10.1016/s0304-3959(99)00145-1

Melzack, R., \& Katz, J. (2004). The gate control theory: Reaching for the brain. In K. D. Craig \& T. Hadjistavropoulos (Eds.), Pain Psychological Perspectives. Lawrence Erlbaum Associates.

Melzack, R., \& Wall, P. D. (1966). Pain mechanisms: A new theory. Pain Forum, 5(1), 3-11. https://doi.org/10.1016/s1082-3174(96)80062-6

Merskey, H., \& Bogduk N. (1994). Classification of chronic pain (2nd ed.). IASP Press.

McCracken, L. M. (1998). Learning to live with the pain: Acceptance of pain predicts adjustment in persons with chronic pain. Pain, 74(1), 21-27. https://doi.org/10.1016/s03043959(97)00146-2

McCracken, L. M. (1999). Behavioral constituents of chronic pain acceptance: Results from factor analysis of the Chronic Pain Acceptance Questionnaire. Journal of Back and Musculoskeletal Rehabilitation, 13(2-3), 93-100. https://doi.org/10.3233/bmr-1999-132306

McCracken, L. M. (2005). Contextual cognitive-behavioral therapy for chronic pain: Progress in pain research and management. International Association for the Study of Pain (vol. 33). IASP Press. 
McCracken, L. M. (2015). Act for chronic pain. https://www.div12.org/wpcontent/uploads/2015/06/ACT-for-Chronic-Pain-manual-McCracken.pdf

McCracken, L. M., Barker, E., \& Chilcot, J. (2014). Decentering, rumination, cognitive defusion, and psychological flexibility in people with chronic pain. Journal of Behavioural Medicine, 37(6), 1215-1225. https://doi.org/10.1007/s10865-014-9570-9

McCracken, L., MacKichan, F., \& Eccleston, C. (2007). Contextual cognitive-behavioral therapy for severely disabled chronic pain sufferers: Effectiveness and clinically significant change. European Journal of Pain, 11(3), 314-322. https://doi.org/10.1016/j.ejpain.2006.05.004

McCracken, L. M., Spertus, I. L., Janeck, A. S., Sinclair, D., \& Wetzel, F. T. (1999). Behavioral dimensions of adjustment in persons with chronic pain: Pain-related anxiety and acceptance. Pain, 80(1-2), 283-289. https://doi.org/10.1016/s0304-3959(98)00219-x

McCracken, L. M., \& Turk, D. C. (2002). Behavioral and cognitive-behavioral treatment for chronic pain: Outcome, predictors of outcome, and treatment process. Spine, 27(22), 2564-2573. https://doi.org/10.1097/01.BRS.0000032130.45175.66

McCracken, L. M., \& Vowles, K. E. (2006). Acceptance of chronic pain. Current Pain and Headache Reports, 10(2), 90-94. https://doi.org/10.1007/s11916-006-0018-y

McCracken, L. M., \& Vowels, K. E. (2014) Acceptance and commitment therapy and mindfulness for chronic pain: Model, process, and progress. American Psychologist, 69(2), 178-197. https://doi.org/10.1037/a0035623

McCracken, L. M., Vowles, K. E., \& Eccleston, C. (2004). Acceptance of chronic pain: component analysis and a revised assessment method. Pain, 107(1), 159-166. https://doi.org/10.1016/j.pain.2003.10.012 
McCracken, L. M., Vowels, K. E., \& Eccleston, C. (2005). Acceptance-based treatment for persons with complex, long standing chronic pain: A preliminary analysis of treatment outcome in comparison to a waiting phase. Behaviour Research and Therapy, 43(10), 1335-1346. https://doi.org/10.1016/j.brat.2004.10.003

McCracken, L. M., Vowles, K. E. \& Eccleston, C. (2004). Acceptance of chronic pain: component analysis and a revised assessment method. Pain, 107(1), 159-166. https://doi.org/10.1016/j.pain.2003.10.012

McCracken, L. M., \& Yang, S. Y. (2006). The role of values in a contextual cognitive-behavioral approach to chronic pain. Pain, 123(1), 137-145.

https://doi.org/10.1016/j.pain.2006.02.021

McCracken, L. M., \& Zhao-O’Brien, J. (2010). General psychological acceptance and chronic pain: There is more to accept than the pain itself. European Journal of Pain, 14(2), 170175. https://doi.org/10.1016/j.ejpain.2009.03.004

Mirza, S. K., \& Deyo, R. A. (2007). Systematic review of randomized trials comparing lumbar fusion surgery to nonoperative care for treatment of chronic back pain. Spine, 37(7), 816823. https://doi.org/10.1097/01.brs.0000259225.37454.38

Moayedi, M., \& Davis, K. D. (2012). Theories of pain: From specificity to gate control. Journal of Neurophysiology, 109(1), 5-12. https://doi.org/10.1152/jn.00457.2012

Molarius, A., Tegelberg Å., \& Öhrvik, J. (2008). Socio-economic factors, lifestyle, and headache disorders: a population-based study in Sweden. The Journal of Head and Face Pain. 48(10), 1426-1437. https://doi.org/10.1111/j.1526-4610.2008.01178.x 
Morgan, C. L., Conway, P., \& Currie, C. J. (2011). The relationship between self-reported severe pain and measures of socio-economic disadvantage. European Journal of Pain, 15(10), 1107-1111. https://doi.org/10.1016/j.ejpain.2011.04.010

Nash, V. R., Ponto, J., Townsend, C., Nelson, P., \& Bretz, M. (2013). Cognitive behavioral therapy, self-efficacy, and depression in persons with chronic pain. Pain Management Nursing, 14(4), e236-e243. https://doi.org/10.1016/j.pmn.2012.02.006

National Institute on Drug Abuse. (2018a). What are prescription opioids. National Institute of Health. https://www.drugabuse.gov/publications/drugfacts/prescription-opioids

National Institute on Drug Abuse. (2018b). Opioid Summaries by State. National Institute of Health. https://www.drugabuse.gov/drugs-abuse/opioids/opioid-summaries-by-state

National Institute on Drug Abuse. (2019). Overdose Death Rates. National Institute of Health. https://www.drugabuse.gov/related-topics/trends-statistics/overdose-death-rates

National Institutes of Health. (2010). Pain Management. U.S. Department of Health and Human Services. https://report.nih.gov/nihfactsheets/ViewFactSheet.aspx?csid=57

National Institutes of Health. (2018). Pain Management. https://report.nih.gov/nihfactsheets/viewfactsheet.aspx?csid=57

Öst, L. G. (2008). Efficacy of the third wave of behavioral therapies: A systematic review and meta-analysis. Behaviour Research and Therapy, 46(3), 296-321. https://doi.org/10.1016/j.brat.2007.12.005

Patel, V. B., Wasserman, R., \& Imani, F. (2015). Interventional therapies for chronic low back pain: A focused review (efficacy and outcomes). Anesthesiology and Pain Medicine, 5(4), e29716. https://doi.org/10.5812/aapm.29716. 
Peacock, S., \& Patel, S. (2008). Cultural influences on pain. Reviews in Pain , 1(2), 6-9. https://doi.org/10.1177/204946370800100203

Pearson, E.S. (1930), A further development of tests for normality, Biometrika, 22, 239-249. https://doi.org/10.2307/2332073

Pearson, A. N., Follette, V. M., \& Hayes, S. C. (2012). A pilot study of acceptance and commitment therapy as a workshop intervention for body dissatisfaction and disordered eating attitudes. Cognitive and Behavioral Practice, 19(1), 181-197. https://doi.org/10.1016/j.cbpra.2011.03.001

Peppin, J. F., Cheatle, M. D., Kirsh, K. L., \& McCarberg, B. H. (2015). The complexity model: A novel approach to improve chronic pain care. Pain Medicine, 16(4), 653-666. https://doi.org/10.1111/pme.12621

Perruchoud, C., Eldabe, S., Batterham, A. M., Madzinga, G., Adult, D. H., Brookes, M., Durrer, A., Rosato, M., Bovet, N., West, S., Bovy, M., Rutschmann, B., Gulbe, A., Garner, F., \& Buchser, E. (2013). Analgesic efficacy of high-frequency spinal cord stimulation: A randomized double-blind placebo-controlled study. Neuromodulation Technology at the Neural Interface, 16(4), 363-369. https://doi.org/10.1111/ner.12027

Pfingsten, M., Leibing, E., Harter, W., Kröner-Herwig, B., Hemple, D., Kronshage, U., \& Hildebrandt, J. (2001). Fear-avoidance behavior and anticipation of pain in patients with chronic low back pain: A randomized controlled study. Pain Medicine, 2(4), 259-266. https://doi.org/10.1046/j.1526-4637.2001.01044.x

Privitera, G. J. (2015). Statistics for the behavioral sciences (2nd ed.). Sage Publications. 
Reinecke, H., Weber, C., Lange, K., Stein, C., \& Sorgatz, H. (2015). Analgesic efficacy of opioids in chronic pain: recent meta-analyses. British Journal of Pharmacology, 172(2), 324-333. https://doi.org/10.1111/bph.12634.

Rodrigues-de-Souza, D. P., Palacios-Ceña, D., Moro-Gutiérrez, L., Camargo, P. R., Salvini, T. R., \& Alburquerque-Sendín, F. (2016). Socio-cultural factors and experience of chronic low back pain: A Spanish and Brazilian patients' perspective. A qualitative study. PLoS ONE, 11(7), e0159554. https://doi.org/10.1371/journal.pone.0159554

Rosenstiel, A. K., \& Keefe, F. J. (1983). The use of coping strategies in chronic low back pain patients: Relationship to patient characteristics and current adjustment. Pain, 17(1), 3344. https://doi.org/10.1016/0304-3959(83)90125-2

Roy, R. (2008). Brief therapies. In R. Roy (Ed.), Psychosocial interventions for chronic pain: In search of evidence (pp. 101-115). Winnipeg, Canada: Springer Science and Business Media. https://doi.org/10.1007/978-0-387-76296-8

Seminowicz, D. A., Shpaner, M., Keaser, M. L., Krauthamer, G. M., Mantegna, J., Dumas, J. A., \& Naylor, M. R. (2013). Cognitive-behavioral therapy increases prefrontal cortex grey matter in patients with chronic pain. Journal of Pain, 14(12), 1573-1583. https://doi.org/10.1016/j.jpain.2013.07.020

Shapiro, S. S., \& Wilk, M. B. (1965). An analysis of variance test for normality (complete samples). Biometrika. 53(3-4), 591. https://doi.org/10.2307/2333709

Society of Clinical Psychology (2016). Treatment: Acceptance and commitment therapy for chronic pain. Diagnosis: Chronic or Persistent Pain in General. https://www.div12.org/treatment/acceptance-and-commitment-therapy-for-chronic-pain/ 
Staal, J. B., de Bie, R., de Vet, H. C. W., Hildebrandt, J., \& Nelemans, P. (2008). Injection therapy for subacute and chronic low-back pain. Cochrane Database of Systematic Reviews, 3(CD001824). https://doi.org/10.1002/14651858.CD001824.pub3

Stewart, W. F. (2003). Lost productive time and cost due to common pain conditions in the US workforce. Journal of the American Medical Association. 290(18), 2443-2454. https://doi.org/10.1001/jama.290.18.2443

Sullivan, M. J. L., Bishop, S. R., \& Pivik, J. (1995). The Pain Catastrophizing Scale: Development and validation. Psychological Assessment, 7(4), 524-532. https://doi.org/10.1037/1040-3590.7.4.524

Sullivan, M. J., Thorn, B., Haythornthwaite, J. A., Keefe, F., Martin, M., Bradley, L. A., \& Lefebvre, J. C. (2001). Theoretical perspectives on the relation between catastrophizing and pain. The Clinical Journal of Pain, 17(1), 52-64. https://doi.org/10.1097/00002508200103000-00008

Tan, G., Nguyen, Q., Cardin, S. A., \& Jensen, M. P. (2006). Validating the use of two-item measures of pain beliefs and coping strategies for a veteran population. The Journal of Pain, 7(4), 252-260. https://doi.org/10.1016/j.jpain.2005.11.007.

Tolin, D. F., McKay, D., Forman, E. M., Klonsky, E. D., \& Thombs, B. D. (2015). Empirically supported treatment: Recommendations for a new model. Clinical Psychology: Science and Practice, 22(4), 317-338. https://doi.org/10.1111/cpsp.12122

Tang, N. K. (2009). Cognitive-behavioral therapy for sleep abnormalities of chronic pain patients. Current Rheumatology Reports, 11(6), 451-460. https://doi.org/10.1007/s11926009-0066-5 
Thorn, B. E., Day, M. A., Burns, J., Kuhajda, M. C., Gaskins, S. W., Sweeney, K., \& Cabbil, C. (2011). Randomized trial of group cognitive behavioral therapy compared with a pain education control for low-literacy rural people with chronic pain. Pain, 152(12), 27102720. https://doi.org/10.1016/j.pain.2011.07.007

Treede, R.-D., Rief W., Barke, A., Aziz, Q., Bennett, M. I., Benoliel, R., Cohen, M., Evers, S., Finnerup, N. B., First, M. B., Giamberardino, M. A., Kaasa, S., Kosek, E., Lavand'homme, P., Nicholas, M., Perrot, S., Scholz, J., Schug, S., Smith, B. H., Svensson, P., Vlaeyen, J. W., \& Wang S. J. (2015) A classification of chronic pain for ICD-11. Pain, 156(6), 1003-1007. https://doi.org/10.1097/j.pain.0000000000000160

Trost, Z., France, C. R., \& Thomas, J. S. (2011). Pain-related fear and avoidance of physical exertion following delayed-onset muscle soreness. Pain, 152(7), 1540-1547. https://doi.org/10.1016/j.pain.2011.02.038

Twohig, M. P. (2012). Introduction: The basics of Acceptance and Commitment Therapy. Cognitive and Behavioral Practice, 19(4), 499-507. https://doi.org/10.1016/j.cbpra.2012.04.003

United States Census Bureau. (2016). The census data show differences between urban and rural populations. https://www.census.gov/newsroom/press-releases/2016/cb16-210.html United States Department of Agriculture (2018). Opioid misuse in rural America. https://www.usda.gov/topics/opioids

Violon, A., \& Giurgea, D. (1984). Familial models for chronic pain. Pain, 18(2), 199-203. https://doi.org/10.1016/0304-3959(84)90887-x

Vlaeyen, J. W. S., Crombez, G., \& Linton, S. J. (2016). The fear-avoidance model of pain. Pain, 157(8), 1588-1589. https://doi.org/10.1097/j.pain.0000000000000574 
Von Korff, M., Crane, P., Lane, M., Miglioretti, D. L., Simon, G., Saunders, K., Stang, P., Brandenburg, N., \& Kessler, R. (2005). Chronic spinal pain and physical-mental comorbidity in the United States: results from the national comorbidity survey replication. Pain, 113(3), 331-339. https://doi.org/10.1016/j.pain.2004.11.010

Vowles, K. E., \& McCracken, L. M. (2008). Acceptance and values-based action in chronic pain: A study of treatment effectiveness and process. Journal of Consulting and Clinical Psychology, 76(3), 397-407. https://doi.org/10.1037/0022-006x.76.3.397

Vowles, K. E., McCracken, L. M., McLeod, C., \& Eccleston, C. (2008). The Chronic Pain Acceptance Questionnaire: Confirmatory factor analysis and identification of patient subgroups. Pain, 140(2), 284-291. https://doi.org/10.1016/j.pain.2008.08.012

Vowles, K. E., \& Sorrell, J. T. (2007). Life with chronic pain: An acceptance-based approach. https://contextualscience.org/files/CP_Acceptance_Manual_09.2008.pdf

Wall, P. D., \& Sweet, W. H. (1967). Temporary abolition of pain in man. Science, 155(3758), 108-109. https://doi.org/10.1126/science.155.3758.108

Whitman, S. M. (2007). Pain and suffering as viewed by the Hindu religion. The Journal of Pain, 8(8), 607-613. https://doi.org/10.1016/j.pain.2007.02.430

Williams, D. A. (2013). The importance of psychological assessment in chronic pain. Current Opinion in Urology, 23(6), 554-559. https://doi.org/10.1097/MOU.0b013e3283652af1

Zettle, R. D. (2011). The evolution of a contextual approach to therapy: From comprehensive distancing to ACT. International Journal of Behavioral Consultation and Therapy, 7(1), 76-82. https://doi.org/10.1037/h0100929 


\section{Tables}

\section{Table 1}

Participant Demographics

\begin{tabular}{|c|c|c|}
\hline \multirow{2}{*}{ Variable } & \multicolumn{2}{|c|}{ Frequency } \\
\hline & $\%$ & $n$ \\
\hline \multicolumn{3}{|l|}{ Sex } \\
\hline Male & 52.6 & 10 \\
\hline Female & 47.4 & 9 \\
\hline \multicolumn{3}{|l|}{ Age (Years) } \\
\hline $30-35$ & 5.3 & 2 \\
\hline $36-40$ & 5.3 & 2 \\
\hline $41-45$ & 5.3 & 2 \\
\hline $46-50$ & 10.5 & 4 \\
\hline $51-55$ & 7.9 & 3 \\
\hline $56-60$ & 5.3 & 2 \\
\hline $61-65$ & 5.3 & 2 \\
\hline $71-75$ & 5.3 & 2 \\
\hline \multicolumn{3}{|l|}{ Geographical Location } \\
\hline Rural & 52.6 & 10 \\
\hline Non-Rural & 47.4 & 9 \\
\hline \multicolumn{3}{|l|}{ Education } \\
\hline Less than High School Diploma & 10.5 & 2 \\
\hline General Education Diploma & 15.8 & 3 \\
\hline High School Diploma & 15.8 & 3 \\
\hline Some College & 31.6 & 6 \\
\hline Bachelor's Degree & 15.8 & 3 \\
\hline Graduate Degree & 10.5 & 2 \\
\hline
\end{tabular}

Note. $n=19$ 
Table 2

Participant Pain Demographics

\begin{tabular}{|c|c|c|c|}
\hline \multirow{2}{*}{\multicolumn{2}{|c|}{ Variable }} & \multicolumn{2}{|c|}{ Frequency } \\
\hline & & $\%$ & $n$ \\
\hline \multicolumn{4}{|l|}{ Duration of pain } \\
\hline & 6 months - 1 year & 5.3 & 1 \\
\hline & $2-5$ years & 0 & 0 \\
\hline & $6-10$ years & 15.8 & 3 \\
\hline & $11-20$ years & 42.1 & 8 \\
\hline & $21-30$ years & 31.8 & 6 \\
\hline & $31-40$ years & 5.3 & 1 \\
\hline \multicolumn{4}{|l|}{ Location of Pain } \\
\hline & Lower Extremity Region & 52.6 & 10 \\
\hline & Lumbar Region & 47.4 & 9 \\
\hline & Thoracic Region & 42.1 & 8 \\
\hline & Upper Extremity Region & 26.3 & 5 \\
\hline & Groin Region & 26.3 & 5 \\
\hline & Cervical Region & 26.3 & 5 \\
\hline & Buttocks Region & 26.3 & 5 \\
\hline & Abdomen Region & 21.1 & 4 \\
\hline & Shoulder Region & 15.8 & 3 \\
\hline
\end{tabular}

Note. $n=19$ 
Table 3

Descriptive of Study Variables Pre-ACT Workshop and Post-Act Workshop

\begin{tabular}{lcccc} 
& \multicolumn{2}{c}{ Pre-ACT workshop } & & \multicolumn{2}{c}{ Post-ACT workshop } \\
\cline { 2 - 5 } \multicolumn{1}{c}{ Coping measure } & $M$ & $S D$ & & $M$ \\
\hline 1. CPAQ- R Full Scale & 65.76 & 17.80 & 73.84 & 12.07 \\
2. CPAQ- R AE Subscale & 35.03 & 13.55 & 39.71 & 9.41 \\
3. CPAQ- R PW Subscale & 30.79 & 8.82 & 34.13 & 8.37 \\
4. 2-PCQ & 3.18 & 1.34 & 3.43 & 1.37
\end{tabular}

Note. $n=19$; CPAQ-R= Chronic Pain Acceptance Questionnaire-Revised; CPAQ-R AE Subscale = Chronic Pain Acceptance Questionnaire - Revised Activity Engagement subscale; CPAQ-R

PW Subscale $=$ Chronic Pain Acceptance Questionnaire - Revised Pain Willingness subscale; 2PCQ = Two-Item Pain Catastrophizing Questionnaire; Post-ACT workshop $=$ four-weeks postintervention. 
Table 4

Paired-Samples t-Test for Pre-Workshop and Post-Workshop Comparison

\begin{tabular}{|c|c|c|c|c|c|c|c|c|}
\hline & & & & $\begin{array}{r}95 \\
\text { Confi } \\
\text { Interva } \\
\text { Diffe }\end{array}$ & $\begin{array}{l}\% \\
\text { lence } \\
\text { of the } \\
\text { ence }\end{array}$ & & & \\
\hline & Mean & SD & $\begin{array}{l}\text { Std. } \\
\text { Error } \\
\text { Mean }\end{array}$ & Lower & Upper & $t(18)$ & $\mathrm{df}$ & $\begin{array}{l}\text { Sig. (2- } \\
\text { tailed) }\end{array}$ \\
\hline $\begin{array}{l}\text { CPAQ-R Total Score } \\
\text { Pre-Test - CPAQ-R } \\
\text { Total Score Post-Test }\end{array}$ & -8.08 & 14.42 & 3.31 & -15.03 & -1.13 & -2.44 & 18 & .025 \\
\hline $\begin{array}{l}\text { CPAQ-R AE Subscale } \\
\text { Pre-Test - CPAQ-R AE } \\
\text { Subscale Score Post- } \\
\text { Test }\end{array}$ & -4.68 & 11.29 & 2.59 & -10.12 & .76 & -1.81 & 18 & .087 \\
\hline $\begin{array}{l}\text { CPAQ-R PW Subscale } \\
\text { Pre-Test - CPAQ-R PW } \\
\text { Subscale Score Post- } \\
\text { Test }\end{array}$ & -3.34 & 5.24 & 1.20 & -5.86 & -.81 & -2.78 & 18 & .012 \\
\hline $\begin{array}{l}\text { 2-PCQ Pre-Test - 2- } \\
\text { PCQ Score Post-Test }\end{array}$ & -.25 & 1.18 & .27 & -.82 & .32 & -.92 & 18 & .370 \\
\hline
\end{tabular}

Note. $n=19$; CPAQ-R= Chronic Pain Acceptance Questionnaire-Revised; CPAQ-R AE Subscale = Chronic Pain Acceptance Questionnaire - Revised Activity Engagement subscale; CPAQ-R

PW Subscale $=$ Chronic Pain Acceptance Questionnaire - Revised Pain Willingness subscale; 2PCQ = Two-Item Pain Catastrophizing Questionnaire; Post-ACT workshop $=$ four-weeks postintervention. $\mathrm{p}<.05$ is considered significant. 
Table 5

Summary of Age Tested as Predictor of Outcome Measures

\begin{tabular}{lccc|ccc}
\hline Variable & \multicolumn{3}{c}{ Pre-ACT Workshop } & \multicolumn{3}{c}{ Post-ACT Workshop } \\
\cline { 2 - 7 } & $B$ & $S E B$ & $\beta$ & $B$ & $S E B$ & $\beta$ \\
\hline Pain Acceptance & .38 & .34 & .26 & -.06 & .24 & -.06 \\
Activity Engagement & .20 & .26 & .18 & -.06 & .18 & -.08 \\
Pain Willingness & .18 & .17 & .26 & .00 & .16 & .00 \\
Pain Catastrophizing & .01 & .03 & .12 & -.03 & .03 & -.22 \\
\end{tabular}

Note. $n=19$. The impact of demographic variable 'age' on outcome measures was examined pre and post-test. The demographic variables were used to predict pain acceptance pre-workshop and post-workshop. 


\section{Table 6}

Summary of Pain Duration Tested as Predictor of Outcome Measures

\begin{tabular}{lccc|ccc}
\hline Variable & \multicolumn{3}{c}{ Pre-ACT Workshop } & \multicolumn{3}{c}{ Post-ACT Workshop } \\
\cline { 2 - 7 } & $B$ & SE B & $\beta$ & $B$ & $S E B$ & $\beta$ \\
\hline Pain Acceptance & -.63 & .47 & -.31 & -.44 & .32 & .32 \\
Activity Engagement & -.59 & .35 & -.38 & -.34 & .25 & -.32 \\
Pain Willingness & -.04 & .25 & -.04 & -.10 & .23 & -.11 \\
Pain Catastrophizing & -.01 & .04 & -.09 & -02 & .04 & -.13 \\
\hline
\end{tabular}

Note. $n=19$. The impact of demographic variable 'pain duration' on outcome measures was examined pre and post-test. The demographic variables were used to predict pain acceptance preworkshop and post-workshop. 
Table 7

Summary of Sex Tested as Predictor of Outcome Measures

\begin{tabular}{lccc|ccc}
\hline Variable & \multicolumn{3}{c}{ Pre-ACT Workshop } & \multicolumn{3}{c}{ Post-ACT Workshop } \\
\cline { 2 - 7 } & $B$ & $S E B$ & $\beta$ & $B$ & $S E B$ & $\beta$ \\
\hline Pain Acceptance & -4.30 & 8.35 & -.12 & -9.52 & 5.22 & -.40 \\
Activity Engagement & -2.69 & 6.38 & -.10 & -6.10 & 4.20 & -.33 \\
Pain Willingness & -1.71 & 4.15 & -.10 & -3.41 & 3.87 & -.21 \\
Pain Catastrophizing & .55 & .62 & .21 & .18 & .65 & .07 \\
\end{tabular}

Note. $n=19$. The impact of demographic variable 'sex' on outcome measures was examined pre and post-test. The demographic variables were used to predict pain acceptance pre-workshop and post-workshop. 


\section{Table 8}

Summary of Education Tested as Predictor of Outcome Measures

\begin{tabular}{lccc|ccc}
\hline Variable & \multicolumn{3}{c}{ Pre-ACT Workshop } & \multicolumn{3}{c}{ Post-ACT Workshop } \\
\cline { 2 - 7 } & $B$ & $S E B$ & $\beta$ & $B$ & $S E B$ & $\beta$ \\
\hline Pain Acceptance & 1.78 & 2.84 & .15 & .70 & 1.94 & .09 \\
Activity Engagement & .60 & 2.18 & .66 & .15 & 1.52 & .02 \\
Pain Willingness & 1.24 & 1.38 & .21 & .54 & 1.35 & .10 \\
Pain Catastrophizing & .12 & .22 & .14 & .10 & .22 & .11 \\
\end{tabular}

Note. $n=19$. The impact of demographic variable 'education' on outcome measures was examined pre and post-test. The demographic variables were used to predict pain acceptance preworkshop and post-workshop.

\section{Table 9}

Summary of Demographic Variables Influence on Pain Acceptance Change Score

\begin{tabular}{lccccc}
\hline Total Pain Acceptance & $B$ & $S E B$ & $\beta$ & $t$ & $p$ \\
\hline Age & -.55 & .28 &,- 47 & -1.95 & .072 \\
Duration of Pain & .70 & .45 & .43 & 1.57 & .140 \\
Sex & -11.44 & 7.15 & -.41 & 1.60 & .132 \\
Education & -.73 & 2.39 & -.08 & -.31 & .765
\end{tabular}

Note. $n=19$. The impact of demographic variables on pain acceptance change score (postworkshop pain acceptance mean - pre-workshop pain acceptance mean). 


\section{Table 10}

Summary of Demographic Variables Influence on Activity Engagement Change Score

\begin{tabular}{lccccc}
\hline Activity Engagement & $B$ & $S E B$ & $\beta$ & $t$ & $p$ \\
\hline Age & -.36 & .23 & -.39 & -1.57 & .140 \\
Duration of Pain & .62 & .36 & .48 & 1.70 & .111 \\
Sex & -8.68 & 5.78 & -.40 & -1.50 & .155 \\
Education & -.50 & 1.93 & -.07 & -.26 & .799
\end{tabular}

Note. $n=19$. The impact of demographic variables on activity engagement change score (postworkshop activity engagement mean - pre-workshop activity engagement mean).

\section{Table 11}

Summary of Demographic Variables Influence on Pain Willingness Change Score

\begin{tabular}{lccccc}
\hline Pain Willingness & $B$ & $S E B$ & $\beta$ & $t$ & $p$ \\
\hline Age & -.19 & .11 & -.45 & -1.78 & .098 \\
Duration of Pain & .08 & .17 & .13 & .45 & .660 \\
Sex & -2.60 & 2.73 & -.25 & -.95 & .360 \\
Education & -.26 & .91 & -.07 & -.28 & .783 \\
& & & & &
\end{tabular}

Note. $n=19$. The impact of demographic variables on pain willingness change score (postworkshop pain willingness mean - pre-workshop pain willingness mean). 


\section{Table 12}

Summary of Demographic Variables Influence on Pain Catastrophizing Change Score

\begin{tabular}{lccccc}
\hline Pain Catastrophizing & $B$ & $S E B$ & $\beta$ & $t$ & $p$ \\
\hline Age & -.05 & .02 & -.48 & -1.89 & .080 \\
Duration of Pain & .02 & .04 & .14 & .48 & .64 \\
Sex & -.61 & .62 & -.26 & -.98 & .344 \\
Education & .09 & .21 & .11 & .42 & .679
\end{tabular}

Note. $n=19$. The impact of demographic variables on pain catastrophizing change score (postworkshop pain catastrophizing mean - pre-workshop pain catastrophizing mean).

\section{Table 13}

Descriptive Statistics for Q1 and Q2 on the Two-Item Client Satisfaction Questionnaire.

\begin{tabular}{cccccc}
\hline & Mean & SD & Minimum & Maximum & $\begin{array}{c}\text { Percentage } \\
\text { above } \geq 80 \% \\
\text { threshold }\end{array}$ \\
\cline { 2 - 6 } CS Question 1 & 4.89 & 1.20 & 3.00 & 6.00 & $83 \%$ \\
CS Question 2 & 5.00 & 1.37 & 2.00 & 6.00 & $83 \%$ \\
\hline
\end{tabular}

Note. $n=19$; Question 1 = "Please rate your level of satisfaction based on the group you attended"; Question 2 = "How likely are you to refer a friend of family member to the workshop you attended. 


\section{Table 14}

Bivariate Correlation Analysis for Client Satisfaction and Demographic Variables

$\begin{array}{lllllll}\text { Measure } & 1 & 2 & 3 & 4 & 5 & 6\end{array}$

1. Age

2. Duration of Pain Sx

3. Sex

4. Education

5. Client Satisfaction Q1

6. Client Satisfaction Q2
.22

$-.07 \quad .45$

.35

.35

.06

.02

.40

.09

.01

.17

.45

.08

.08

$.95^{* *}$

Note. $n=19 ; \mathrm{CS}=$ Client satisfaction; Question $1=$ "Please rate your level of satisfaction based on the group you attended"; Question 2 = "How likely are you to refer a friend of family member to the workshop you attended; ** $p<.01$ (2-tailed).

\section{Table 15}

Bivariate Correlation Analysis for Client Satisfaction and Outcome Variables Pre-Workshop

\begin{tabular}{lllllll}
\hline Measure & 1 & 2 & 3 & 4 & 5 & 6
\end{tabular}

1. Total Pain Acceptance

2. Activity Engagement

$.88 * * \quad-$

3. Pain Willingness

$.66^{* *} \quad .22$

4. Pain Catastrophizing

.24

$-.07$

$.59 * *$

5. Client Satisfaction Q1

.24

.12

.30

.04

6. Client Satisfaction Q2

.27

.15

.31

.08

$.95 * *$

Note. $n=19$; CS= Client satisfaction; Question $1=$ "Please rate your level of satisfaction based on the group you attended"; Question 2 = "How likely are you to refer a friend of family member to the workshop you attended; $* * p<.01$ (2-tailed). 


\section{Table 16}

Bivariate Correlation Analysis for Client Satisfaction and Outcome Variables Post-Workshop

\begin{tabular}{lllllll}
\hline Measure & 1 & 2 & 3 & 4 & 5 & 6
\end{tabular}

1. Total Pain Acceptance

2. Activity Engagement $.72 * * \quad-$

3. Pain Willingness

$.63 * * \quad-.08$

4. Pain Catastrophizing

$.59 * * \quad .07 \quad .77 * *$

5. Client Satisfaction Q1

$-.08$

$-.13$

.04

.02

6. Client Satisfaction Q2

$\begin{array}{lll}-.06 & -.14 \quad .08\end{array}$

$.04 \quad .95^{* *}$

Note. $n=19 ; \mathrm{CS}=$ Client satisfaction; Question $1=$ "Please rate your level of satisfaction based on the group you attended"; Question 2 = "How likely are you to refer a friend of family member to the workshop you attended; $* * p<.01$ (2-tailed). 
Figures

\section{Figure 1}

Histogram of Pre-Workshop Pain Acceptance Total Scores.

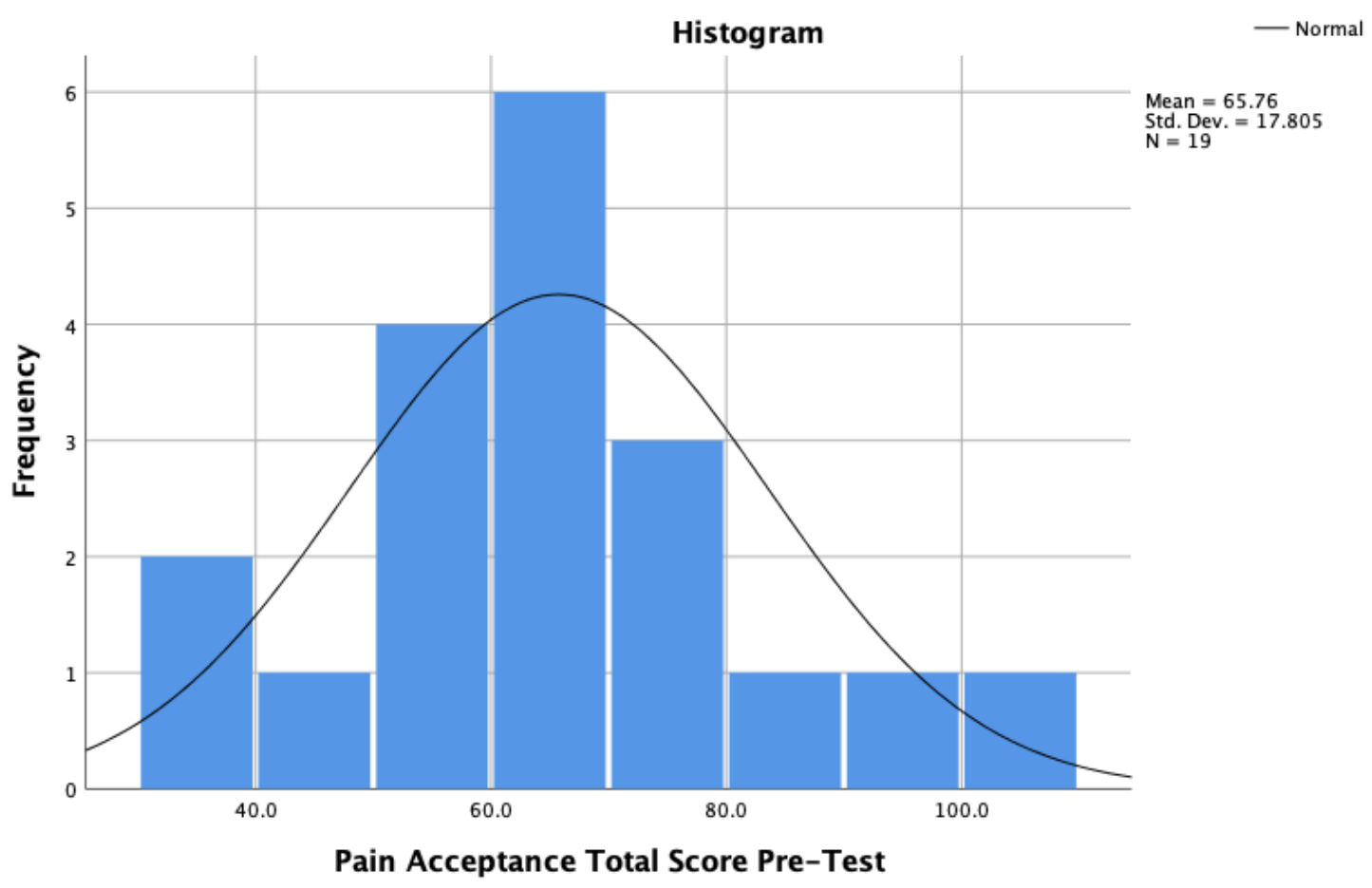

Figure 2

Histogram of Post-Workshop Pain Acceptance Total Scores.

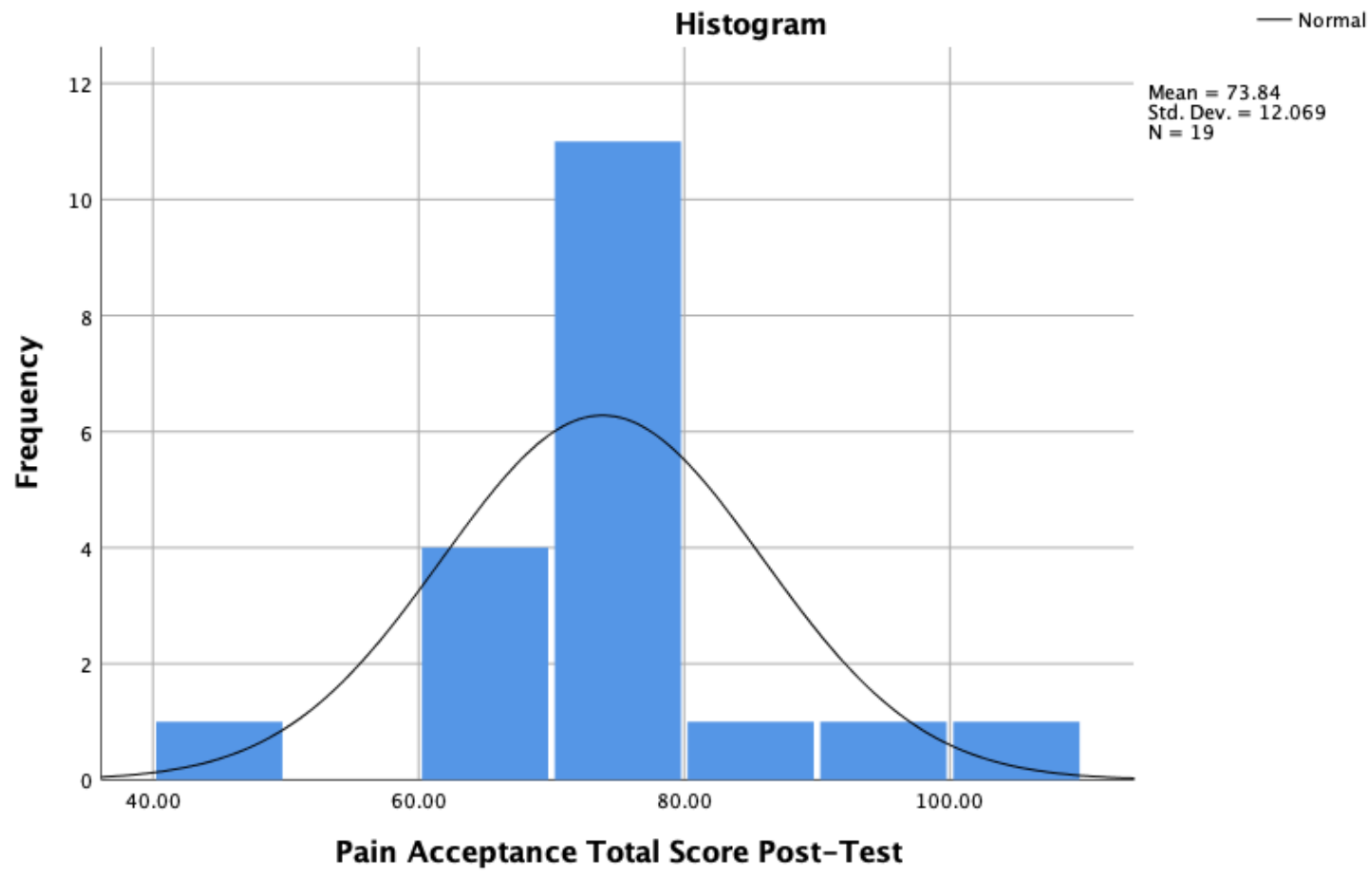




\section{Figure 3}

Histogram of Pre-Workshop Activity Engagement Subscale Scores.

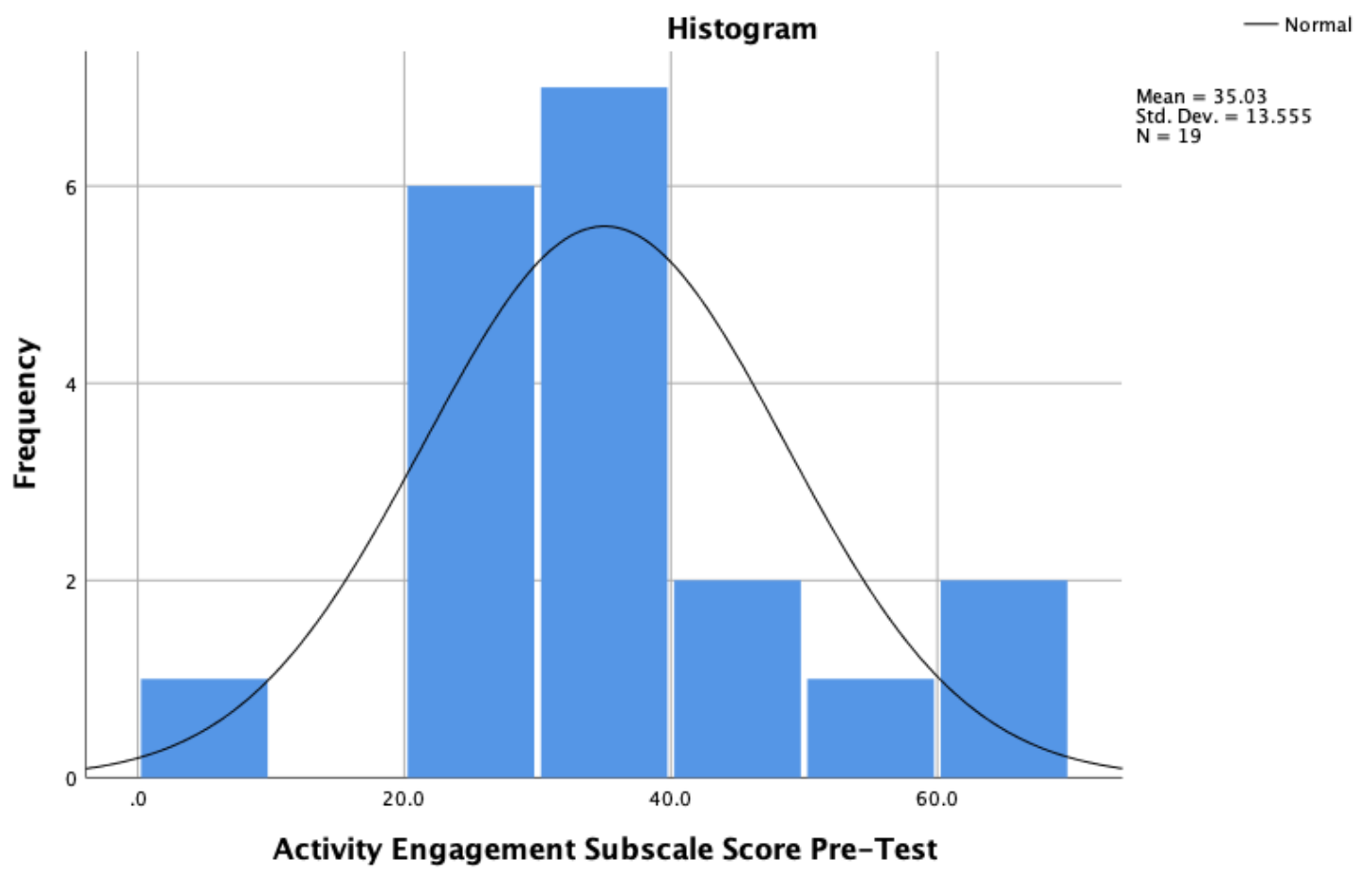

\section{Figure 4}

Histogram of Post-Workshop Activity Engagement Subscale Scores.

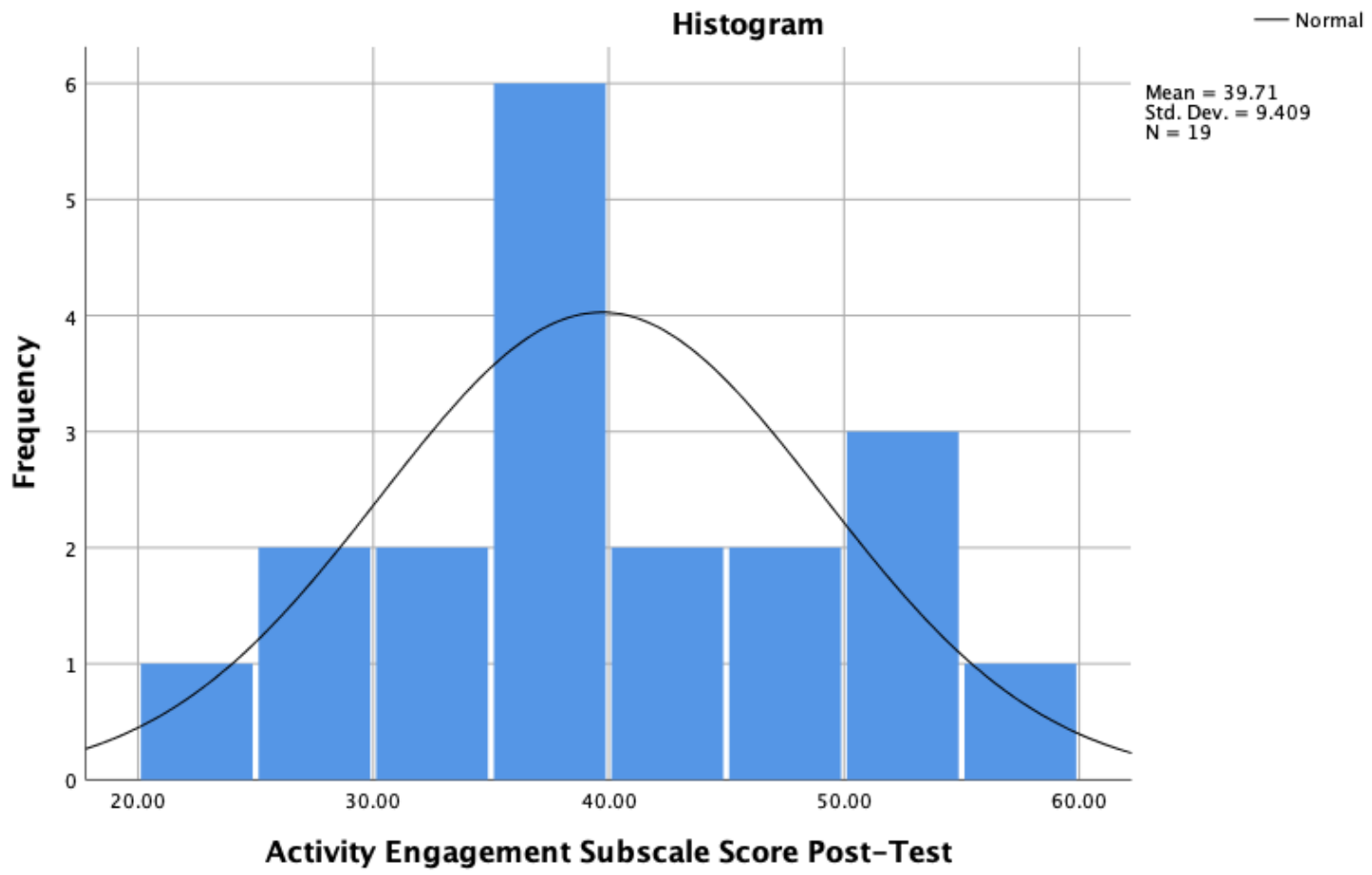


Figure 5

Histogram of Pre-Workshop Pain Willingness Subscale Scores.

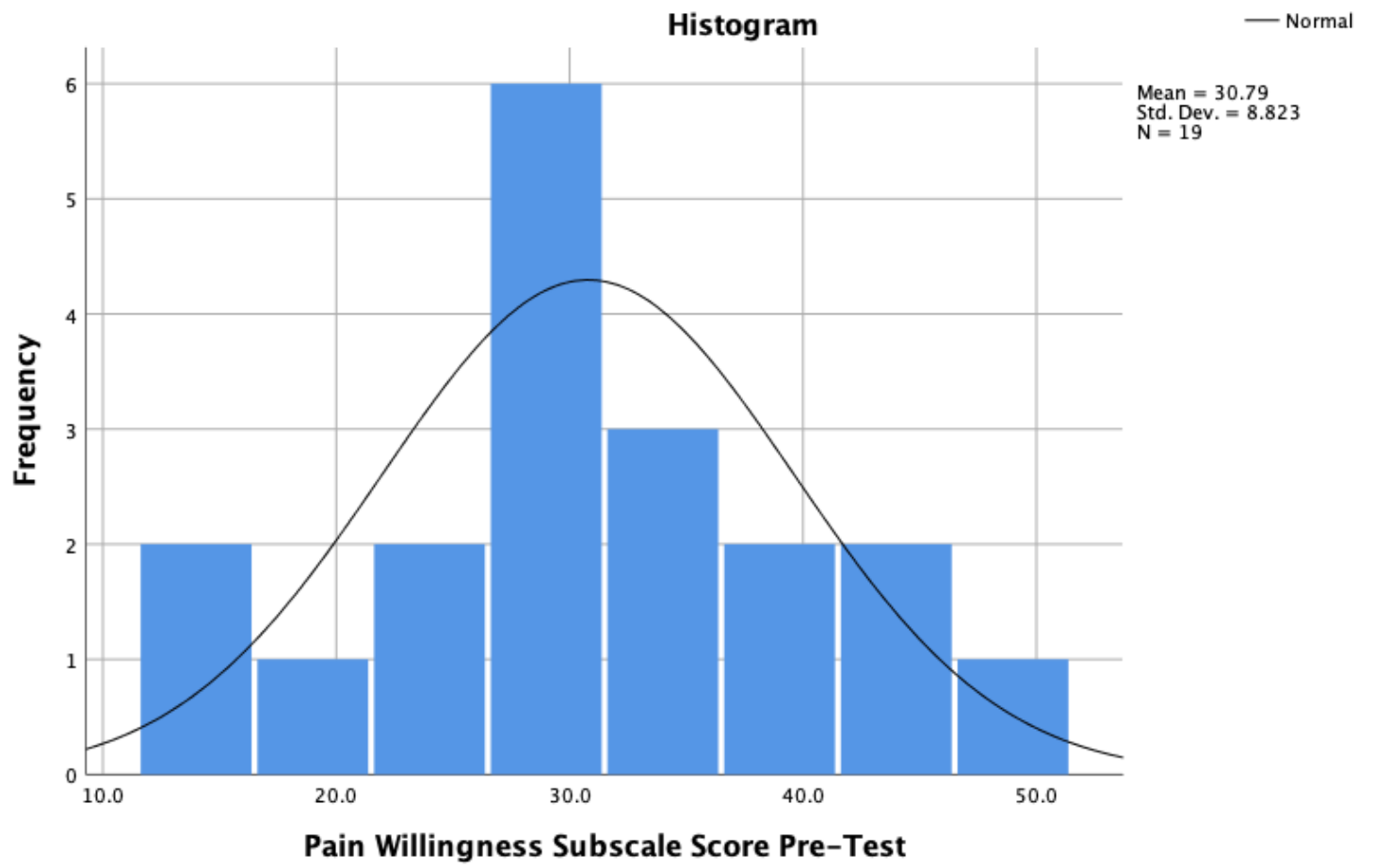

Figure 6

Histogram of Post-Workshop Pain Willingness Subscale Scores.

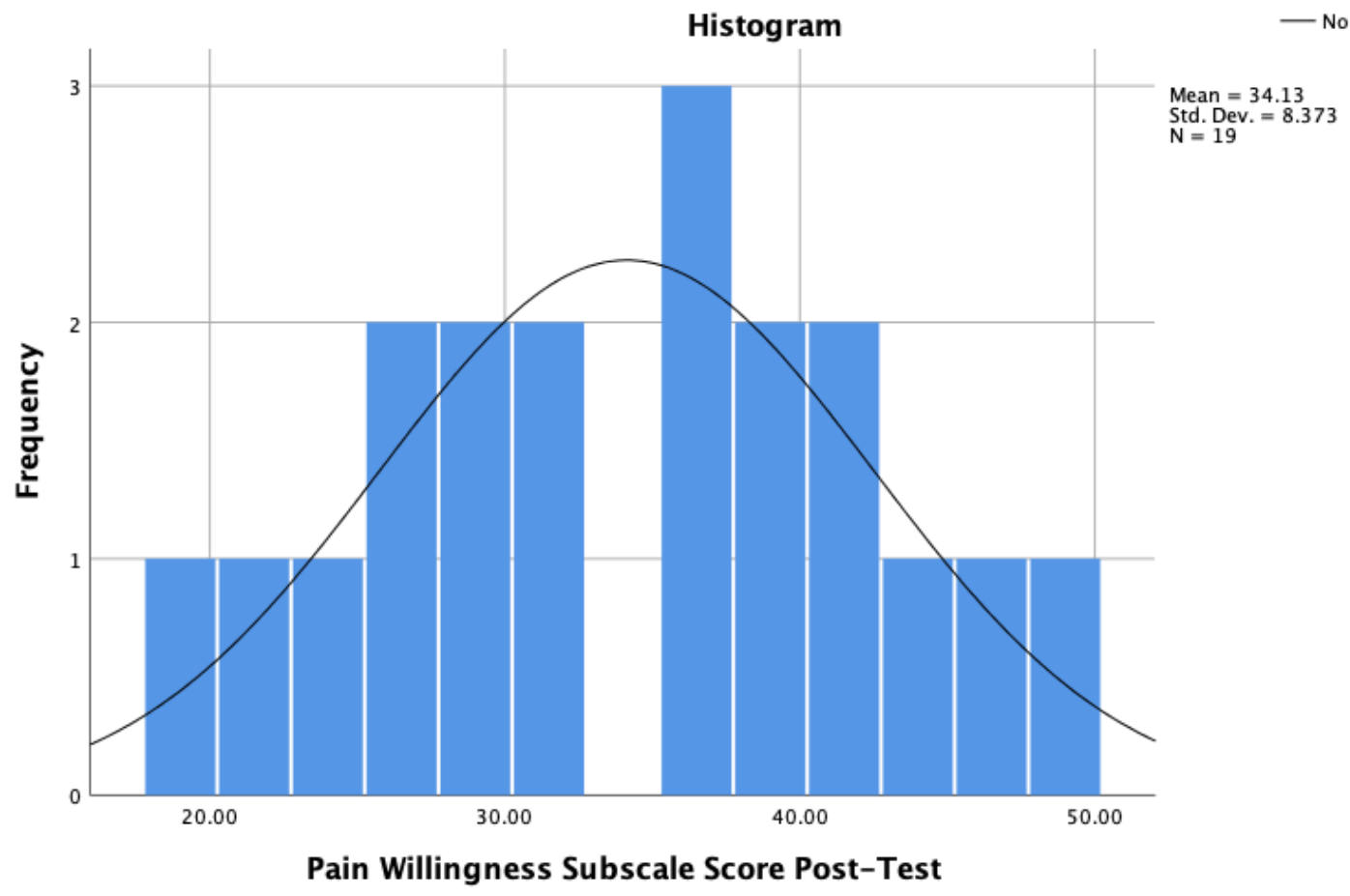


Figure 7

Histogram of Pre-Workshop Pain Catastrophizing Scores.

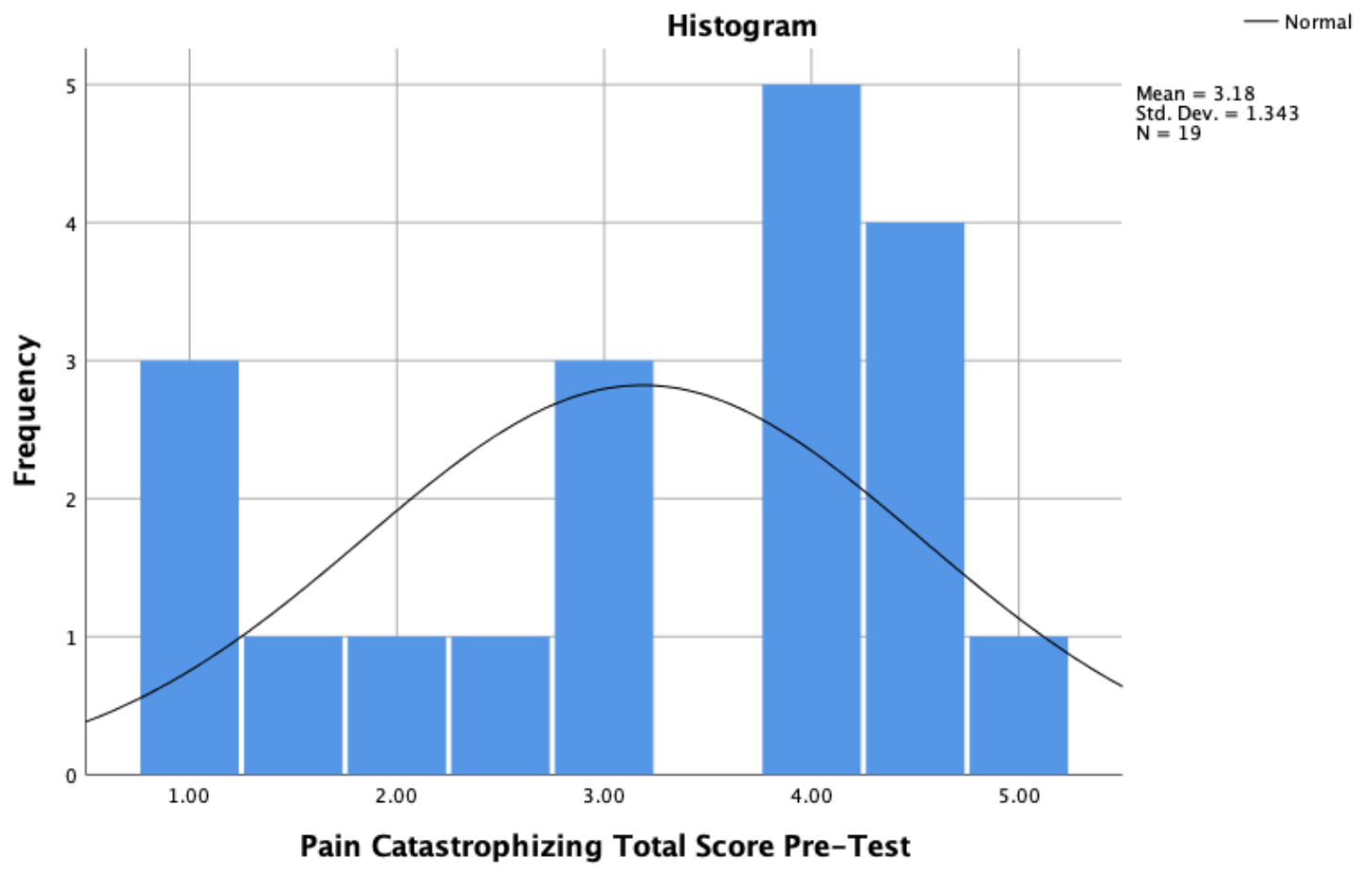

Figure 8

Histogram of Post-Workshop Pain Catastrophizing Scores.

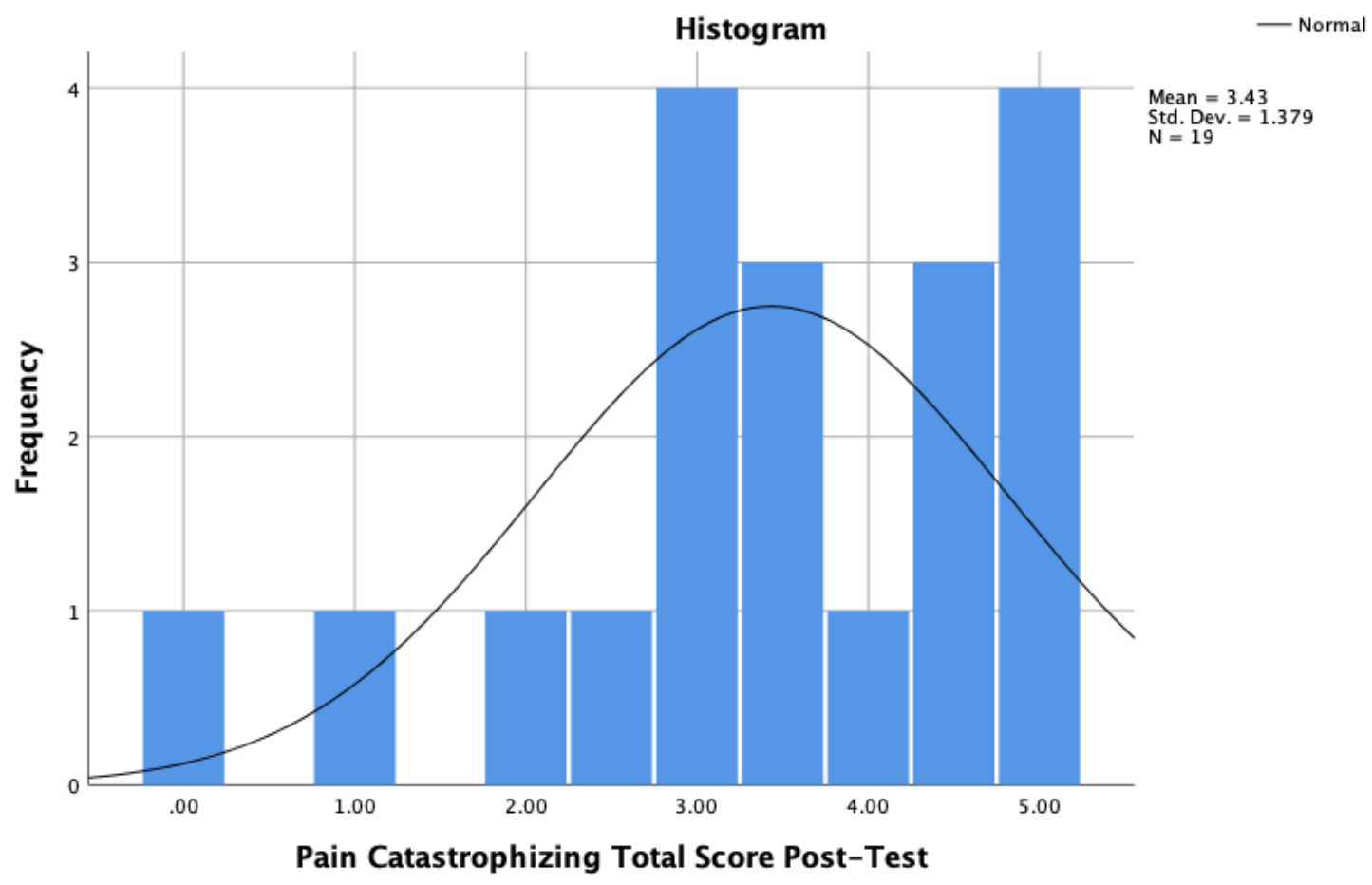




\title{
Appendices
}

\section{Appendix A: Informed Consent for Treatment}

\section{W- WestVirginiaUniversity.}

\author{
Human Research Protocol \\ Only Minimal Risk Consent Form \\ (With HIPAA)
}

\section{Only Minimal Risk \\ Consent Information and HIPAA Form}

Principal Investigator

Department

Protocol Number

Study Title

Co-Investigator(s)

Sponsor (if any)
Kelly Thomas

Counseling, Rehabilitation Counseling, and Counseling Psychology 1906601289

A One-Session, Brief, Acceptance and Commitment Therapy Workshop for Chronic Pain Patients: A Quasi-Experimental Prospective Exploratory Trial

Kelly Thomas, M.S.

N/A

\section{Contact Persons}

In the event you experience any side effects or injury related to this research, you should contact Kelly Thomas via email at kat0016@mix.wvu.edu. If you have any questions, concerns, or complaints about this research, you should contact Kelly Thomas via email at kat0016@mix.wvu.edu

For information regarding your rights as a research subject, to discuss problems, concerns, or suggestions related to the research, to obtain information or offer input about the research, contact the Office of Research Integrity and Compliance at (304) 293-7073.

In addition, if you would like to discuss problems, concerns, have suggestions related to research, or would like to offer input about the research, contact the Office of Research Integrity and Compliance at 304-293-7073.

\section{Introduction}

You have been asked to participate in this research study, which has been explained to you by your medical provider. This study is being conducted by Kelly Thomas and Jeff Daniels in the Department of Counseling, Rehabilitation Counseling, and Counseling Psychology at West Virginia University.

\section{Purpose(s) of the Study}

The purpose of the study is to explore chronic pain acceptance and pain catastrophizing in regard to individuals with chronic pain through the utilization of a single-session Acceptance and Commitment Therapy (ACT) workshop.

\section{Description of Procedures}


This study involves participation in an ACT workshop and will take approximately one hour for you to complete. Before attending the workshop, you will be asked questions regarding your chronic pain acceptance and worry about your pain in the future. This should take approximately 15 minutes. 4 weeks after treatment is complete, you will be asked to fill out the same questionnaires regarding your chronic pain acceptance and worry about your chronic pain in the future. Additionally, you will be asked how you felt about the treatment you received. This will take approximately 20 minutes though a phone-call interview. You do not have to answer all the questions. You will have the opportunity to see the questionnaire before signing this consent form.

\section{Discomforts}

There are no known or expected risks from participating in this study, except for A SMALL POSSIBILITY OF the mild frustration associated with participating the group activities and answering the questions.

\section{Benefits}

Each participant in the group, AND WHO COMPLETES THE FOLLOW-UP PHONE INTERVIEW, will receive a $\$ 10$ Walmart gift card that will be mailed to their house. You may not receive any direct benefit from this study. The knowledge gained from this study may eventually benefit others.

\section{Financial Considerations}

There are no special fees for participating in this study.

\section{Confidentiality}

Any information about you that is obtained as a result of your participation in this research will be kept as confidential as legally possible. Your research records and test results, just like hospital records, may be subpoenaed by court order or may be inspected by the study sponsor or federal regulatory authorities without your additional consent.

In any publications that result from this research, neither your name nor any information from which you might be identified will be published without your consent.

\section{HIPAA}

We know that information about you and your health is private. We are dedicated to protecting the privacy of that information. Because of this promise, we must get your written authorization (permission) before we may use or disclose your protected health information or share it with others for research purposes.

You can decide to sign or not to sign this authorization section. However, if you choose not to sign this authorization, you will not be able to take part in the research study. Whatever choice you make about this research study will not have an effect on your access to medical care.

\section{Persons/Organizations Providing the Information}

West Virginia University Hospitals

\section{Persons/Organizations Receiving the Information}

- The research site(s) carrying out this study. This includes UHA or UHA Affiliated, WVU, WVU Hospitals. It also includes each site's research staff and medical staff

- Health care providers who provide services to you as part of this research study. 


\section{The Following Information Will Be Used}

Information from your existing medical records and new information about you that is created or collected during the study such as: age, sex, education, medical diagnoses, duration of pain symptoms, and current/past treatments, residence city, imaging scans and study forms.

\section{The Information is Being Disclosed for the Following Reasons}

(delete sections that do not apply)

- $\quad$ Review of your data for quality assurance purposes

- $\quad$ Publication of study results (without identifying you)

- $\quad$ Other research purposes such as reviewing the safety or effectiveness of the study drug and other products or therapies; conducting performance reviews of the study drug; evaluating other products or therapies for patients; developing a better understanding of disease; improving the design of future clinical trials

\section{Voluntary Participation}

Participation in this study is voluntary. You are free to withdraw your consent to participate in this study at any time.

Refusal to participate or withdrawal will involve no penalty to you. Refusal to participate or withdrawal will not affect your future care at West Virginia University.

In the event new information becomes available that may affect your willingness to participate in this study, this information will be given to you so that you can make an informed decision about whether or not to continue your participation.

You have been given the opportunity to ask questions about the research, and you have received answers concerning areas you did not understand.

Upon signing this form, you will receive a copy.

I willingly consent to participate in this research.

\section{Signatures}

Signature of Subject

\section{Printed Name}

Date

Time

The participant has had the opportunity to have questions addressed. The participant willingly agrees to be in the study. 
Signature of Investigator or Co-Investigator

Printed Name

Date

Time 
Appendix B: Demographic Questionnaire

Name:

Best phone number to reach you for follow-up (required for \$10 Walmart gift card):

Current zip code of residency:

Please Indicate your sex (Please check one):

Male / Female / Intersex / Other / Prefer not to say

Level of Education (Please check one):

Less than High School Diploma

GED

High School Diploma

Some College

Bachelor's Degree

Graduate Degree

How long have you had difficulties with chronic pain?

Please estimate to the best of your ability the number of months or years you have been experiencing chronic pain:

Location of Pain (Please circle parts on the figure where you experience pain): 

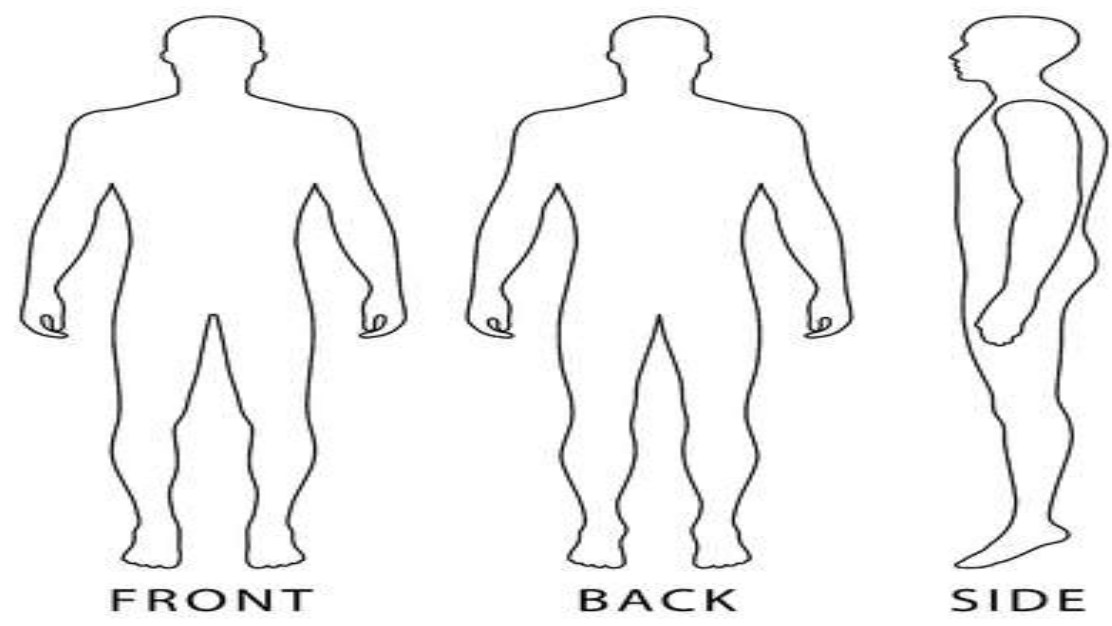


\section{Appendix C: Chronic Pain Acceptance Questionnaire - Revised (CPAQ-R) CHRONIC PAIN ACCEPTANCE QUESTIONNAIRE}

Below you will find a list of statements. Please rate the truth of each statement as it applies to you. Use the following rating scale to make your choices. For instance, if you believe a statement is 'Always True,' you would write a 6 in the blank next to that statement.

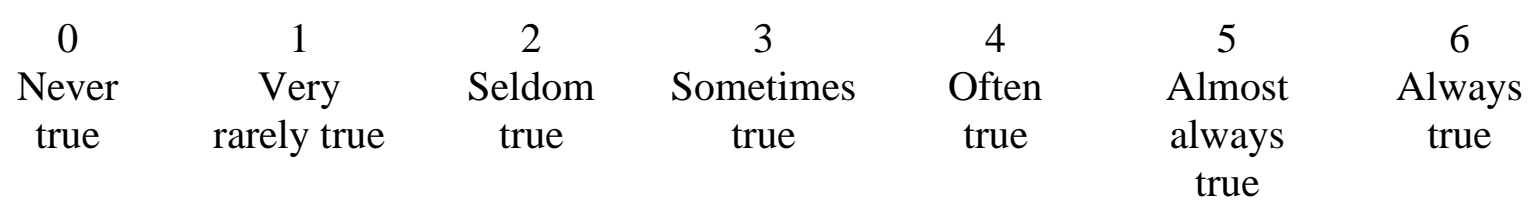

1. I am getting on with the business of living no matter what my level of pain is.

2. My life is going well, even though I have chronic pain.

3. It's OK to experience pain.

4. I would gladly sacrifice important things in my life to control this pain better.

5. It's not necessary for me to control my pain in order to handle my life well.

6. Although things have changed, I am living a normal life despite my chronic pain.

7. I need to concentrate on getting rid of my pain.

8. There are many activities I do when I feel pain.

9. I lead a full life even though I have chronic pain.

10. Controlling my pain is less important than any other goals in my life.

11. My thoughts and feelings about pain must change before I can take important steps in my life.

12. Despite the pain, I am now sticking to a certain course in my life.

13. Keeping my pain level under control

14. Before I can Make any serious plans, I have to get some control over my pain.

15. When my pain increases, I can still take care of my responsibilities

16. I will have better control over my life if I can control my negative thoughts about pain.

17. I avoid putting myself in situations where my pain might increase.

18. My worries and fears about what pain will do to me are true.

19. It's a great relief to realize that I don't have to change my pain to get on with life.

20. I have to struggle to do things when I have pain. 


\section{Appendix D: Two-Item Pain Catastrophizing Questionnaire (2-PCQ)}

Instructions: Individuals who experience pain have developed a number of ways to cope, or deal with their pain. These include saying things to themselves when they experience pain or engaging in different activities. Below is a list of things that people have reported doing when they feel pain. For each statement, please indicate, using a scale from 0 to 6 , how much you engage in that statement when you feel pain. 0 indicates you never do that when you are experiencing pain, a 3 indicates you sometimes do that when you are experiencing pain, and a 6 indicates you always do it when you are experiencing pain. Remember, you can use any point along the scale.

1. It is terrible and I feel it is never going to get better.

$\begin{array}{cccccc}0 & 2 & 3 & 5 & 6 \\ \begin{array}{c}\text { Never } \\ \text { do }\end{array} & \begin{array}{c}\text { Sometimes } \\ \text { do that }\end{array} & \begin{array}{c}\text { Always } \\ \text { do that }\end{array}\end{array}$

2. I feel I can't stand it anymore.

$\begin{array}{cccccc}0 & 1 & 2 & 3 & 4 & 5\end{array}$




\section{Appendix E: Two-item Client Satisfaction Questionnaire}

1. Please rate your level of satisfaction with the workshop you attended.

$\begin{array}{ccccc}0 & 2 & 3 & 5 & 6 \\ \begin{array}{c}\text { Very } \\ \text { Dissatisfied }\end{array} & \begin{array}{c}\text { Neither } \\ \text { Satisfied } \\ \text { nor } \\ \text { Dissatisfied }\end{array} & \begin{array}{c}\text { Very } \\ \text { Satisfied }\end{array} \\ & & \end{array}$

2. How likely are you to refer a friend or family member to the workshop you attended?

$\begin{array}{cccccc}0 & 2 & 3 & 5 & 6 \\ \text { Very } & 1 & \text { Neither } & & \text { Very } \\ \text { Unlikely } & \text { Likely nor } & & \text { Likely } \\ \text { Unlikely } & & \end{array}$




\section{Appendix F: Participant Invitation Flyer}

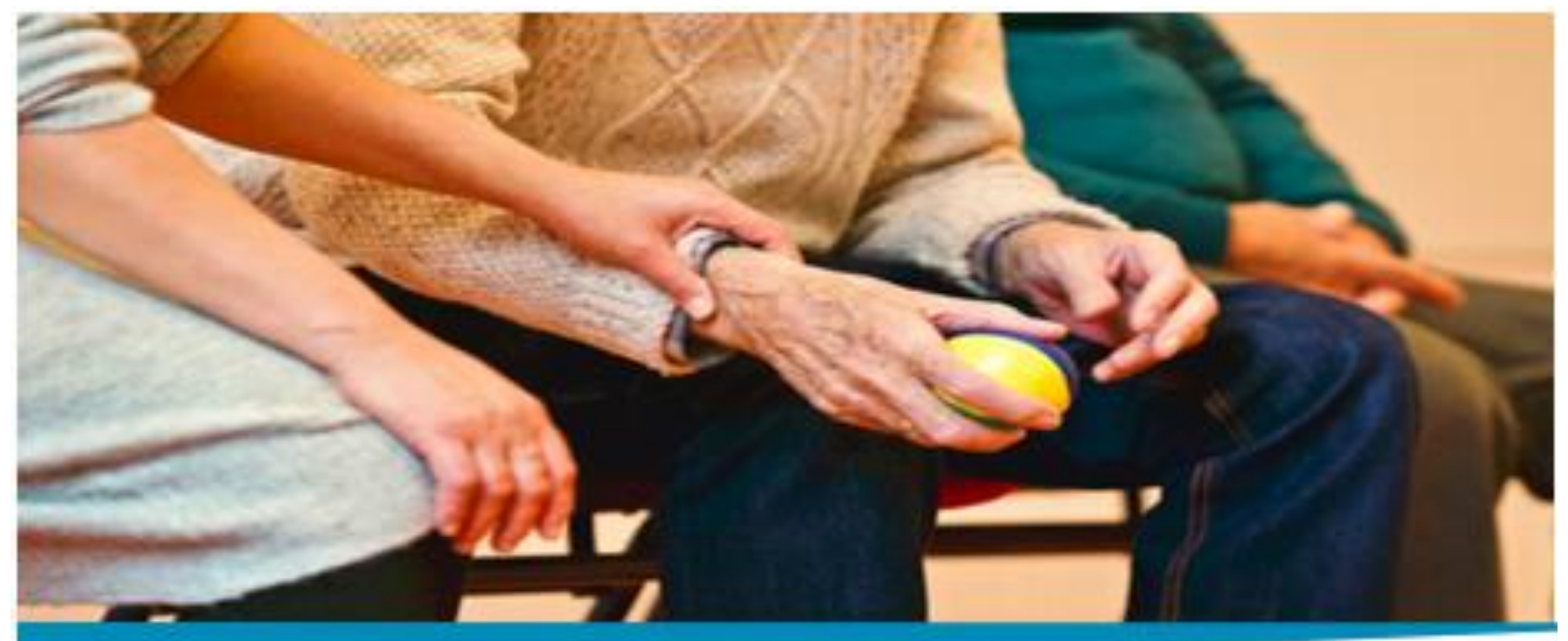

This program may help you:

CHRONIC PAIN FREE WORKSHOP

Taking charge of your life:

$A$ research study working to help you live your life meaningfully with chronic pain

When you have chronic pain, you may feel like you have many different challenges, both physically and emotionally. This workshop may help to increase coping and management skills

- A free 1.5-hour workshop

- If you know someone, or if you have chronic pain, then this workshop is for you

- Based on research in Contextual Behavioral Science
- Understand your pain experience differently than before

- Move towards the things in your life that are meaningful to you

What to expect:

- Participation in a research study

- An open, interactive environment for $\underline{1.5 \text {-hours }}$

- Learning and gaining support from others who also suffer from chronic pain.

- A four-week follow-up resulting in a $\$ 10$ Walmart gift-card

To register:

Ask your doctor for a referral

Write name and number on sign-up sheet

Workshop takes place on:

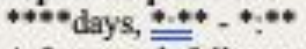

A four-week follow-up call will be conducted

WVU IRB approval on file.

IRB protocol number: 1906601289 


\section{Appendix G: Workshop Outline and Handout}

Taking Charge of Your Life:

Living Meaningfully with Chronic Pain

Workshop Developed by Kelly Thomas

Note: Participants received copies of the slides. Workshop leader utilized the slides and the notes for a basic outline of the workshop.

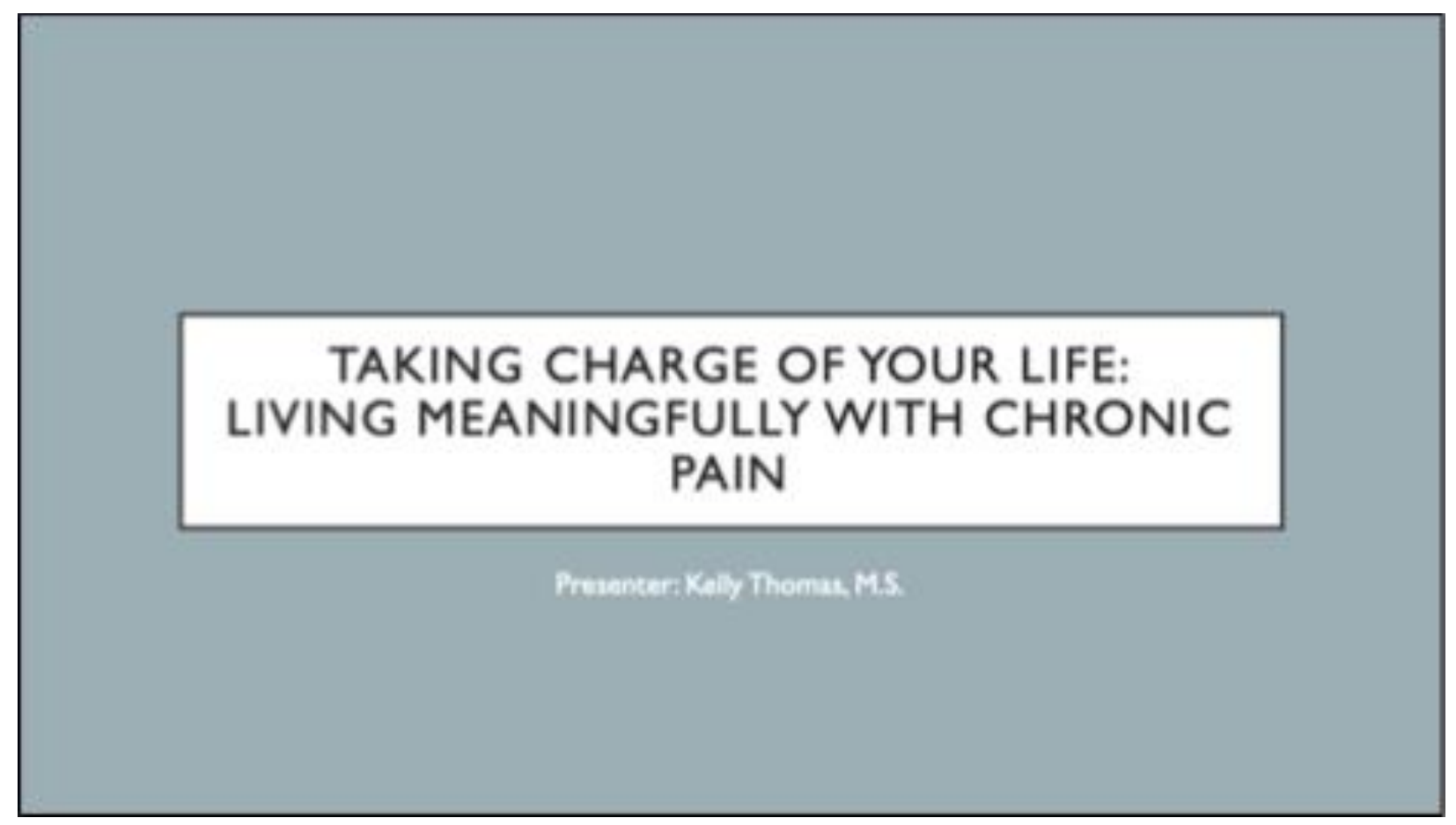




\section{INTRODUCTIONS}

- What is your name?

-Where were you born?

- Favorite Activity (past or present)

- One thing you wish to achieve by being here today.

\section{PAIN VS. SUFFERING}

\footnotetext{
What is pain?

- Arvical sensatien you have in the bedy

- Whrns you that semething is wrong

* What is suffering?

- As I the sensation of pain isn't enough, the wflering that comes sleng with is can make lite teel even more diffeult.
}

Pain vs. Suffering

\section{Pain}

Who here feels like an expert on pain? 


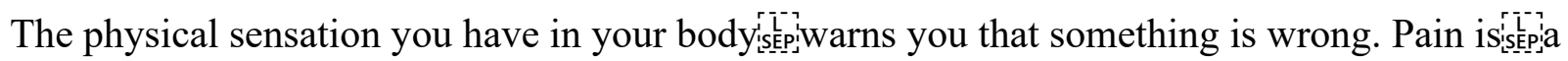
completely subjective experience: No one, not even the people sitting next to you, is experiencing your pain the way that you experience it. However, that does not mean that having support from one another is not helpful.

\section{Sufferingispep}

As if the sensation of pain isn't enough, the suffering that comes along with it can make life feel even more difficult:s[s:in example of suffering may be the feeling like you are missing out, or that you were not living the same way as before: Maybe you have lost relationships, jobs, or feel like no one understands.s[sp?

- Example: How many of you have stayed home from an important activity, or not seen a friend or family member because of your pain? Does anyone here want to share a recent experience they have had with pain and suffering?

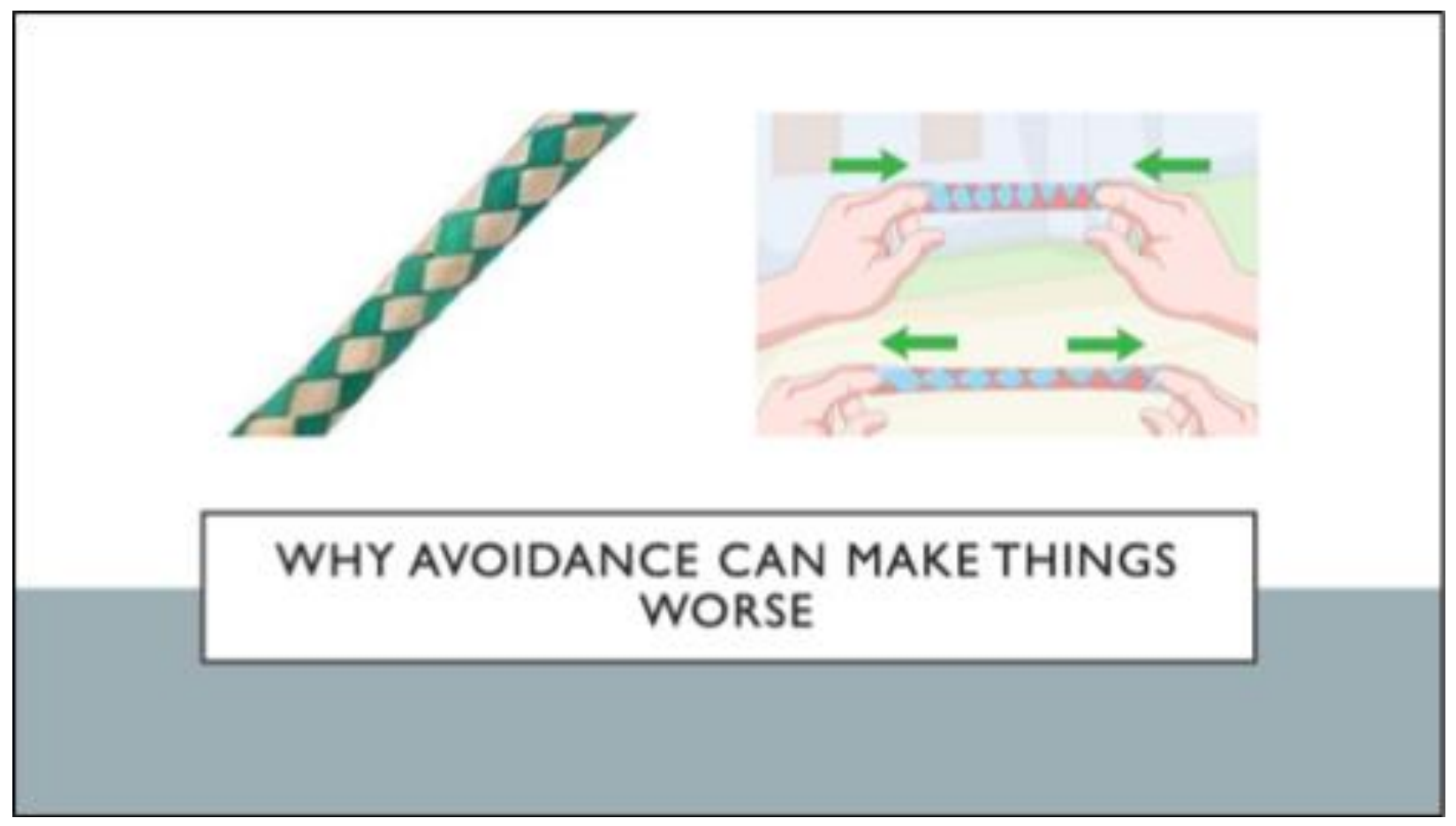


I wonder if pain is something like this

Check this out. This is just a tube of woven straw. Now, push both index fingers in, one into each end, and see what happens. You notice that as you pull them back out, the straw catches and tightens. You may notice other things that happen, such as in your feelings or thoughts. What's happening here? See, the harder you pull, the smaller the tube gets and the tighter it holds your fingers.

Maybe, this situation with pain, distress, and other experiences that come with it, is something like this trap. You have tried every way to get out of the trap, but nothing seems to work.

However, have you noticed something else about this tube? With this tube, the only way to get some room is to push your fingers in, which makes the tube bigger. That may be hard to do at first, because everything in your mind tells you to do the opposite. But your past experiences tell you to fight as hard as you can to get out of the trap. Maybe you need to come at this situation from a whole different angle, different than what your mind tells you to do with your experience of suffering.

The problem with chronic pain is that the pain signals never stop, and you may constantly be trying to pull your fingers out of the trap. Because pain is a bad experience, we are taught to need to fight against it, but have those things ever worked for you? What treatments have your tried that have not worked? Medications? What happens to your mood and thoughts after a failed treatment? 


\section{YOU'RE THE BUS DRIVER}

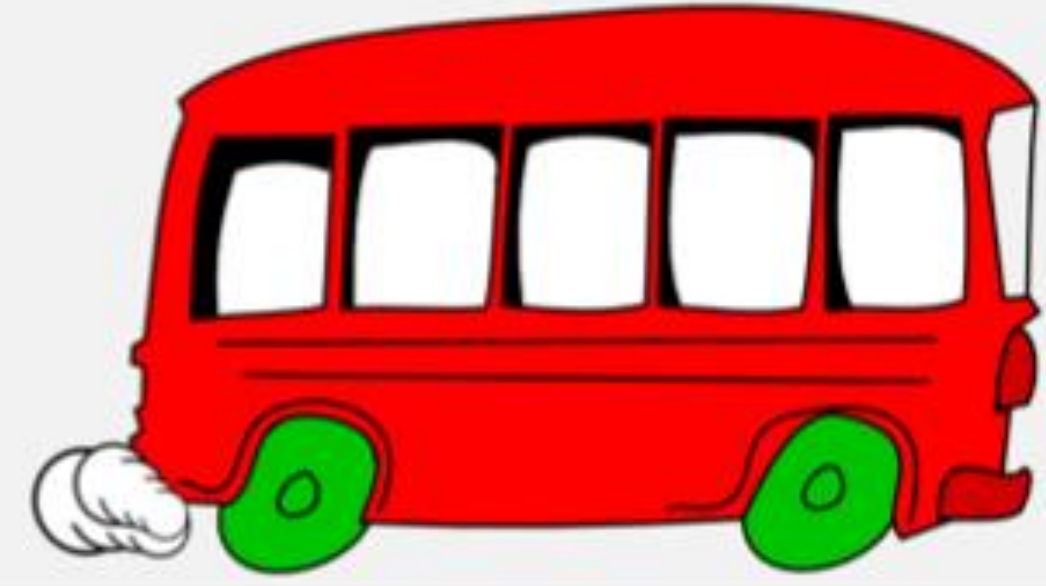

The purpose of what I am trying to discuss with you, is how to continue to live your life meaningfully with chronic pain, which I can understand is a very difficult thing to do. What I want for you, is to feel like you can take control of your life again, even with chronic pain.

\section{Metaphor}

It is like you are a bus driver and you want to go where you want to go. At the same time on this bus are these scary passengers. They don't always want to go where you want to go, and when you don't do their way they let you know about it. They may rush up behind you, crawl all over you, and threaten you. They essentially bully you so you do what they say. You choose not to go where you want to go and they settle down, into the back of the bus and out of sight. In the meantime, you're driving around in circles and not going anywhere in particular, just driving aimlessly. Now you may get fed up with this eventually. You may stop the bus and try to toss these passengers off, but there are many and they fight you. And noticed that all the time you fight them the bus is not going anywhere. And so it's back to the old agreement, if they leave you alone you will only go where they say and nowhere else. Notice this interesting part, the key things, these passengers have never done you any physical harm, they cannot, and never will. All 
they got over you is the ability to intimidate. The only power they have over you is the power you give them. You are the driver yet you trade your control over the bus to keep the passengers away. You may say this is silly or that you do not have to put up with this. The truth is you do have passengers and they are your thoughts, feelings, sensations, urges, memories and the like.

How many of you are frustrated that chronic pain is "all of you"? something because you thought something bad was going to happen? you want to achieve in life or something you want to do? What are passengers keeping you from doing in your life right now?

\section{GAINING CONTROL}
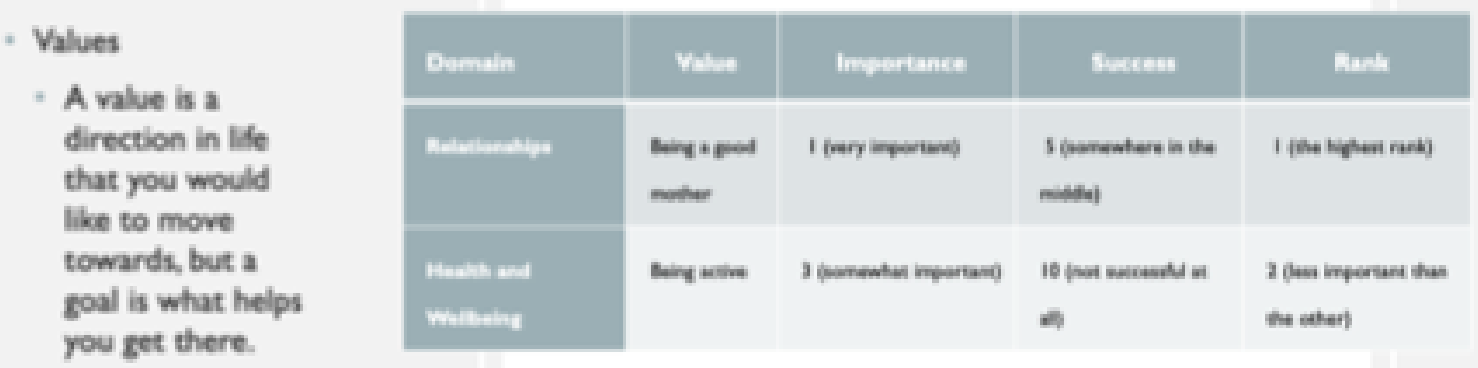

If you feel comfortable, share the highest ranked values on your list. Share what they mean to you.

Do any of your group members share the same experience? 


\section{BUT WHAT ABOUT CHRONIC PAIN GETTING IN THE WAY?}

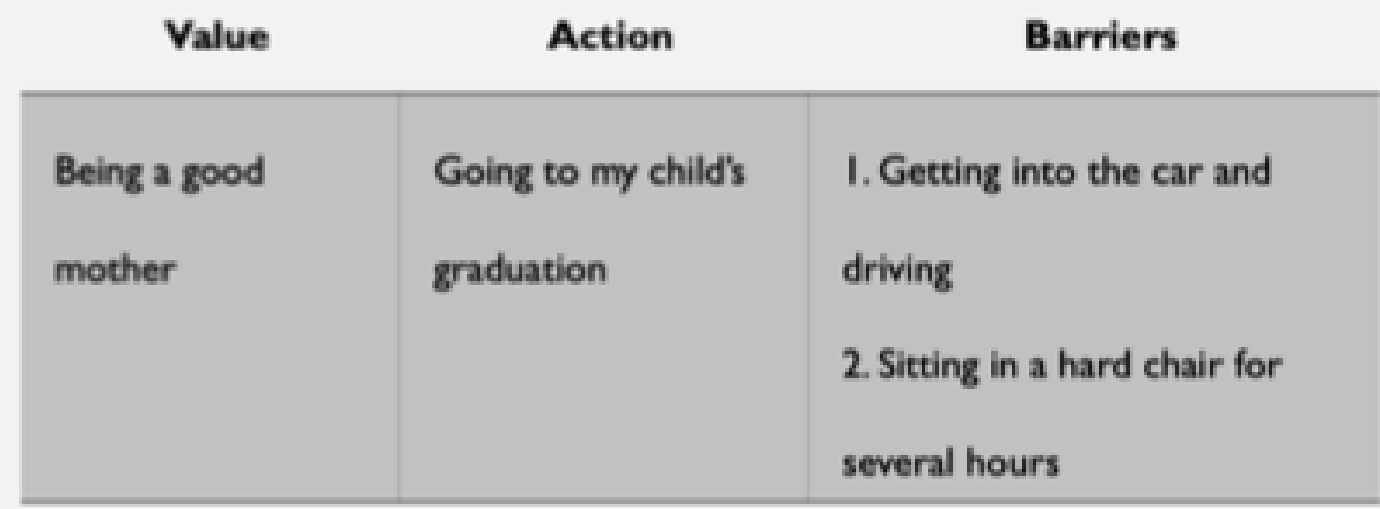

- We often only think of the barriers and the negatives when chronic pain is in charge. However, it's important to consider the positives to doing these things.

- For this example

1. Knowing my child will enjoy it would be great. is

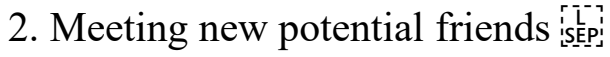

3. Being social and getting out is in-pi

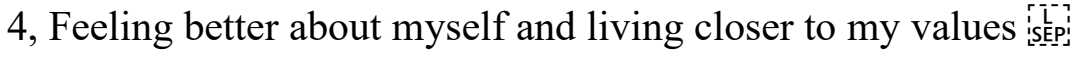

- Can you think of any positives to your values and actions you have written? 


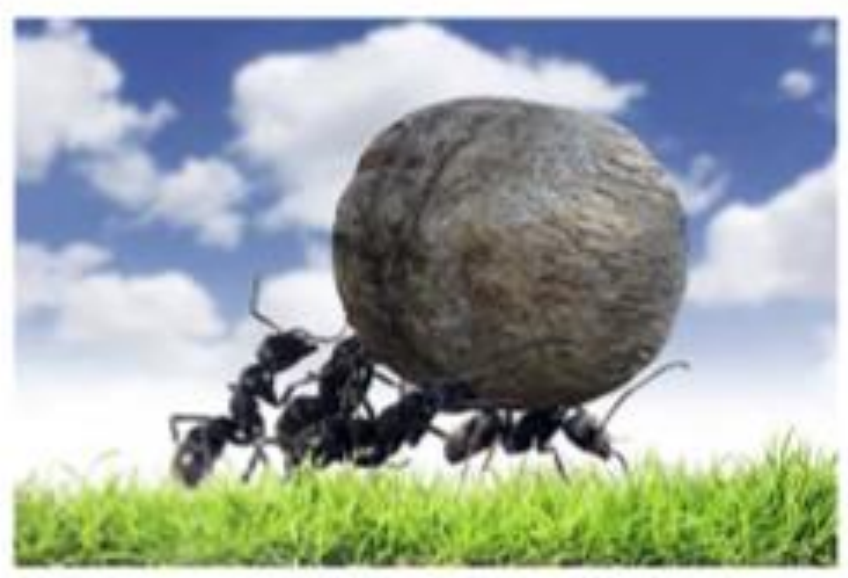

Close your eres and picture yourvell encaging in the sctions you have listed an your warkaheet. Do you believe you can do these thing living with the pain you have right now!

Are there ways to modify you barriers so that you can live clover to your viluet?

Close your eyes and picture yourself engaging in the actions you have listed on your worksheet. Do you believe you can do these things living with the pain you have right now?

What is keeping you from doing these things?

Are you willing and committed to doing the activity you have chosen from your worksheet, even when experiencing chronic pain?

Do you believe you will be able to move forward with your life, in a way that is valuable to you, even with chronic pain?

My hope for you is that you will be able to live a life that works for you. 


\section{Appendix H: Gift Card Letter to Participants}

\section{WestVirginiaUniversity}

College of Education and Human Services

Dear Participant,

I want to personally thank you for participating in a recent research study (Protocol \# 1906601289). Attached is the $\$ 10 \mathrm{Walmart}$ gift card as a result of your participation in the follow-up phone call and group.

In the event you experience any side effects or injury related to this research, you should contact Kelly Thomas via email at kat0016@ mix.wvu.edu. If you have any questions, concerns, or complaints about this research, you should contact Kelly Thomas via email at kat0016@mix.wvu.edu

For information regarding your rights as a research subject, to discuss problems, concerns, or suggestions related to the research, to obtain information or offer input about the research, contact the Office of Research Integrity and Compliance at (304) 293-7073.

In addition, if you would like to discuss problems, concerns, have suggestions related to research, or would like to offer input about the research, contact the Office of Research Integrity and Compliance at 304-293-7073.

Again, I appreciate your willingness to participate in this study.

Sincerely,

Kelly Thomas, M.S.

Counseling Psychology Doctoral Candidate

Department of Counseling, Rehabilitation Counseling \& Counseling Psychology 